\title{
Southwest Regional Climate Hub and California Subsidiary Hub Assessment of Climate Change Vulnerability and Adaptation and Mitigation Strategies
}

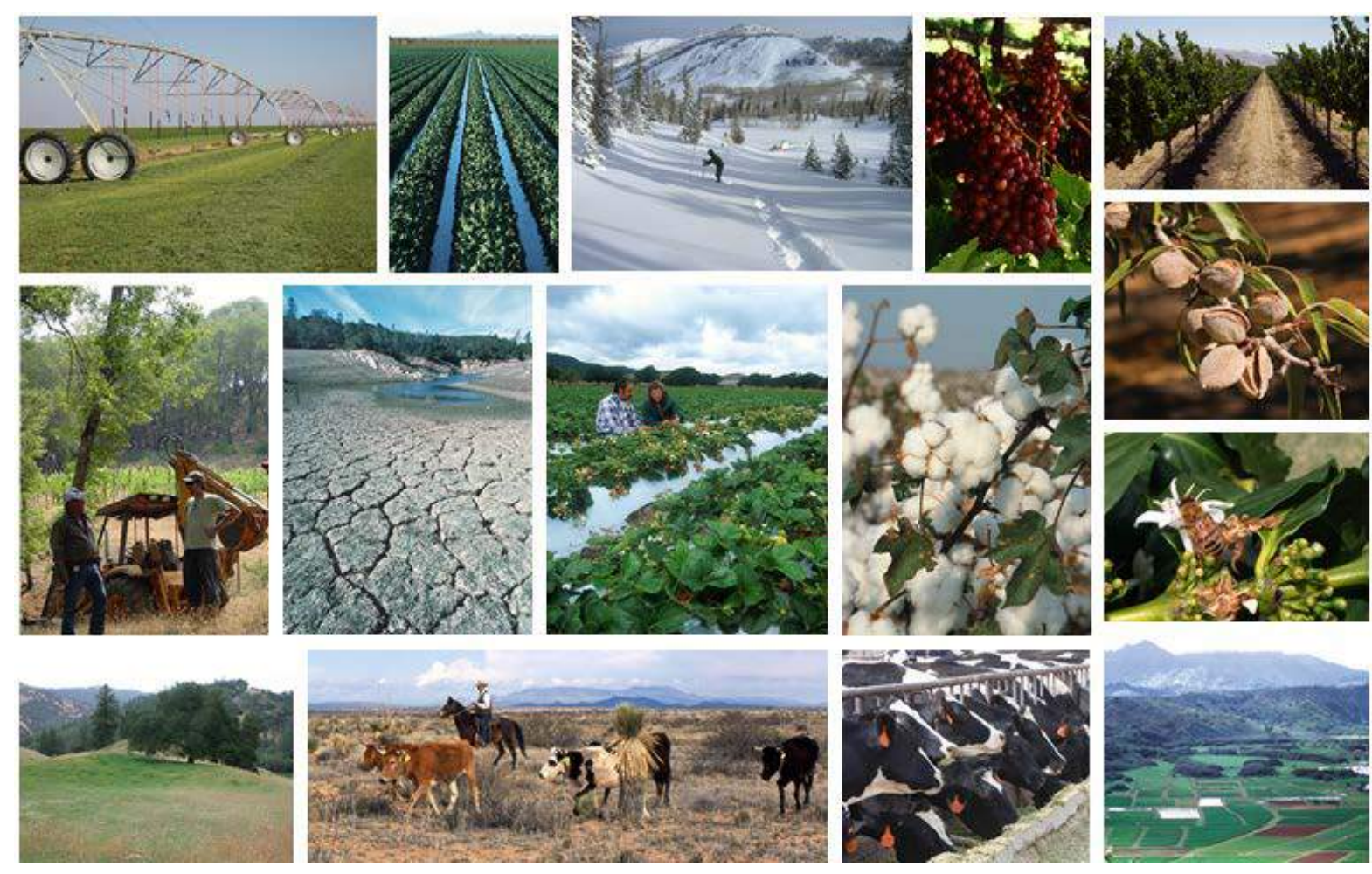

Authors: Emile Elias, USDA SW Hub Deputy Director; Caiti Steele, USDA SW Hub Deputy Director; Kris Havstad, USDA-Agricultural Research Service Jornada Experimental Range Research Leader; Kerri Steenwerth, CA Sub Hub Co-Director; Jeanne Chambers, U.S. Forest Service; Helena Deswood, U.S. Department of Agriculture (USDA) Southwest (SW) Hub Coordinator; Amber Kerr, California (CA) Sub Hub Coordinator; Albert Rango, Hub Director; Mark Schwartz, John Muir Institute of the Environment Director; Peter Stine, CA Sub Hub Co-Director; and Rachel Steele, National Climate Hubs Coordinator. Southwest Regional Climate Hub, 2995 Knox Street, Las Cruces, NM 88003. California Subsidiary Hub, 1 Shields Avenue, Davis, CA 95616.

\section{August 2015}

Contributors: Our thanks to Shaun McKinney, NRCS; Luana Kiger, NRCS; Robert Tse, RD; Wendy Hall, APHIS; Marlene Cole, APHIS; Ricardo Lopez, USFS; Sharon Hestvik, RMA; Oscar Gonzales, FSA; and Molly Manzanares, FSA. We acknowledge ICF International for its contributions to the Greenhouse Gas Profile. 
Acknowledgments: We thank John Abatzoglou, Ruben Baca, Carolyn Cook, Dave DeWalt, Peg Gronemeyer, Amrith Gunasekara, Russ Henly, Estrella Herrera, Andrew Holguin, Ryann Smith, Scott Schrader, Jim Thorne, and Derrick Vinson.

We appreciate the assistance of the following experts who reviewed selected crops: Malli Aradhya (stone fruit), Paul Brown (cotton), Greg Browne (almonds), Eli Carlisle (tomatoes), David Crowley (avocadoes), Oleg Daugovish (strawberries and broccoli), Louise Ferguson (citrus and pistachios), Tim Hartz (melons and carrots), Jim Hill (rice), Lee Jackson (small grains: wheat, barley and oats), Dan Kluepfel (almonds and stone fruit), Bruce Lampinen (walnuts), Bruce Linquist (rice), Joe Nuñez (carrots), Richard Percy (cotton), Carol Shennan (strawberries), Richard Smith (lettuce and onions/garlic), Scott Stoddard (tomatoes), Dianne Velasco (almonds), and Larry Williams (grapes). Any errors or omissions in this document remain the responsibility of the authors.

We acknowledge the World Climate Research Programme's Working Group on Coupled Modelling, which is responsible for CMIP, and we thank the climate modeling groups for producing and making available their model output. For CMIP the U.S. Department of Energy's Program for Climate Model Diagnosis and Intercomparison provides coordinating support and led development of software infrastructure in partnership with the Global Organization for Earth System Science Portals.

Edited by: Terry Anderson, ARS

Suggested Citation: Elias, E., C. Steele, K. Havstad, K. Steenwerth, J. Chambers, H. Deswood, , A. Kerr, A. Rango, M. Schwartz, P. Stine, R. Steele, 2015: Southwest Regional Climate Hub and California Subsidiary Hub Assessment of Climate Change Vulnerability and Adaptation and Mitigation Strategies, T. Anderson, Ed., United States Department of Agriculture, 76 pp.

Contributors: S. McKinney, L. Kiger, R. Tse, W. Hall, M. Cole, R. Lopez, S. Hestvik, O. Gonzales, M. Manzanares 


\section{Contents}

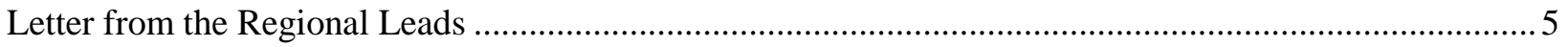

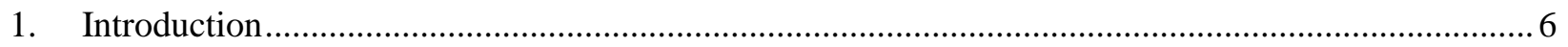

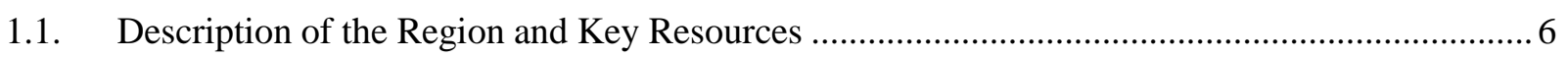

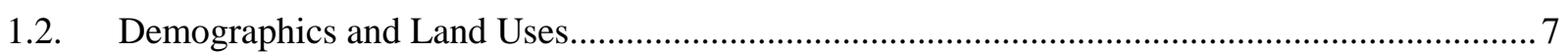

1.3. General Climate Conditions, Extremes, and Past Effects ........................................................ 7

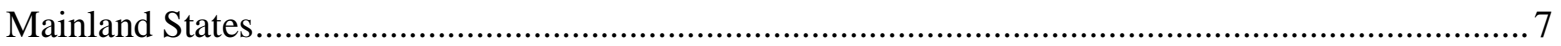

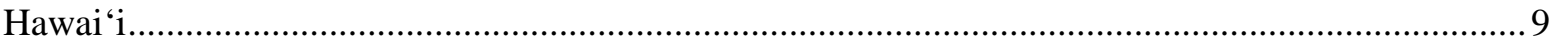

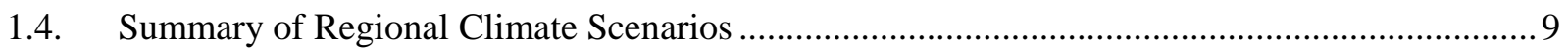

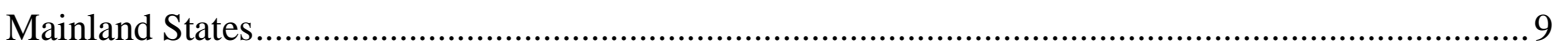

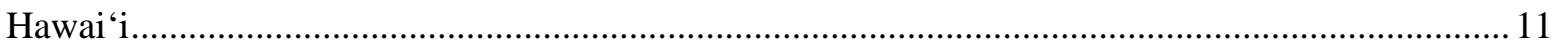

2. Regional Agriculture's Sensitivity to Climate Change and Adaptation Strategies........................... 13

2.1. Cropping Systems Overview of Risks, Vulnerabilities, and General Adaptation Strategies...... 13

Regional Issues for Southwest Cropping Systems..................................................................... 13

Crop-Specific Vulnerabilities and Adaptation Strategies: California Specialty Crops...................... 15

Crop-Specific Vulnerabilities and Adaptation Strategies: Southwest Field Crops............................ 22

Crop-Specific Vulnerabilities and Adaptation Strategies: Hawai ‘ $i$.................................................. 26

2.2. Livestock Systems Overview of Risks, Vulnerabilities, and General Adaptation Strategies ..... 28

Effects of Climate Change on Southwestern Animal Agriculture .................................................. 28

Regional Issues for Southwest Animal Agriculture and Rangeland Ecosystems .............................29

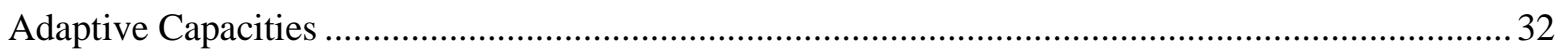

3. Forest Systems Overview of Risks, Vulnerabilities, and General Adaptation Strategies................... 34

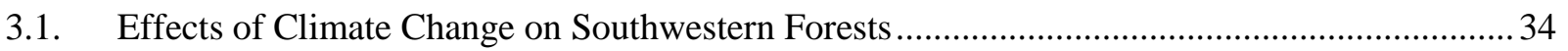

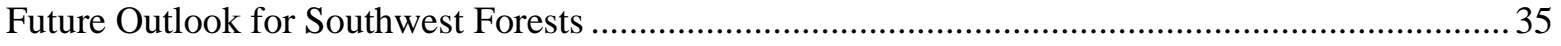

Regional Issues for Southwest Forest Systems ............................................................................. 36

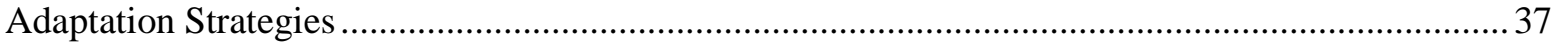

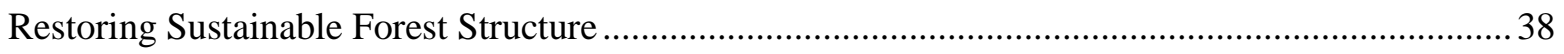

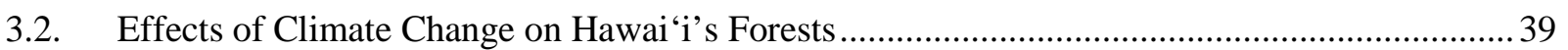

4. Greenhouse Gas Emissions Profile from Agriculture and Forests, and Mitigation Opportunities

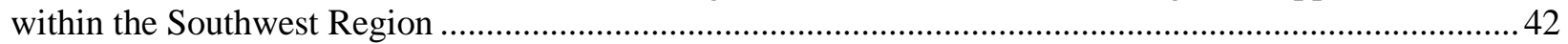

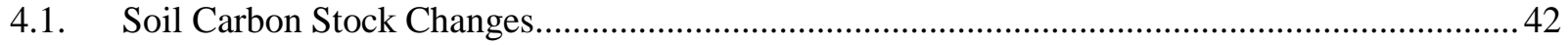

4.2. Nitrous Oxide Emissions in the Southwest Region ........................................................... 42

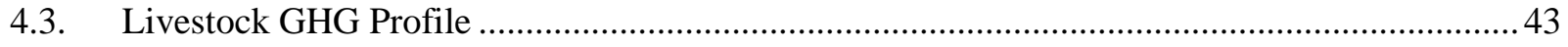

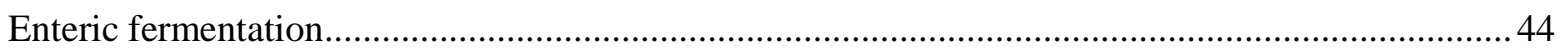

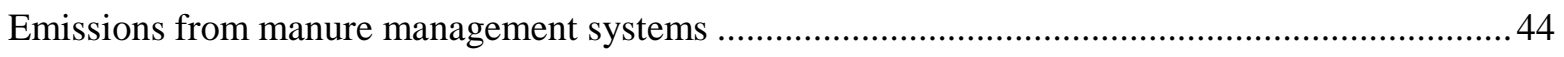

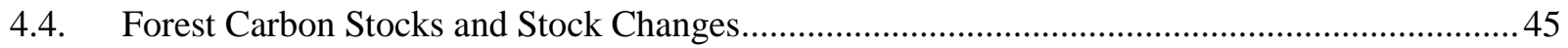




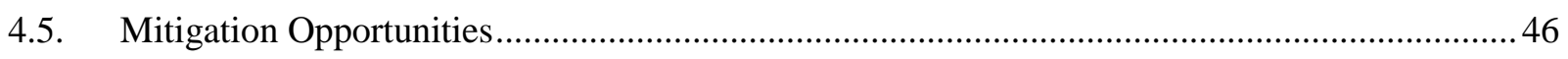

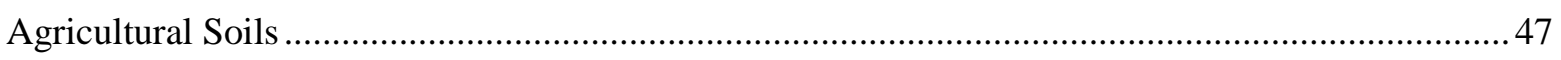

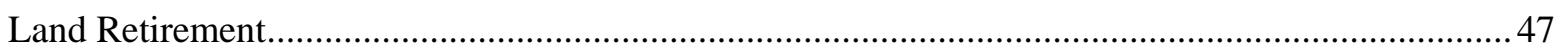

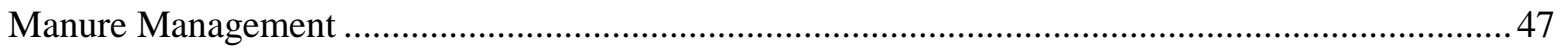

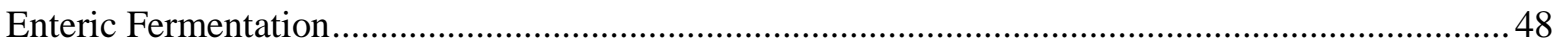

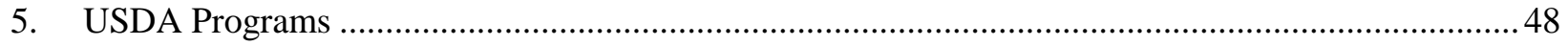

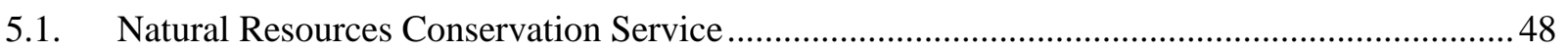

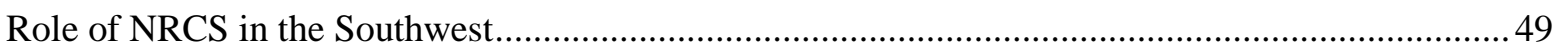

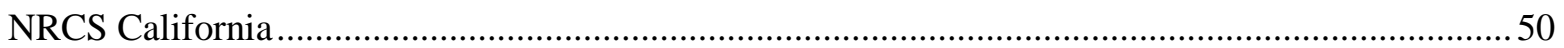

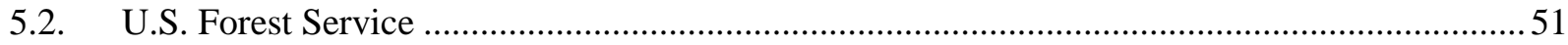

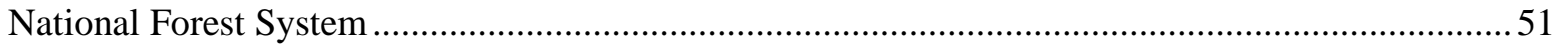

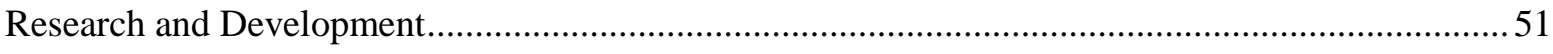

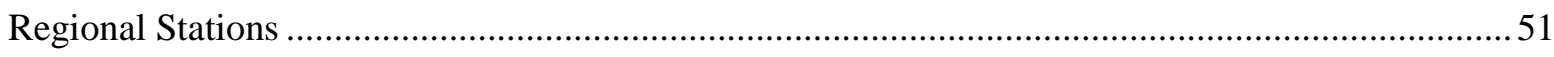

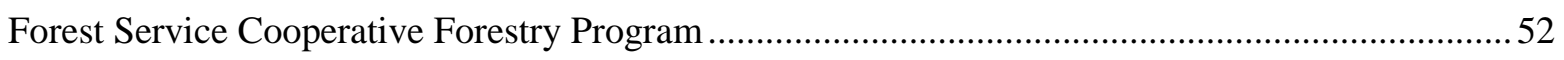

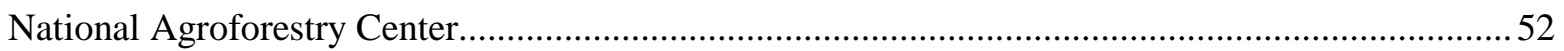

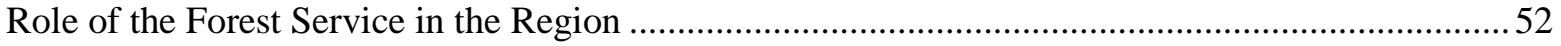

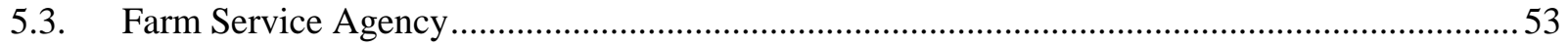

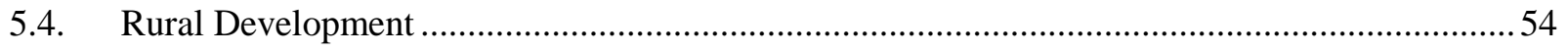

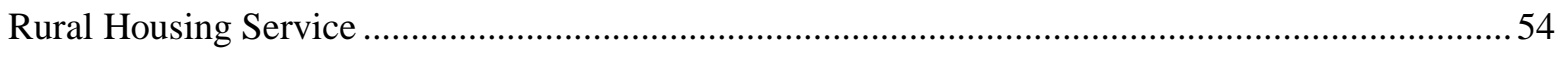

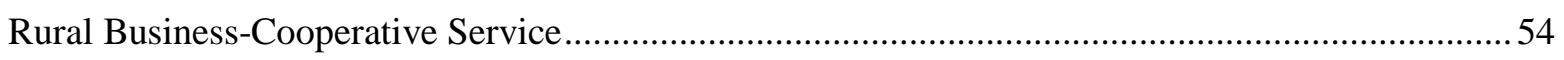

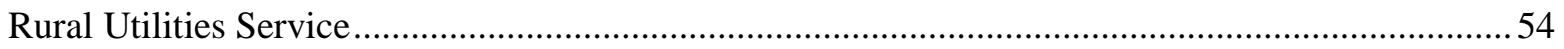

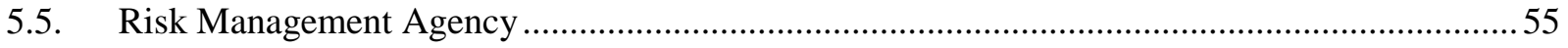

5.6. Animal and Plant Health Inspection Service …..................................................................... 57

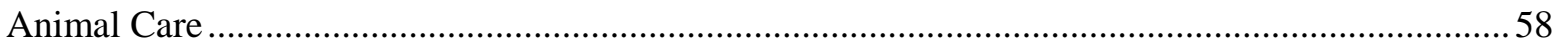

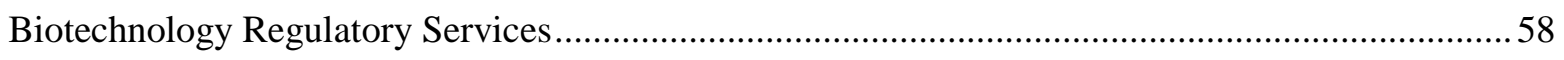

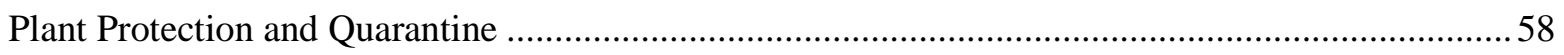

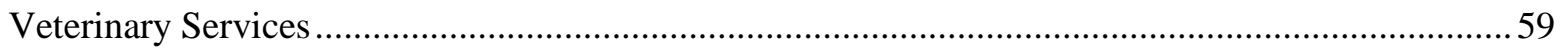

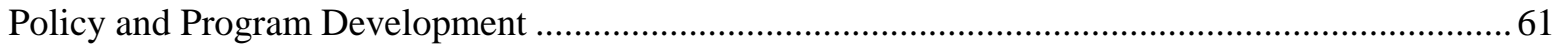

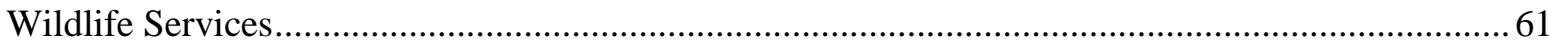

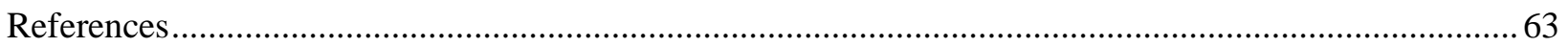




\section{Letter from the Regional Leads}

This report is a joint effort of the Southwest Regional Climate Hub and the California Subsidiary Hub (Sub Hub). The Southwest Regional Climate Hub covers Arizona, California, Hawai'i and the U.S. affiliated Pacific Islands, Nevada, New Mexico, and Utah and contains vast areas of western rangeland, forests, and high-value specialty crops (Figure 1). The California Sub Hub works with the issues of climate change effects on forests and agriculture in California, including internationally important specialty crops. The southwestern region contains high climatic diversity, with locations that claim the highest and lowest amounts of annual precipitation, and the highest and lowest elevations in the 48 contiguous states. Within the region, producers cope with severe drought effects on crop and animal systems, catastrophic wildfires, insect outbreaks, and sea level rise. The Southwest States grow diverse agricultural crops, including cotton, lettuce, tree fruit, cantaloupes, grapes, onions, macadamia nuts, coffee, and pecans. The region relies on irrigation more heavily than any other region in the United States. Water supplies, primarily from winter snowfall in the Sierra Nevada and Rocky Mountains, are critical to meeting irrigation needs in the Southwest. Total farm income for the region exceeded $\$ 56$ billion in 2012, $\$ 45$ billion of which was produced in California. Livestock account for approximately one-third of the agricultural profits in these six States.

Variations in weather and, ultimately climate, affect all agricultural systems. These variations include temperature extremes, excess or deficit precipitation, severe storms, and wind. Freshwater resources in all States of the southwestern region are limited. Climate change is projected to increase temperatures across the region by 2040 to 2069 by 2 to $4^{\circ} \mathrm{C}\left(3.5\right.$ to $\left.7.2^{\circ} \mathrm{F}\right)$. The projected increase in Hawai ${ }^{\circ} \mathrm{i}$ is somewhat less. In addition, precipitation may increase in the northern portion of the continental southwestern U.S. and decrease in the southern portion of the region. Regardless of the likely slight increase or decrease in future precipitation, elevated temperatures will likely lead to less available surface water by increasing evaporation and transpiration.

Increasing temperature and decreasing available water will affect agricultural and forest production. Ranchers may need to alter rangeland stocking rates. Some field and specialty crops may be adversely affected by elevated temperatures during certain phenological stages. Perennial specialty crops may not receive the winter chilling requirement necessary for viable production. Plant diseases and pests may persist longer and new ones may become established. The spatial distribution of forest species will also likely change. Dry conditions combined with insect and pathogen outbreaks can lead to greater wildfire extent and severity in southwestern forests. All of these changes increase the pressure faced by farmers, ranchers, and foresters while striving to conduct profitable and sustainable operations. Although these changes will likely lead to many interrelated and cumulative effects, here we try to outline the most direct and likely effects to highly valuable or abundant crops, animal agriculture, and forest systems of the region.

The Southwest Regional Climate Hub and California Sub Hub are working across a range of crops and livestock to assemble the available information into tools and practices that can increase the resilience of agricultural systems to climate change. At the foundation of this effort is establishment of a communication network with Cooperative Extension agents to work with farmers, ranchers, and foresters across the Southwest. We are also developing education modules to provide information about the effects of climate change on the regional hydrologic cycle and agricultural systems. These activities reflect the core mission of the Climate Hubs: to provide unbiased scientific information and assistance in support of adaptation of agricultural and forest ecosystems to a changing climate.

Albert Rango

Southwest Regional Climate Hub Lead
Kerri Steenwerth

California Sub Hub Lead 


\section{Introduction}

This report describes the potential vulnerability of specialty crops, field crops, forests, and animal agriculture to climate-driven environmental changes. Here, vulnerability is defined as a function of exposure to climate change effects, sensitivity to these effects, and adaptive capacity. The exposure of specific sectors of the agricultural and forestry industries varies across the region because the Southwest is climatically and topographically diverse. There is also variability in the sensitivity of different systems to the effects of climate change. Most significantly, there is potential within agricultural and forestry systems to adjust to climaterelated effects either through inherent resilience or through conservative management practices. The purpose of this analysis is to describe regional vulnerabilities to climate change and adaptive actions that can be employed to maintain productivity of working lands in the coming decades.

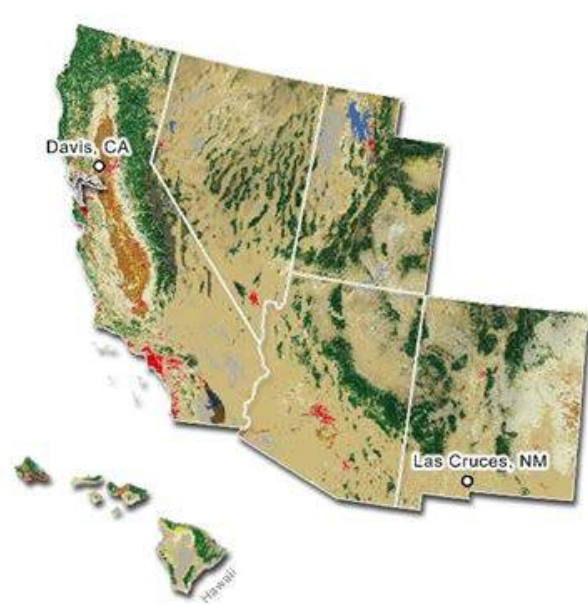

Figure 1: Southwest Regional Climate Hub and California Subsidiary Hub.

\subsection{Description of the Region and Key Resources}

The Southwest is the most extensive dry region of the United States. As such, agricultural production relies upon the provision of fresh water via major water projects and mining groundwater reserves. Most of the region receives less than 15 inches of mean annual precipitation. High-elevation snowpack in the Sierra Nevada and Rocky Mountains supply much of the regional surface water. Nearly one-third of the 2012 agricultural economic value came from animal agriculture, mainly cattle. The region produces many high-value specialty crops, grown primarily in California, which account for nearly 80 percent of the 2012 crop production value across the six-State region. In most parts of the region, agricultural water use exceeds other water uses, but population growth will add additional stress to already limited regional water resources It is probable that future population demands for water may come from leases or transfers of water formerly allocated to agriculture.

Although there are portions of seven Land Resource Regions (LRRs) in the Southwest Regional Climate Hub region, two major LRRs, 1) the Western Range and Irrigated Land Region and 2) the California Subtropical Fruit, Truck and Specialty Crop Region, comprise more than 84 percent of the total land area of the region (Natural Resources Conservation Service, 2006). The Western Range and Irrigated Region covers almost 434,000 square miles within the five mainland States, about 74 percent of the Southwest Climate Hub area. It is predominantly low- and high-elevation desert and semidesert and includes the Great Basin Desert, Mojave Desert, Sonoran Desert, and the Chihuahuan Desert. Daily freshwater withdrawal in the Western Range and Irrigated Region averages around 30,000 million gallons. The ratio of surface water to groundwater used is approximately $3: 1$, but these changes in drought years when groundwater extraction increases to make up for the shortfall in surface water supplies. About 86 percent of the water in this region is used for irrigation (Natural Resources Conservation Service, 2006), not counting water for environmental flows.

The California Subtropical Fruit, Truck and Specialty Crop Region comprises 62,350 square miles, around 10.5 percent of the Southwest Regional Climate Hub area, and accounts for more than half of national specialty crop production. For many other specialty crops such as wine grapes, strawberries, and leaf lettuce, California's share approaches or exceeds 90 percent of U.S. production (Starrs \& Goin, 2010). Low mountains and broad valleys characterize the regional topography. Although this region has a 
long growing season, which is ideal for raising specialty crops, it also has low precipitation (Natural Resources Conservation Service, 2006). Daily freshwater withdrawals average around 30,000 million gallons with 54 percent from surface water and 46 percent from groundwater. Irrigation accounts for approximately 79 percent of the water used in the State of California (not counting environmental flows) and irrigation water management is a high priority (Natural Resources Conservation Service, 2006).

Other mainland LRRs include the Western Great Plains Range and Irrigated Region (5.7 percent); the Rocky Mountain Range and Forest Region (5.3 percent); the Northwestern Forest, Forage, and Specialty Crop Region (3 percent); and Central Great Plains Winter Wheat and Range Region (1.7 percent).

The Hawai 'i Region covers only around 1 percent of the Southwest Regional Climate Hub area (roughly 6,265 square miles), but crop and animal agriculture, as well as the use of forest resources, are a very important part of Hawaiian culture and identity. The eight main Hawaiian Islands are located between $19^{\circ} \mathrm{N}$ and $22^{\circ} \mathrm{N}$, to the south and west of the North Pacific High (NPH) in the Central North Pacific. The $\mathrm{NPH}$ is the source of the northeasterly trade winds over the islands. The trade winds are important because they bring precipitation. The mountains of the Hawaiian Islands ( 0 to 4,000 $\mathrm{m}$ ) act as a barrier to the trade winds, strongly affecting rainfall distribution. Windward sides of the islands are much wetter than leeward sides, with the Kona area on the leeward side of Hawai ' $\mathrm{i}$ Island as an exception to this rule. Hualalai and Mauna Loa block the course of moisture-laden trade winds, air flows around these barriers and up the leeward slopes of Hawai' $i$ Island, creating a belt of precipitation (Giambelluca et al., 2013). Daily freshwater withdrawals in the Hawai' $i$ region average around 1,190 million gallons per day split equally between surface and groundwater sources (Natural Resources Conservation Service, 2006).

\subsection{Demographics and Land Uses}

The six main States covered by the Southwest Regional Climate Hub total just over 377 million acres in area. Of this, 15.4 million acres are cropland, 194 million acres are grassland pasture and range, 2.4 million acres are miscellaneous farmland, and 86.8 million acres are forest lands with 56 percent of forested area (38.2 million acres) classified as forest grazing land (Economic Research Service, 2014). The Southwest contains a few large cities within a rural landscape; urbanized areas and urban clusters account for 7.8 million acres within the region with California and Hawai' $i$ containing higher relative proportions of urban land (Economic Research Service, 2014). A dominant feature of the rural land of the region is extensive public lands managed by various Federal agencies (e.g., 60 percent of the Western Range and Irrigated Land Region is federally owned), as well as the lands of around 180 federally recognized tribal entities of the region.

In 2010, the combined population of the six States was 52.5 million, with more than 70 percent of the population living in California; in most States more than 90 percent of the population are located in urban areas (U.S. Census Bureau, 2015). For several decades, the mainland Southwest has had the most rapid urban growth in the Nation.

\subsection{General Climate Conditions, Extremes, and Past Effects}

\section{Mainland States}

The Southwest region spans $31^{\circ}$ to $42^{\circ}$ in latitude and is topographically variable; elevation differences and mountain ranges cause particularly large spatial variations in climate (Kunkel et al., 2013). The average annual temperature varies greatly, from $>70^{\circ} \mathrm{F}$ in southwest Arizona and southeast California to $<40^{\circ} \mathrm{F}$ over mountains and in the northern portion of the region. Generally, average annual temperature decreases as latitude and/or elevation increase. California's coastal regions and Central Valley (composed of the Sacramento Valley in the north and the San Joaquin Valley in the south) have a Mediterranean climate of cool and wet winters and warm, dry summers.

Introduction

Page $\mid 7$ 


\section{Temperature}

Temperatures are already warming in the Southwest (Overpeck et al., 2013), and scientists agree that temperatures will continue to increase in coming

decades. Average annual temperatures in the Southwest have increased over the past 115 years with two marked warming periods in the 1920s-1930s and from the mid-1970s to 2000. During the period of 1895-2011, the magnitude of significant positive temperature anomalies ${ }^{1}$ range from $0.16^{\circ} \mathrm{F}$ and $0.17^{\circ} \mathrm{F}$ per decade for spring, summer, and fall and $0.21^{\circ} \mathrm{F}$ per decade for winter (Table 1) (Kunkel et al., 2013). The freeze-free season (the time between the last occurrence of $32^{\circ} \mathrm{F}$ in spring and the first occurrence of $32^{\circ} \mathrm{F}$ in the fall) has lengthened and is now about 2 weeks longer on average now than it was in the1960s and 1970s (Kunkel et al., 2013).

\section{Precipitation}

Average annual precipitation also varies greatly for the Southwest region, from more than 60 inches on California's northwest coast to less than 5

Table 1: Trends (1895-2011) in temperature anomaly for each season and the year as a whole.

\begin{tabular}{|c|c|}
\hline Season & $\begin{array}{l}\text { Temperature } \\
\text { ( }{ }^{\circ} \text { F/decade) }\end{array}$ \\
\hline Winter & +0.21 \\
\hline Spring & +0.16 \\
\hline Summer & +0.17 \\
\hline Fall & +0.16 \\
\hline Annual & +0.17 \\
\hline \multicolumn{2}{|c|}{$\begin{array}{l}\text { Source: Kunkel (2013) based } \\
\text { on a new gridded version of } \\
\text { COOP data from the National } \\
\text { Climatic Data Center, the } \\
\text { CDDv2 data set for the } \\
\text { northeastern United States. }\end{array}$} \\
\hline
\end{tabular}
inches in the lower Colorado River valley (Kunkel et al., 2013). However, with much of the region classified as arid or semiarid, the annual average rainfall region-wide is around 15 inches.

Precipitation in California falls mostly in winter months, delivered by storms moving in from the Pacific Ocean (Langford et al., 2014). The position of the mid-latitude storm track also has a major influence over winter precipitation over the entire region and is particularly important for snow accumulation in mountainous areas. Highelevation winter snowpack in the Sierra Nevada and Rocky Mountains acts as a natural reservoir and is a vital source of water during drier summer months. In Arizona and New Mexico, the North American monsoon season (June 15September 15) has a major control over summer

precipitation. In monsoon season, some areas receive half of their total annual precipitation in July and

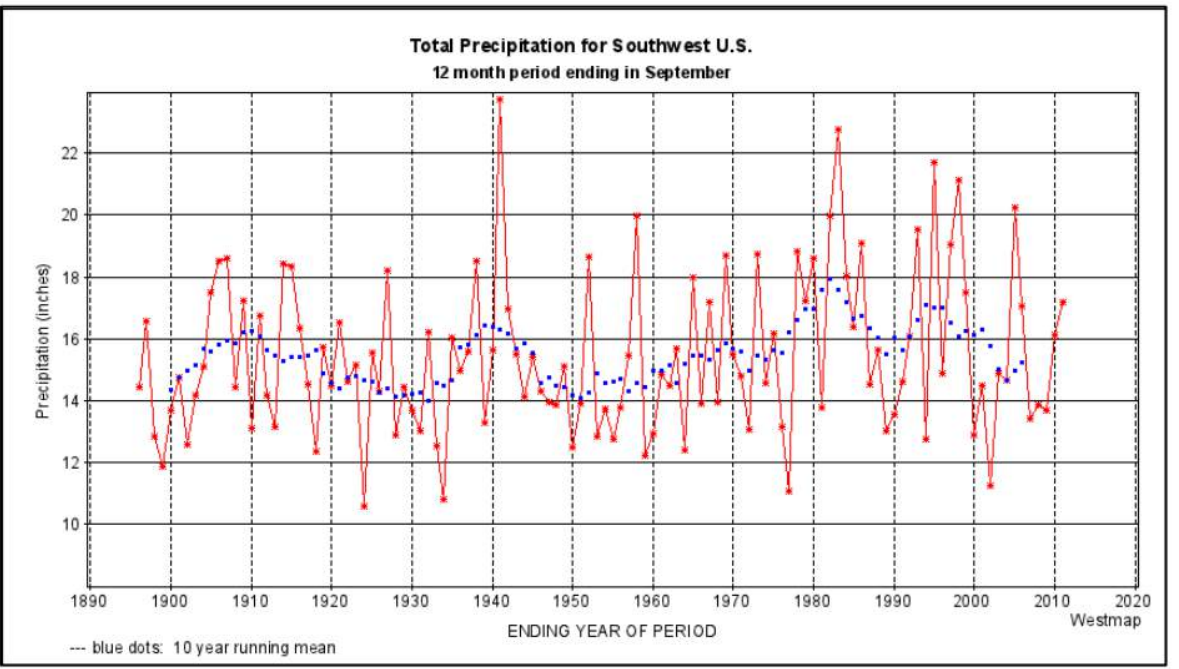

Figure 2: Annual water year (October-September) precipitation (inches/month) for Arizona, California, Colorado, Nevada, New Mexico, and Utah, 1895/96-2010/11. Annual values in red, 10-year running means in blue. PRISM data from WestMap (Kunkel et al., 2013). August.

The Southwest region experiences a wide range of weather and climate events including droughts, heat waves, and floods. Notable wet periods in the last 115 years include 1940-1941, and the 1980s and 1990s. Region-wide severe droughts occurred in 1900, the mid-1950s, and early 2000s (see Figure 2)

\footnotetext{
${ }^{1}$ A temperature anomaly is a departure from a reference value over a long-term average. Positive anomalies demonstrate that the observed temperature was warmer than the reference value, and negative anomalies indicate the observed temperatures were cooler than the reference value (National Oceanic and Atmospheric Administration, 2015).
} 
(Kunkel et al., 2013) and, at the time of writing, California and parts of Nevada are experiencing exceptional drought.

\section{Hawai'i}

Typical features of the Hawaiian climate include the northeasterly trade winds, mild temperatures throughout the year, moderate humidity, large differences in rainfall within short distances, and infrequent severe storms (Price, 1983). Near sea level, average daily temperatures usually range between $79^{\circ} \mathrm{F}$ and $90^{\circ} \mathrm{F}$. Temperatures decrease with elevation (lapse rate of about $3.6^{\circ} \mathrm{F}$ per 1,000 feet). Recent research reveals a warming trend in the Hawaiian Islands, with average monthly temperatures increasing between 1919 and $2006\left(0.07^{\circ} \mathrm{F}\right.$ over the full period $)$, and accelerated warming $\left(0.29^{\circ} \mathrm{F}\right.$ per decade $)$ occurring between 1975 and 2006 (Giambelluca et al., 2008).

\section{Temperature}

Interannual and decadal patterns in sea surface temperature have significant effects on climate in the Central North Pacific. The El Niño-Southern Oscillation (ENSO) is the most pronounced interannual phenomenon. In La Niña years, total annual precipitation is higher with more frequent heavy precipitation events (Chu et al., 2010). El Niño years are typically dry. The effects of ENSO are intensified when El Niño and La Niña events are synchronous with positive and negative Pacific Decadal Oscillation (PDO) phases (Chu \& Chen, 2005). Temperature data show consistency with the increased occurrence of trade wind inversion and a drop in trade wind frequency over Hawai 'i since the late 1970s (Figure 3).

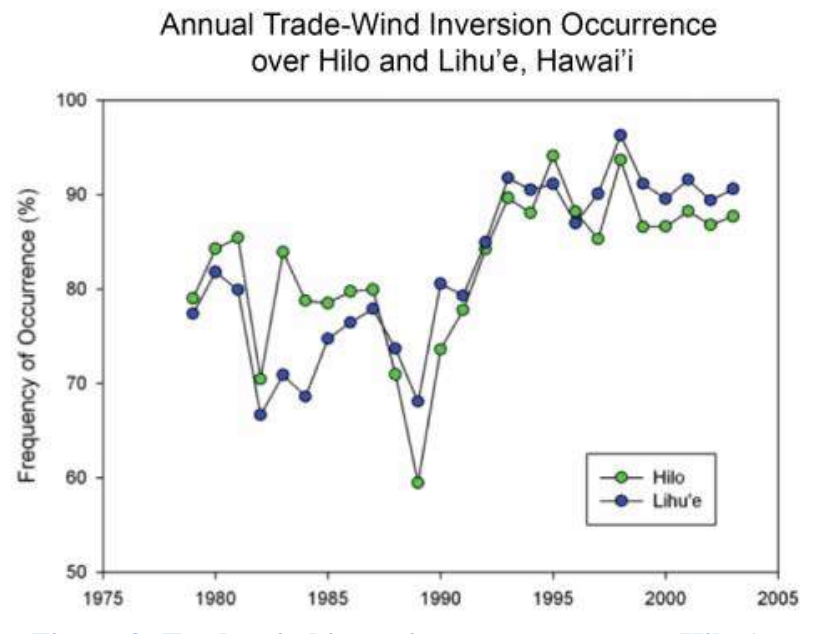

Figure 3: Trade-wind inversion occurrence over Hilo (green) and Lihu'e (blue), Hawai'i (Keener et al., 2013).

\section{Precipitation}

In Hawai'i, annual precipitation can vary from 8 inches near the top of Mauna Kea to 400 inches on the windward slope of Haleakalā, Maui (Keener et al., 2013). Precipitation can come in the form of rain, hail, snow, or fog. The dry season is typically from May to October, and the rainy season is from November to April. Although ENSO and PDO episodes have caused much precipitation variability over the last century, analysis of data from climate stations indicates a general downward trend (Giambelluca et al., 2013). The frequency of the occurrence of trade wind inversion increased during the 1990s from less than 80 percent to around 90 percent of the time-consistent with current observations of reduced precipitation particularly at high elevations (see Figure 3) (Keener et al., 2013). Climate change can affect ENSO and PDO patterns, thus introducing further uncertainty into precipitation predictions in Hawai ' $i$ (Keener et al., 2013).

\subsection{Summary of Regional Climate Scenarios}

\section{Mainland States}

Possible effects of the increase in both maximum and minimum temperatures are serious. They include reduced capacities for forage production, lower specialty and field crop yields, diminished quality and quantity of particularly temperature sensitive crops such as corn and wheat shifts in where crops are grown, adverse effects on livestock welfare, and increased severity of forest fires. 
This assessment uses projections from phase 5 of the World Climate Research Program's Coupled Model Intercomparison Project (CMIP5). The crop and rangeland sections use mean future temperatures for the 2040-2069 period with assumptions that greenhouse gas emissions will continue to increase through the 21 st century (representative concentration pathway; RCP 8.5 ). The forestry section uses a climatic envelope approach with moderate and high predictions for two time periods (2040-2060 and 2061-2080) to yield a range of results. Abatzoglou and Brown (2012) predict that in the Southwest region, maximum temperatures will increase by 3.6 to $7.2^{\circ} \mathrm{F}$ by $2040-2069$ (Figure 4). Highest increases are expected in Utah, with average annual maximum temperatures rising about $7.2^{\circ} \mathrm{F}$ statewide; southwest Arizona and the Pacific Coast of California are expected to experience the lowest change in maximum temperature of about $4.5^{\circ} \mathrm{F}$. New Mexico, most of Arizona and Nevada are expected to increase in temperature by about $5.4^{\circ} \mathrm{F}$. The largest temperature increase will occur in the summer months (June-August) across much of the Southwest region. Average minimum temperatures by 2040-2069 are also projected to rise between $3.6^{\circ} \mathrm{F}$ and $7.2^{\circ} \mathrm{F}$ in the southwestern United States.
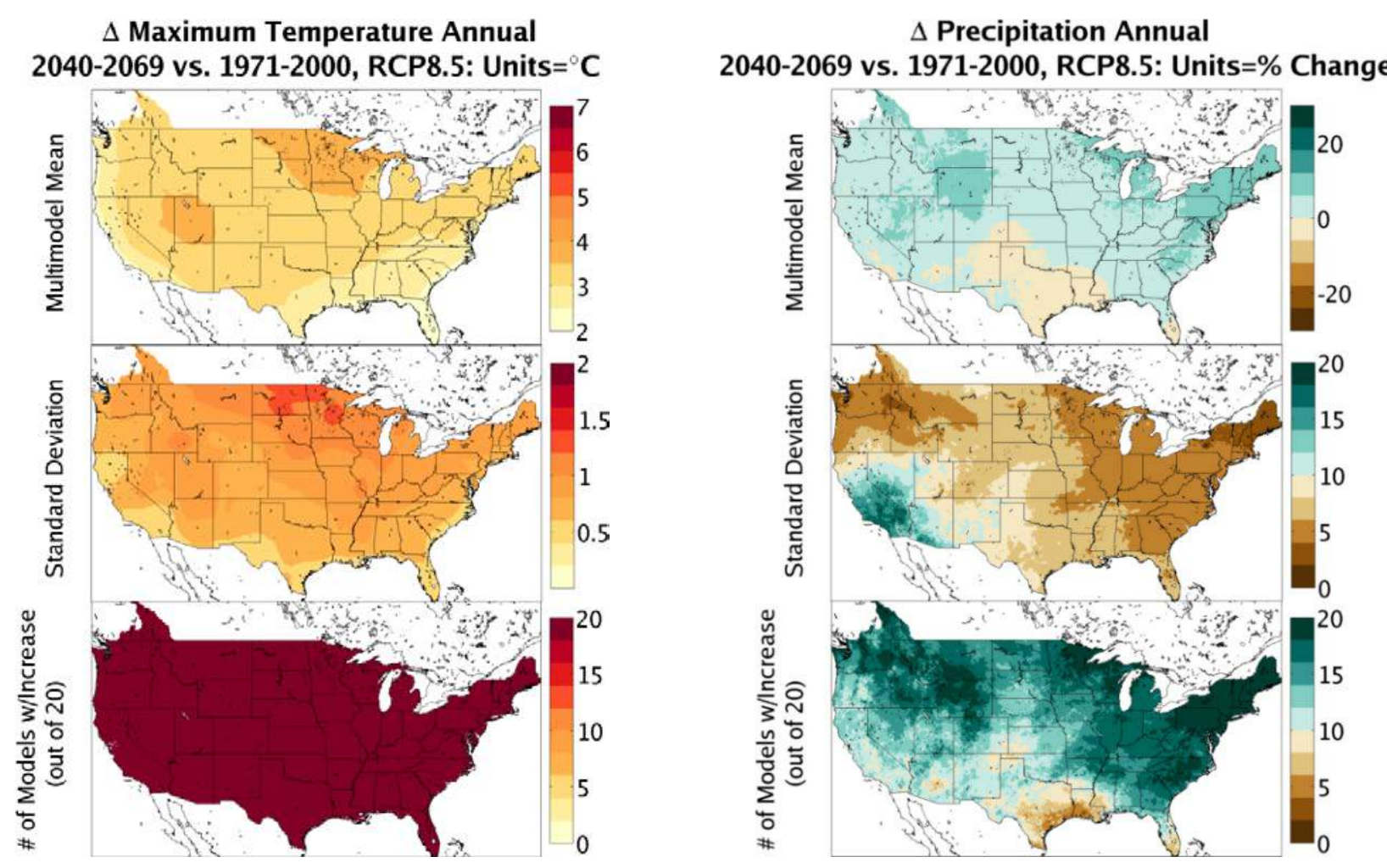

Figure 4:Period change analysis (1970-2000 to 2040-2069) of maximum temperature and mean precipitation changes based on the mean of 20 coupled model intercomparison project 5 (CMIP5) models (Representative Concentration Pathway 8.5) (Abatzoglou \& Brown, 2012).

Precipitation projections are less certain than temperature projections. The mean of 20 CMIP5 annual precipitation model projections shows a slight decrease in parts of New Mexico, central Arizona, and southwestern California, and a slight increase in other parts of the region (Abatzoglou \& Brown, 2012).

It is noteworthy that in most locations, more than half of the models indicate an increase in mean annual precipitation, indicating more uncertainty about future regional precipitation than temperature. Other recent research has shown that CMIP5 general circulation models underestimate the risk of 21st century droughts (Ault et al., 2014; Langford et al., 2014). Ault et al. (2014) estimate the risk of decadal drought at between 70 to 90 percent, and multidecadal megadrought at 5 to 10 percent. Whereas annual 
precipitation projections show both slight increases and decreases depending on model and region, springtime precipitation (March-May) over most of the Southwest is projected to decrease by as much as 20 percent.

\section{Hawai'i}

The eight main islands of the Hawaiian archipelago are located between $19^{\circ} \mathrm{N}$ and $22^{\circ} \mathrm{N}$ in the Central North Pacific, more than 2,000 miles from mainland United States. To the north and east of Hawaii, in the central east Pacific, lays a persistent zone of high sea level pressure known as the North Pacific High $(\mathrm{NPH})$; the position of the NPH has primary influence on the climate of Hawai 'i, giving rise to the northeasterly trade winds. Other typical features of the Hawaiian climate are mild temperatures throughout the year, moderate humidity, large differences in rainfall within short distances, and infrequent severe storms (Price, 1983). The low-latitude position of the Hawaiian archipelago means that the islands experience only small seasonal differences in solar radiation, which in turn, means there is little difference in temperature (around 0.56 to $3.33^{\circ} \mathrm{C}\left[1-5.9^{\circ} \mathrm{F}\right]$ ) between the warmest and coolest months (Keener et al., 2013). Near sea level, average daily temperatures are largely moderated by the ocean and usually range between $26^{\circ} \mathrm{C}\left(79^{\circ} \mathrm{F}\right)$ and $32^{\circ} \mathrm{C}\left(90^{\circ} \mathrm{F}\right)$. Temperatures decrease with elevation at rates between 0.55 to $1^{\circ} \mathrm{C}\left(1-1.8^{\circ} \mathrm{F}\right)$ per $100 \mathrm{~m}$ (Figure 5).
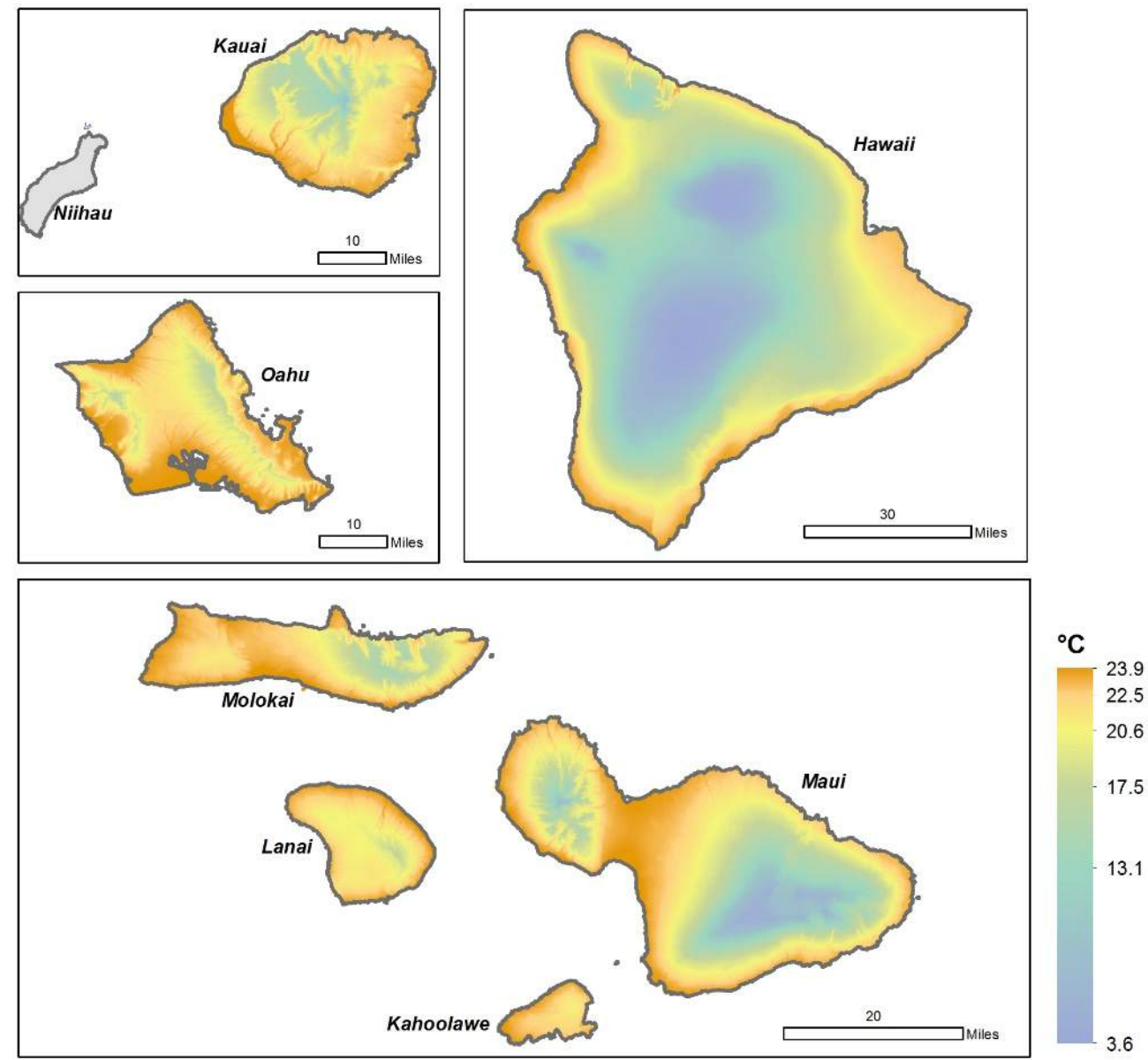

Figure 5: Annual average temperature $\left({ }^{\circ} \mathrm{C}\right)$ in the Hawaiian Islands (Giambelluca et al., 2013).

Recent research reveals a warming trend in the Hawaiian Islands (Diaz et al., 2011; Giambelluca et al., 2008). Giambelluca et al. (2008) found that average monthly temperature in Hawai' $i$ has increased between 1919 and $2006\left(0.04^{\circ} \mathrm{C}, 0.07^{\circ} \mathrm{F}\right.$ over the full period $)$, with accelerated warming $\left(0.2^{\circ} \mathrm{C}, 0.4^{\circ} \mathrm{F}\right.$ per 
decade) occurring over the three decades between 1975 and 2006. Faster rates of warming were documented for higher elevations, and nighttime temperatures are increasing, reducing the diurnal temperature range; minimum daily temperatures $\left(\mathrm{T}_{\min }\right)$ are increasing rapidly at high elevations by $0.5^{\circ} \mathrm{C}$ $\left(1^{\circ} \mathrm{F}\right)$ per decade and, in winter, minimum daily temperatures are also increasing at lower elevations (Giambelluca et al., 2008). Diaz et al. (2011) present data that show evidence of recent decreases in the frequency of freezing temperatures at higher elevations on Maui and the Big Island, and an increase in the elevation at which freezing occurs.

There is great diversity in precipitation over Hawai ' $i$ (Figure 6, (Giambelluca et al., 2013). In the vicinity of the islands, open-ocean rainfall averages around 600 to $750 \mathrm{~mm}$ per year. Rainfall over Hawai' $\mathrm{i}$ is higher than the surrounding ocean because the marine influence on precipitation patterns is modified by the mountainous terrain (Blumenstock \& Price, 1972). The islands range from 1,000 to higher than 4,000 $m$ in elevation, exerting strong orographic effects on rainfall, with more precipitation (sometimes exceeding 7,500 $\mathrm{mm}$ ) falling on the northeast, windward sides of the islands than on the leeward sides and surrounding ocean (Keener et al., 2012).
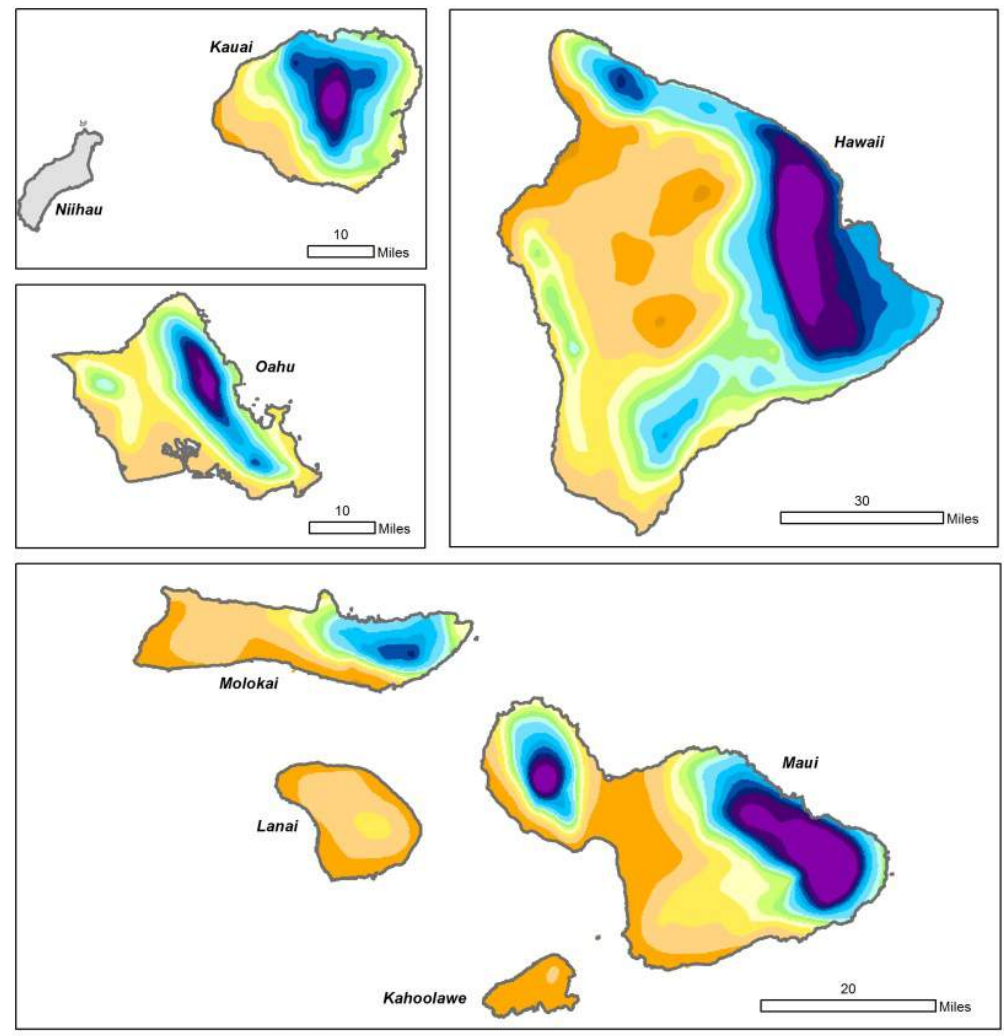

Annual mean precipitation $(\mathrm{mm})$

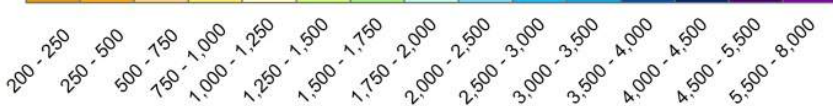

Figure 6: Annual average rainfall in the Hawaiian Islands (Giambelluca et al., 2013).

Global climate models (GCMs) predict warming temperatures over Hawai 'i through the 21 st century.

Reported figures vary because different research groups use different GCMs, different warming scenarios, and different downscaling techniques. Lauer et al. (2013) assessed output from the Weather Research and Forecasting (WRF) model, which was forced using boundary conditions from 10 GCMs and two CMIP5 warming scenarios (RCP 4.5 and RCP 8.5). They compared the historical decade 1990 to 1999 with the 
future decade 2090 to 2099. Model results for RCP 4.5 are within the same range reported by Keener et al. (2013) and suggest an increase in near-surface temperature of between $2.1^{\circ} \mathrm{F}$ and $5.2^{\circ} \mathrm{F}$. Model results for RCP 8.5 suggest an increase of between $4.1^{\circ} \mathrm{F}$ and $8.8^{\circ} \mathrm{F}$ (Lauer et al., 2013).

Some GCM analyses suggest precipitation will increase over the 21st century (Keener et al., 2013). Lauer et al. (2013) predict small absolute changes in precipitation over Hawai ${ }^{i} i$, with increasing summer precipitation and decreasing winter precipitation. Other work predicts overall decreasing precipitation but spatial variability in precipitation trends. Elison Timm et al. (2015) analyzed the ensemble mean of 32 CMIP5 model outputs for present day, RCP4.5 and RCP8.5 warming scenarios. Their results show strong drying on the leeward sides of Kauai, Oahu, Maui, and the Big Island, and slight increases in precipitation in windward areas.

There is uncertainty as to how ENSO events will change in the future in response to climate change (Cobb et al., 2013; Lauer et al., 2013). Evidence from central Pacific fossil coral data shows ENSO variability over the last century has been much higher than it has been over the preceding 7,500 years (Cobb et al., 2013). This is not definitive proof that ENSO is driven by enhanced greenhouse forcing, but it implies that this variability will continue and possibly intensify in the future.

\section{Regional Agriculture's Sensitivity to Climate Change and Adaptation Strategies}

In this chapter we review the sensitivity of cropping systems and animal agriculture to the effects of climate change and summarize potential adaptation strategies. The mainland crops included here (Section 2.1) represent the largest acreage or the highest economic value in the region. Three crops grown in the Hawaiian Islands are also included in this review; these were selected because of their economic and cultural importance to Hawai ' $i$. Of the selected mainland crops, 80 percent of the 2012 production value resulted from the sale of Southwest specialty crops, primarily grown in California. Grapes and almonds are particularly economically important, each representing more than 16 percent of the total regional production value (National Agricultural Statistics Service, 2013). Field crops (hay, corn, cotton, small grains, safflower, and rice) represent 20 percent of the 2012 regional production value, and most of which supports animal agriculture in the Southwest. Regional animal agriculture (Section 2.2) represents onethird of the total 2012 Southwest production value.

\subsection{Cropping Systems Overview of Risks, Vulnerabilities, and General Adaptation Strategies}

Regional Issues for Southwest Cropping Systems

Southwestern agriculture is defined by water availability

More than 92 percent of the region's cropland is irrigated, and although the amount of water used varies regionally, agriculture accounts for 79 percent of all water withdrawals in the region (Kenny et al., 2009). Future water availability depends on the annual distribution of precipitation, the proportion of winter precipitation falling as snow, groundwater resources, and changing urban and agricultural demands for water. Currently, much of the water used in mainland southwestern agriculture comes from winter snowpack or groundwater resources. Increasing winter temperatures result in more precipitation occurring as rain rather than snow, less storage of water in the snowpack reservoir, and earlier snowmelt runoff, possibly leading to irrigation scheduling and water use challenges. A warmer, drier climate (and increasing urban population) may lead to increasing transfers of irrigation water to urban areas, directly affecting local agriculture and associated communities. Water availability may drive transformational shifts. In some locations, current irrigated acres may shift to rain-fed agriculture. In other locations, rain- 
fed agriculture may no longer be economical. In rain-fed rangelands, few if any management alternatives are available to maintain current ecosystem services.

Rising temperatures and shifting precipitation patterns, especially in the southern portion of the region, will alter crop-water requirements, crop-water availability, crop productivity, and costs of water access. Higher temperatures will increase losses from both evaporation and transpiration. Detrimental effects on crop health will in turn drive changes in cropland allocations and production systems. High nighttime temperatures effectively increase the minimum temperatures. Temperature increases result in more precipitation occurring as rain rather than snow and earlier snowmelt runoff, possibly leading to irrigation scheduling and water use challenges.

\section{Elevated temperatures are associated with reduced yields and/or quality in some crops}

For grain crops, high nighttime temperatures increase the rate and decrease the length of the grain-filling period, resulting in smaller grain yields. Perennial specialty crops have a winter chilling requirement ranging from 200 to 2,000 cumulative chill-hours. Yields decline if the chilling requirement is not completely satisfied, because floral initiation and viability is low. Winter chill periods are projected to fall below the duration necessary for many California trees to bear nuts and fruits, which will result in lower yields. Projections show that chilling requirements for some fruit and nut trees in California will not be met by the middle to the end of this century (Luedeling, 2012; Luedeling, Zhang, \& Girvetz, 2009; Luedeling, Zhang, Luedeling, et al., 2009). In 2012, fruit, tree nuts and berries accounted for $\$ 17.9$ billion in sales, the largest revenue from a commodity group in the Southwest. Whereas grape yields may be less affected by increasing temperatures, grape quality (flavor development and sensory characteristics) can be highly sensitive to temperature, leading to a likely negative effect on winegrowing (Lobell \& Field, 2011; Nicholas et al., 2011).

\section{Failure of some crops may occur at elevated temperatures}

Warm-season vegetable crops may not be viable under hotter climate conditions (Dominati et al., 2010; O'Neal et al., 2005). Temperature increases beyond optimum thresholds, such as those projected for the decades beyond 2050, can cause large decreases in crop yields.

Crops grown in some areas might not be viable under future climate conditions, but other crops could likely replace them

For example, wheat is more sensitive to drought and elevated temperatures than barley. The deep taproot of safflower makes it well suited for the mainland Southwest. The cumulative effects of a longer frostfree season, less frequent cold spells, and more frequent heat waves accelerates crop ripening and maturity; reduces yields of corn, stone fruit, and wine grapes; and increases agricultural water consumption. This combination of climate changes is projected to continue and intensify, possibly requiring a northward shift in crop production, displacing existing growers and affecting farming communities (Frisvold et al., 2013).

Elevated temperatures and decreased soil moisture may limit production of nonirrigated field crops such as barley, hay, and safflower grown on arable dryland.

\section{Under warmer winter temperatures, some pests can persist year-round and new pests and diseases} may become established

For example, the codling moth (a common pest of fruit and nut orchards) may increase from two to three or even four generations per year with long, warm summers and late, mild winters (University of California Davis, 2013).

Many adjustment costs such as those to relocate processing and handling facilities or irrigation infrastructure are expected to result from climate change

These costs may be especially significant for long-lived perennial crops such as grape vines. 
Agricultural and forested landscapes are increasingly subject to Federal Endangered Species Act regulations, which may drive future resource allocation

Many States have similar acts, such as the California Endangered Species Act (Vicente-Serrano et al., 2014). Climate change is resulting in less moisture and cooling available from fog in coastal areas and less in ground fog inland, with associated changes in the microorganisms and other species that rely on the moisture and shade. Many threatened and endangered terrestrial and aquatic species rely on such habitat for food, shelter, nesting or spawning. Increasing attention will be paid to the effects on these populations.

\section{Lack of flexibility in water rights legislation may limit adaptive management}

The prior system of water rights appropriation will favor holders of older water rights, whereas their neighbors with newer rights could have no access to water. This establishes a legal divide that is contrary to sustainable, community-based management for agriculture and ecosystems. Although historically this has been a limiting factor to adaptability, now climate change will further expose the need to modify the prior water rights appropriation system. Holders of old water rights may also lease or sell those rights.

Simply improving on-farm irrigation will not necessarily improve watershed-scale water deficits

Although it is necessary to improve irrigation at the farm scale, surface water recharge and basin water budgets may be unchanged by on-farm conservation; they may even be decreased by the lack of shallow groundwater recharge.

\section{An increase in extreme weather will affect crop growth and sales, water quality, and soil resources}

Climate change projections suggest an increase in extreme heat, severe drought, and heavy precipitation. The timing of extreme events will be critical because they may occur at sensitive stages in the development of agricultural crops. Extreme events at vulnerable times could have major effects on growth or productivity. The Southwest produces more than half of the Nation's high-value specialty crops. Drought and extreme weather affect the market value of fruits and vegetables more than other crops because they have high water content and sales depend on good visual appearance.

\section{Pollinators may be vulnerable to climate change effects}

Many specialty crops such as almonds, cherries, and watermelons are completely dependent on insect pollination. Bee populations have declined drastically in the past decade, and the relative contribution of pesticides and herbicides, pathogens, habitat loss, and climate change is unknown and deserves more investigation. Both native pollinators and managed honeybee colonies appear to be at risk from these stresses.

\section{Water quality is likely to decline as a result of climate change}

In coastal areas, rising sea levels and falling groundwater tables are likely to lead to increasing saltwater intrusion, thus jeopardizing irrigation supplies for high-value crops such as strawberries, broccoli, and avocados. In inland areas, such as the Central Valley of California, overdraft of groundwater is often accompanied by increases in salinity and other water quality issues.

\section{Crop-Specific Vulnerabilities and Adaptation Strategies: California Specialty Crops}

Researchers have focused increasing attention in the past decade on the potential effects of climate change on specialty crops in California and the Southwest region, but at present, there are still more questions than answers. Detailed biophysical modeling of future climate effects has been carried out for some high-value specialty crops such as wine grapes (Hannah et al., 2013) and orchard crops (Luedeling, Zhang, \& Girvetz, 2009), but for the majority of specialty crops, climate change effects remain largely unexplored. Two recent reviews of specialty crops and climate change deserve special mention: a multifactorial spatial analysis of vulnerability in California agriculture (Jackson et al., 2012), and a 
California-focused assessment of climate threats and adaptation options for specialty crops (California Department of Food and Agriculture, 2013).

Specialty crops are a diverse group. The USDA lists 208 fruits, tree nuts, vegetables, and herbs (plus dozens more nursery crops) that are commonly considered specialty crops. (Agricultural Marketing Service, 2014). However, only a handful of crops account for the large majority of specialty crop value and land area in the Southwest. In this assessment, we limit analysis to the top 10 specialty crops by value (Table 2). California accounts for more than half of specialty crop production nationwide. For many specialty crops (e.g., almonds, artichokes, figs, raisins, walnuts, pistachios, nectarines, olives, dates, and prunes), California is the Nation's only commercial producer. For other specialty crops (e.g., wine grapes, strawberries, leaf lettuce, garlic, broccoli, and Brussels sprouts), California's share approaches or exceeds 90 percent of U.S. production (Starrs \& Goin, 2010).

\section{Grapes}

Changes in temperature regimes can affect grape development (e.g. phenolic composition; (Nicholas et al., 2011) and may necessitate shifts in wine grape varieties that are more tolerant to those conditions. For example, some varieties (e.g. Cabernet Sauvignon) can develop und temperatures are not reached, but shifting to Rhone varieties may diminish this effect. Hannah et al. (2013) predicted that the area currently suitable for producing high-quality wine grapes may decrease by 70 percent under the 2050 RCP 8.5 scenario, potentially leading to increases in freshwater demand to mist canopies and create cooler temperatures. Misting is one of a variety of management practices that can be employed for climate change adaptation (Battany, 2012).

Table grapes may be more tolerant to increases in temperature. Table grape production has recently been established in parts of Mexico where the summer heat arrives earlier in the year than it does in California, leading to an earlier ripening and higher prices as grapes are released onto the market earlier than California grapes (M.A. Walker, personal communication).

Grapes are not as drought-sensitive as many crops, but their vast acreage and economic importance means that optimizing their water use in the future will be a high priority. Further efficiency gains are possible with irrigated grapes through, for example, transitioning table and raisin grapes from flood irrigation to drip irrigation, and better quantifying effective deficit irrigation regimes for different types of grapes in different locations. Ensuring minimal water stress during critical periods such as flowering can keep yields high even in drought conditions. However, there is a current trend in the raisin and table grape industry to adopt gable trellis and overhead trellis systems, which may lead to greater irrigation demands (L. Williams, personal communication, 5 January 2015).

The current drought has revived interest in dry-farming grapes (Pierson, 2014), and drought conditions may actually afford grapes a competitive advantage over other crops; for example, avocado growers in southern California have recently been switching to grapes because grapes use as little as one-tenth as much water per acre (Cabrera et al., 2014).

Regional Agriculture's Sensitivity to Climate Change and Adaptation Strategies Page $\mid 16$ 
Water quality, specifically increasingly salinity of groundwater, is already a concern for the coastal winegrowing regions such as Paso Robles. This problem is expected to worsen in the future as sea level rise and aquifer depletion lead to saltwater intrusion.

Effects from increasing pest pressure have been predicted for California grapes, including pests such as the grape mealybug (Pseudococcus maritimus) and the vine mealybug (Planococcus ficus) that serve as vectors for viruses carrying leafroll disease (Golino et al., 2008). Higher temperatures could lead to increases in vine mealybug densities across all regions of California and decrease the capabilities of existing biological control agents for vine mealybug (Gutierrez et al., 2008). Adaptation options include transitioning to more climate-tolerant varieties and breeding desirable traits to augment the available scion and rootstock material. Desirable traits found in Vitis species that could be introgressed into existing grape varieties include resistance to disease pressure from Phylloxera, Pierce's disease, and root-knot nematodes; and drought and salinity tolerance (Walker et al., 2014).

\section{Almonds}

California currently produces 100 percent of the Nation's commercial almond crop and more than 80 percent of the world's almond crop (Almond Board of California, 2013). Luedeling, Zhang, Luedeling, et al. (2009) predict that many suitable almond growing locations in the Central Valley would remain by mid- to late-century; almonds are considered to be only slightly sensitive to the predicted trends in decreasing chill-hours (about 200-400 hours, whereas others tree nut crops generally require 500-1,000). Lobell and Field (2011) argue that warm February temperatures shorten the blooming window and hamper pollination. However, in their analysis, the benefits of warmer springs and summers partly canceled out the negative yield effects of warmer winters, for an overall yield reduction of about 10 percent by 2030 in the absence of adaptation.

The average California almond orchard uses about 40 inches of irrigation water per year (University of California Division of Agriculture and Natural Resources, 2014a), similar to other fruit and nut orchards. During periods of drought, almond farmers may have the option to use deficit irrigation, which reduces irrigation by applying water during vital phenological stages at the expense of more drought-tolerant stages. Although this reduces yields, it allows trees to survive and continue producing until more water becomes available (University of California Division of Agriculture and Natural Resources, 2014a).

Because almonds depend on bees for pollination, any factor that harms bees-whether climate-related or not—can harm almond yields. Encouraging native pollinators may be a helpful management strategy to supplement pollination by honey bees (Kremen, 2013).

Almonds are vulnerable to severe storm events, especially while flowering. A severe rain or hailstorm during peak bloom can devastate the year's crop. In older almond orchards, high winds can cause widespread lodging (tipping over) of trees. Furthermore, warm storms that deliver large amounts of rain, which are expected to become more common with climate change, are known to be correlated with severe fungal disease in almonds, such as shot hole and brown rot (Campbell, 2006).

\section{Strawberries}

Even though strawberries are grown on only 39,000 acres in the coastal areas of central and southern California, they are the most valuable annual crop in the Southwest, worth more than $\$ 2$ billion annually and accounting for about 90 percent of U.S. production (Starrs \& Goin, 2010). Strawberries prefer a cool, coastal climate, which is one main reason that California's strawberry fields are so much more productive than those elsewhere in the country (California Strawberry Commission, 1999). Unusually warm temperatures shorten the growing cycle and promote pests and diseases such as mites, fruit rot, corn earworms, and caterpillars. Lobell and Field (2011) predicted that climate change would decrease yields of California strawberries by about 10 percent by 2050 , with effects somewhat greater in the southern part

Regional Agriculture's Sensitivity to Climate Change and Adaptation Strategies Page | 17 
of the State. Deschenes and Kolstad (2011) reached a more pessimistic conclusion, predicting that strawberry yields would decline 43 percent by 2070-2099.

Water quality and quantity is already a major concern for California strawberry growers (Paddock, 2013), and it will become even more of a concern under future climate scenarios. The water demand of strawberries is not particularly high (especially because they are grown in cool climates and use efficient drip irrigation plus plastic mulching), but the water supply is often problematic. In coastal areas, groundwater salinity is increasing due to sea level rise and excessive withdrawals resulting in saltwater intrusion. This is especially problematic given that strawberries are highly sensitive to salinity.

Some strawberry diseases are promoted by high temperatures, other by low temperatures, and many diseases are exacerbated by humidity (California Strawberry Commission, 1999). In particular, warm, dry weather accelerates mite infestations but reduces gray mold, whereas warm weather in general promotes powdery mildew (O. Daugovish, personal communication, 7 January 2015).

The Salinas Valley, a major strawberry growing region, is sometimes affected by flooding; for example, when the Salinas River overflowed in 1995, the resulting damage to strawberry, lettuce, and broccoli crops made it the third most costly weather event for California agriculture in the past 30 years (Lobell \& Field, 2011). Floods may become more frequent or intense due to the more intense precipitation expected with climate change.

\section{Lettuce}

California and Arizona together produce 95 percent of the nation's lettuce, a remarkable logistical achievement considering the high perishability of the crop. The 2012 lettuce crop was worth nearly $\$ 2$ billion, making it the region's second most valuable annual crop after strawberries. Western Arizona and inland southern California dominate production in December, January, and February; the rest of the year, most lettuce comes from California's Central Coast (Smith et al., 2011).

Lettuce is a cool-season crop with very particular temperature preferences. Ideal growing temperatures are $73^{\circ} \mathrm{F}$ in the daytime and $45^{\circ} \mathrm{F}$ at nighttime (Turini et al., 2011). Warm temperatures can contribute to bolting (rapid elongation and flowering of the stalk), which makes the lettuce head unattractive and bitter. Temperatures in the $90-99^{\circ} \mathrm{F}$ range can cause bitterness almost immediately even if the lettuce is not physiologically ready to bolt (Smith et al., 2003). Jackson et al. (2012) predict that warmer winters in California might result a longer growing season and thus greater productivity for lettuce. Deschenes and Kolstad (2011) concur, predicting a 7.8 percent increase in California lettuce yields by 2070-2099. However, these analyses may overlook more subtle effects of warming, such as the fact that warm nights can promote abnormally rapid growth that in turn can cause tipburn in lettuce (a disorder in which calcium cannot be transported quickly enough to the growing leaf edge, causing it to shrivel and blacken) (Smith, 2014). The most important temperature risk to lettuce may not be from slightly warmer winters, but rather from occasional hot days that exceed its tolerance. A bolted, bitter, or badly wilted lettuce crop has little to no commercial value, and although timely irrigation can help reduce heat stress, it cannot always prevent it. Lettuce varieties that are more heat-tolerant and bolt-resistant may be increasingly needed in the future.

Although an individual lettuce crop does not use a great deal of water, the cumulative water demand of lettuce is still immense for several reasons: 1 ) it covers a very large amount of acreage in the Southwest; 2) several lettuce crops can be grown per year on the same land; and 3) it is often grown in arid areas where it is completely irrigation-dependent (Bonfils et al., 2012). Improving irrigation efficiency could be achieved with increased adoption of drip irrigation compared with sprinkler or furrow irrigation. Another possibility is to select lettuce varieties with particular canopy architectures that reduce transpiration and improve water use efficiency (Hayes, 2013). Also, because water quality is likely to decline along with

Regional Agriculture's Sensitivity to Climate Change and Adaptation Strategies Page 18 
water quantity, it may be necessary to develop salt-tolerant lettuce varieties (especially for coastal regions where saltwater intrusion is a problem).

Significant floods sometimes occur in the Salinas Valley, the number-one lettuce-producing area. A major flood in the Salinas River in 1995 destroyed tens of millions of dollars' worth of lettuce in the field (Lobell et al., 2011), and the risk of such catastrophic events may increase under future climate scenarios.

\section{Walnuts}

California produces 99 percent of the walnut crop in the United States. Production of English walnuts is concentrated in the Sacramento and San Joaquin Valleys, but walnuts are also grown in Lake, San Benito, Contra Costa, and several coastal counties. Just two walnut varieties, Chandler and Hartley, account for 60 percent of California production (Starrs \& Goin, 2010).

Walnuts have relatively high chilling requirements (800-1,000 hours), and no low-chill cultivars are currently available (Pope, 2012). According to projections by (Luedeling, Zhang, \& Girvetz, 2009), by the year 2060, there will no longer be significant acreage in the Central Valley that reliably receives more than 800 chill-hours per year. Predicted reductions in chill-hours may also diminish walnut seed germination rates (California Department of Food and Agriculture, 2014a). Walnuts are also sensitive to damage incurred during extreme heat events during the fruit-set period (Baldocchi \& Wong, 2008).

Walnuts usually require 41-44 inches of irrigation water per year, comparable to that of other nut trees. Deficit irrigation can reduce this by about 12 inches, although yields will suffer (University of California Division of Agriculture and Natural Resources, 2014a).

Higher temperatures may also favor some walnut pests such as codling moth, which can increase from two to three or even four generations per year if fall temperatures are warm enough (University of California Davis, 2013).

\section{Citrus}

California produces 30 percent of the Nation's oranges, 90 percent of lemons, 48 percent of mandarins, and 30 percent of grapefruit (with Florida and Texas accounting for most of the rest) (Starrs \& Goin, 2010). Warmer temperatures may have some negative effects on citrus growers, but this is probably not the highest-priority concern. Citrus are adapted to semitropical conditions, and warm summers can improve crop flavor (Campbell, 2014). However, higher temperatures increase evaporative demand and may exacerbate drought stress. Also, if climate change causes a decrease in normal diurnal temperature fluctuations during fruit development in the autumn, fruit color may be negatively affected because breakdown of chlorophyll and subsequent emergence of carotenoids may be impaired (L. Ferguson, personal communication, 20 January 2015).

Citrus varieties have a moderately high annual irrigation demand of 34-36 inches per year in the San Joaquin Valley (Sanden, 2007) and somewhat less than that near the coast due to cooler temperatures and fog (Grismer et al., 2000). Decreasing quantity and quality of irrigation water will probably be the largest challenge that citrus growers face under future climate. The current severe drought is stunting citrus fruit and killing entire citrus orchards in southern California (Campbell, 2014).

\section{Pistachios}

Pistachio are grown mainly in Kern, Madera, Fresno, Tulare, and Kings counties in the San Joaquin Valley (Starrs \& Goin, 2010). California produces 99 percent of the Nation's pistachios; the small remainder come from Arizona and New Mexico. Pistachios have relatively high annual chilling requirements of about 800-900 hours (Pope, 2012). (Luedeling, Zhang, \& Girvetz, 2009) predicted that by 2060 , areas receiving more than 800 chill-hours per year will nearly disappear from the Central Valley. 
Although this does not bode well for pistachios in the coming century, there may be opportunities to develop low-chill cultivars (Pope, 2012).

Pistachios have an annual irrigation demand of about 40 inches, comparable to that of walnuts and almonds (University of California Division of Agriculture and Natural Resources, 2014). However, unlike almonds and walnuts, pistachios tend to fare relatively well under deficit irrigation, which can cut water use from about 40 to about 30 inches per year (University of California Division of Agriculture and Natural Resources, 2014a). Under duress, pistachio trees can even survive completely unirrigated for a year (Castellon, 2014), although yields will be minimal. Pistachios are also relatively salt-tolerant, making them a promising option for areas of the Central Valley with poor-quality groundwater.

Under damp conditions, pistachios are susceptible to foliar and fruit fungal diseases such as Botrytis blossom and shoot blight (University of California Davis, 2014). Climate change may increase or decrease the prevalence of pistachio diseases, depending on the precise patterns of humidity and temperature change. Major pistachio pests such as the navel orangeworm (Amyelois transitella) may grow more quickly under warmer temperatures, requiring adjustment of integrated pest management guidelines (University of California Davis, 2014).

\section{Tomatoes}

Tomatoes are relatively heat-tolerant. Optimal daytime temperatures for most tomato varieties are 75$95^{\circ} \mathrm{F}$ (Hartz et al., 2008), and optimal night time temperatures are $55-70^{\circ} \mathrm{F}$ (Ozores-Hampton et al., 2012), with cold-induced injury possible when night-time temperatures drop below $50^{\circ} \mathrm{F}$ (LeStrange et al., 2000). Tomatoes are least tolerant to departures from their ideal temperature during the critical developmental stages of pollination and fruit set. Overly warm average temperatures are especially harmful to tomatoes if they continue for days or weeks without a break (Sato et al., 2000). And even brief extreme heat events can ruin tomato yields if they occur at the wrong time; for example, temperatures above $104^{\circ} \mathrm{F}$ can cause flower abortion in a matter of hours (Ozores-Hampton et al., 2012).

Lobell et al. (2007) analyzed historical California climate and yield data and concluded that warmer temperatures favored tomato production up to about $90^{\circ} \mathrm{F}$. Lee et al. (2011) estimated that climate change would have no effect on tomato yields in the Central Valley by 2050, whereas Medellín-Azuara et al. (2012) predicted that by 2050, climate change would cause tomato yields to increase by 2.4 percent in the Sacramento Valley and 1.1 percent in the San Joaquin Valley. Jackson et al. (2012) predicted that tomato acreage would increase by 2050 in response to more favorable climatic conditions.

Tomatoes are less sensitive to suboptimal water quality and quantity than many other crops. Substantial water savings can be achieved either through cutback (slightly reduced watering throughout the season) or cut-off (normal watering followed by an early cessation of watering). For example, in an experiment on processing tomatoes in western Fresno County on deep clay-loam soil, when irrigation was cut off 40 days before harvest instead of the standard 20, there was no loss in yield, and even when the cut-off was 80 days, yields were still 81 percent of the control (University of California Division of Agriculture and Natural Resources, 2014). There is room for additional improvement in irrigation timing and technology, especially if water becomes costly enough that tomato farmers are willing to accept slight yield reductions to achieve major water savings.

\section{Broccoli, cauliflower, and cabbage}

Broccoli, cauliflower, and cabbage are cultivars of the same species (Brassica oleracea) and collectively are known as cole crops. California produces about 90 percent of the Nation's broccoli and cauliflower (Starrs \& Goin, 2010), whereas cabbage production is more widely distributed; California and Arizona together account for only 29 percent of national production (National Agricultural Statistics Service, 2014b). 
Broccoli, cauliflower, and cabbage are cool-season crops. They are grown in many locations in the Southwest, including California's Central Coast (especially the Salinas Valley), southern coast, inland deserts, and western Arizona. In the southern parts of this range, they are planted as winter crops, whereas in the northern parts, they are grown and harvested year-round. Their optimal temperature ranges are fairly narrow: $65-68^{\circ} \mathrm{F}$ for cauliflower (Koike et al., 2009) and $60-65^{\circ} \mathrm{F}$ for broccoli and cabbage (Daugovish et al., 2008; LeStrange et al., 2010). With prolonged temperatures above $26.7^{\circ} \mathrm{C}\left(80^{\circ} \mathrm{F}\right)$, cabbage may bolt (Daugovish et al., 2008) and cauliflower curds may become small and yellow (Koike et al., 2009). Deschenes and Kolstad (2011) estimate that California's broccoli yields will increase by 39 percent by 2070-2099 due to the direct effects of warmer winters and, indirectly, the ability to expand growing areas in the northern parts of the State.

Irrigation requirements vary considerably depending on location and irrigation method, ranging from a low of 14-24 inches for drip-irrigated cabbage in the Central Coast (Daugovish et al., 2008) to a high of 48 inches for furrow-irrigated cauliflower in the southern desert (Koike et al., 2009). In general, drip irrigation can cut water use by about 25 percent compared with sprinkler or furrow irrigation, but drip irrigation has not always been successful in uniformly meeting crop demand under warm conditions (LeStrange et al., 2010). Water limitations are a major concern for these crops under future climate. Their need for constant and uniform soil moisture makes drip irrigation an ineffective option in most cases, although further research and technology development may overcome some of these challenges.

Cole crops are prone to disease and insect damage. High soil temperatures are known to facilitate Fusarium infection, whereas warm nights and days (above $50^{\circ} \mathrm{F}$ and $60^{\circ} \mathrm{F}$, respectively) promote damage by Bagrada bug (O. Daugovish, personal communication, 24 December 2014).

\section{Stone fruit}

Peaches, nectarines, plums, apricots, cherries, and tart cherries - collectively referred to as stone fruit, are a group of closely related tree crops that figure prominently in the Southwest's agricultural output. California produces about 70 percent of all the Nation's peaches, 95 percent of apricots, 95 percent of fresh plums, 99 percent of dried plums, and 100 percent of nectarines (Starrs \& Goin, 2010). Although California produces only about 20 percent of the Nation's sweet cherries, this places it second in the Nation, behind Washington State. Utah produces about 10 percent of the Nation's tart cherries in an average year.

Increasing temperatures are a major threat to stone fruit production. Many farmers have already noticed the loss of chill-hours and the negative consequences for production (Baldocchi \& Wong, 2008; Licht, 2014). Development of low-chill cultivars will be a key adaptation strategy. However, although many stone fruit varieties have cultivars that require only 200-300 chill-hours (Pope, 2012), the low-chill feature often comes at the expense of flavor, texture, or other desirable characteristics. High temperatures in spring and summer can decrease fruit set, damage fruit production, and cause sunburn of tree trunks. The best long-term adaptation strategy is likely to be in the development of more tolerant cultivars (Pope, 2012), but in the short-term, orchard management practices such as early fruit thinning and careful irrigation may help to reduce losses.

All stone fruits grown in California have a similar irrigation demand of about 36-40 inches per year (Schwankl et al., 2007). Curtailing water use in stone fruit is challenging because water stress can cause cosmetic defects that reduce the fruit's value or makes it unmarketable (University of California Division of Agriculture and Natural Resources, 2014). Water stress can also facilitate damage by mites and other pests and pathogens (Johnson et al., 2006). However, some degree of deficit irrigation can be used with minimal losses if the timing is carefully controlled. For example, in early maturing peaches, irrigation can be safely reduced after the fruit is harvested in May or June, but then it must be restored in August and September, when the next year's flowers are developing within the buds (Johnson et al., 2006). Another 
avenue to address this problem is further development of rootstocks that are tolerant to drought and other abiotic stresses.

\section{Avocados}

Avocados are not in the top-ten list of California's specialty crops, but about 92 percent of the Nation's avocados are now grown in southern California (Starrs \& Goin, 2010), and of these, the vast majority (95 percent) are the Hass variety. Research by Lobell et al. (2006) gives a bleak outlook for avocados. In the absence of adaptation, avocado yields in California will decrease 45 percent by 2060 . This prediction was made with a model that related avocado yield to several different temperature metrics (based on historical observations). Lobell et al. (2006) found that warm temperatures in August are highly detrimental to avocado yield the following year, although the biological mechanism is not fully understood (Lobell et al., 2007). Conversely, warm nighttime temperatures in May appeared to boost avocado yields, so the net effect would depend on the temporal pattern of the warming (Lobell et al., 2007). Lobell et al. (2006) also predicted that avocado production will shift from coastal and inland southern California to coastal central California (for example, Santa Barbara County). They postulate that with a $7.2^{\circ} \mathrm{F}$ temperature rise, there will be almost no overlap between current and future avocado-growing areas.

Water will be the single most important issue for California avocado growers under future climate scenarios. The root system of avocados is only about 18 inches deep (Spann, 2014), so irrigation must be frequent and regular to prevent water stress. It takes about 74 gallons of water to grow 1 pound of avocados-compared with 42 gallons for 1 pound of peaches or 12 gallons for oranges (Mekonnen \& Hoekstra, 2011). The current severe drought has already resulted in a loss of more than 14,000 avocado trees in southern California-trees that were allowed to die as water prices climbed and growers could no longer afford to irrigate (Cabrera et al., 2014). Research on deficit irrigation in avocados is sparse, but given the high sensitivity of avocados to drought; for example, 1 week of missed irrigation can cause the complete failure of the subsequent crop, it will be challenging to come up with a deficit irrigation strategy that does not harm yields. Less risky ways to reduce water use include repairing leaky pipes, frequently measuring soil moisture or other metrics of water availability, preventing runoff by accounting for an orchard's slope and infiltration rate, and removing old or unproductive trees (Faber, 2014). Avocados are inherently very sensitive to excessive salinity, which can occur due to insufficient or poor-quality irrigation water (Bender et al., 2013).

\section{Crop-Specific Vulnerabilities and Adaptation Strategies: Southwest Field Crops}

Field crops provide only 20 percent of the total crop revenue in the Southwest, but they are important to world food, feed, and fiber production. Other regions of the United States may produce the greater proportion of national field crops, but the alfalfa, maize, and small grains produced in the Southwest support the southwestern animal agriculture industry. Table 3 summarizes regionally important field crops. These crops were selected because they are widely grown in the region and provide some of the highest regional economic returns.

Several recent studies describe the effects of temperature on individual field crop species. Hatfield et al. (2011) and Walthall et al. (2012) provide synthesized information from a wide variety of scientific studies on climate change effects on cotton, maize, rice, and wheat. Higher temperatures can lead to a decline in crop yield or even crop failure in certain situations. The effect of higher temperatures on crop
Table 3: Field crop production in the Southwest

\begin{tabular}{|c|c|c|}
\hline Crop & Acres* & Value $\nmid$ \\
\hline $\begin{array}{l}\text { Hay and } \\
\text { Alfalfa }\end{array}$ & $3,155,000$ & $3,185,295$ \\
\hline $\begin{array}{l}\text { Cotton (Pima } \\
\text { and Upland) }\end{array}$ & 605,300 & 924,848 \\
\hline Rice & 557,000 & 844,682 \\
\hline Wheat & 777,000 & 498,174 \\
\hline Corn grain & 289,000 & 361,813 \\
\hline Corn silage $\ddagger$ & 635,000 & \\
\hline Barley & 153,000 & 66,696 \\
\hline Safflower & 75,500 & 29,423 \\
\hline Oats & 23,000 & 8,473 \\
\hline \multicolumn{3}{|c|}{ 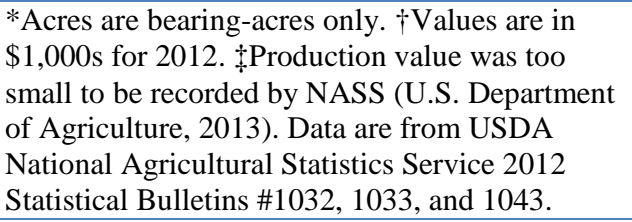 } \\
\hline
\end{tabular}


production will be more severe on those crops grown where production temperatures are presently near optimal, such as in southern deserts. However, temperature effects vary by many factors, including crop and cultivar, plant lifecycle stage, and local microclimatology. For example, canopy cooling will reduce temperatures in the local microclimate, and thus is an inherent adaptive mechanism in alfalfa, cotton, and other crops of the southern desert. Field crops of the Southwest will likely be significantly affected by limited water supplies. Some field crops such as rice require high amounts of water. Most other crops such as alfalfa, corn, and wheat are irrigated. Barley and safflower are considered drought-resistant, but irrigation of these crops is sometimes necessary and typically improves yields. Adaptation options range from development of more heat- and drought-tolerant varieties to shifting production to transition seasons or locations.

Research on alternate irrigation strategies such as precision overhead irrigation for alfalfa and corn may lessen the effects of regional water shortages. Interdisciplinary research on likely changes in climate and consequent effects on regional crops is necessary. Improving drought and heat tolerance through genetic research and genomic selection will help in adaptation to future warmer temperatures and water scarcity.

\section{Hay and alfalfa}

Hay, a general term for grasses, legumes, and other plants used to feed animals, is grown throughout the Southwest. Counties with large revenues from livestock also have large acreage devoted to hay production. In 2012, alfalfa grossed $\$ 2.62$ billion in the region, and total hay, including alfalfa, grossed $\$ 3.19$ billion. Alfalfa is the most important hay commodity in the Southwest and, in 2012, accounted for 66 percent of the total hay acreage and 82 percent of the total dollar value in the Southwest. Alfalfa is a cool-season perennial crop that can be harvested year-round in most of the Southwest.

Alfalfa yield and quality ("summer slump") have declined beginning in July in areas where summer is hot, such as the low-elevation deserts (Ottman \& Mostafa, 2013). More temperate regions exhibit a gradual decline in alfalfa yield in successive harvests. Summer slump has been attributed to shorter days and fall dormancy in northern areas, and excessive heat stress in hot arid zones (Putnam \& Ottman, 2013). Summer slump can affect alfalfa health by reducing root carbohydrates. Water stress, low root carbohydrate levels, and high temperatures cause premature flowering and thus low yield. Summer-slump alfalfa is usually low in quality and not suitable for lactating dairy animals.

Most of the hay planted in the Southwest is irrigated. Of the 152 counties in the region, hay acreage was irrigated in less than 40 percent of only 17 counties. These minimally irrigated counties are located in California and contain fewer than 25,000 acres of hay. In 62 percent of counties, more than 70 percent of the total hay grown is irrigated. Data were unavailable for 25 counties. Although high temperatures and lack of adequate water decrease alfalfa suitability, alfalfa has benefits that support adaptation to climate change. Many varieties of alfalfa have been developed that are resistant to diseases and insect pests. Alfalfa does not need nitrogen fertilizer. It is an important rotation crop because it improves soil structure and adds nitrogen for future crops. Management, such as extending cutting schedules, can be used to maximize yield under a changed climate.

\section{Cotton}

Although cotton (both upland and pima) is grown only in 20 percent of southwestern counties, it represents the second most lucrative regional field crop. Commercial cotton species are of tropical and subtropical origin, require large numbers of heat units to mature, and have fair levels of heat tolerance. However, cotton can be vulnerable to heat stress, especially during humid periods. Yield and growth can be diminished at high temperatures (Oosterhuis, 1999), especially during floral development (Snider et al., 2011). Although cotton can be grown at temperatures higher than $104^{\circ} \mathrm{F}$, reported ideal temperatures from studies in a controlled environment range from $68^{\circ} \mathrm{F}$ to $90^{\circ} \mathrm{F}$ (Burke et al., 1988; Reddy et al., 1991). (Brown, 2008) conducted field, growth chamber, and greenhouse studies and found that fruit retention, 
seed number, and boll size declined as mean temperatures increased above $82^{\circ} \mathrm{F}$, and fruit retention declined at mean temperatures above $90^{\circ} \mathrm{F}$. Floral abnormalities associated with heat stress occurred $\sim 15$ days after exposure to mean temperatures above $86^{\circ} \mathrm{F}$, leading to the conclusion that severe heat stress damages young squares that are about 15 days from flowering, subsequently causing nearly all resulting bolls to abort 3-5 days after bloom (Brown, 2008). One likely reason for elevated rates of heat stressinduced sterility during the monsoon was due to higher relative humidity and reduced transpirational canopy cooling (R. Percy, personal communication, 6 February 2015). Several researchers have reported high nighttime temperatures as a cause of cotton stress, but this finding was not reproduced in Arizona (Brown, 2008). The relationship between high nighttime temperatures and poor fruit retention in Arizona may be related to higher humidity, which inhibits radiative cooling at night and leads to elevated nighttime canopy and air temperatures.

Although temperatures outside optima inhibit growth and reproduction, ambient air temperature and cotton canopy temperatures are not equivalent in the western United States. Cotton canopies can be much cooler than air temperature in arid and semiarid regions. This is one reason cotton is still grown in the lower Arizona desert (P. Brown, personal communication, 2 February 2015). Although temperature contributes to cotton heat stress, humidity associated with the summer monsoon is the factor that most effects Arizona cotton production. Climate change may alter the geographical area suited to cotton production, possibly to higher elevations, especially if warmer summer months also experience a more intense monsoonal season and higher humidity. Because cotton produces throughout the growing season, some of the effects of climate change may be buffered because of this adaptive capacity (Walthall et al., 2012).

All southwestern cotton is irrigated. Temperature is a relatively minor factor when it comes to crop water use. The major factor driving water use is solar radiation, which is already at high levels in the Southwest. In a warmer future environment, a small increase in crop water use may occur on a daily basis, but this may be offset by faster crop development.

Cotton is a thermally driven crop, and warmer temperatures accelerate crop development (degree days or heat units). Also, if conditions warm to the point at which cotton will not grow in a normal summer season, then production may shift to the transition seasons when solar radiation and therefore water use is lower.

Cotton breeders continue to select new varieties, and yields are improving. Through largely conventional breeding it appears that rice varieties are gaining heat and drought tolerance as the climate changes. If future warming accelerates, researchers and farmers will need to rely more on genetic engineering to accelerate variety improvement (P. Brown, personal communication, 2 February 2015).

\section{Rice}

California's Central Valley produces 23 percent of the Nation's rice (and nearly 100 percent of shortgrain and medium-grain rice), making it the second largest rice-producing State (U.S. Department of Agriculture, 2013). Little research has occurred to assess how rising temperatures will affect rice production in California. One recent study (Lee et al., 2011) used crop simulation models and a highemissions climate scenario to predict that California rice yields could decline by approximately 10 percent by 2099. However, they suggested that $\mathrm{CO}_{2}$ fertilization might partly or fully compensate for this temperature-induced yield loss. They did not consider any changes in the availability of irrigation water, which is probably the issue of greater concern for California rice growers.

All rice in California is irrigated; there is no option for rain-fed rice farming because rainfall is minimal during the growing season (B. Lindquist, personal communication, 1 February 2015). Rice is usually grown under flooded conditions and can require large amounts of water, thus it has a reputation as a 
thirsty crop. On the low end, a rice crop can use as little as 34 inches of water, which is comparable to most orchard crops. On the high end, rice may need up to 90 inches to flow through a field (University of California Division of Agriculture and Natural Resources, 2013). Flow-through is sometimes necessary to reduce salinity buildup due to evapoconcentration of salts. However, in California, because percolation and seepage are generally low and rice growers do a much better job of managing flow-through water, recent estimates exhibit an average irrigation water use of 72 inches, percolation/seepage of 11 inches, and evapotranspiration of 34 inches (Hill, personal communication, 28 January 2015; Linquist et al., 2014 , under review). Because California rice has very high average yields (8,500 pounds per acre), its water consumption per unit of food produced compares favorably with that of other crops (California Rice Commission, 2013).

The current drought has had a significant effect on farming. Recent estimates indicate that 20 to 25 percent of California's rice fields were fallowed in 2014 due to insufficient water (Koba, 2014; Ortiz, 2014). Some farmers have been able to substitute corn, beans, or other less water-intensive crops, but others do not have suitable land to do this, and some farmers have found it more profitable to sell their water outright than to use it for growing rice (Koba, 2014). Flooded rice fields are an important source of habitat for migrating waterfowl (Robbins, 2014; Strum et al., 2013), and the current drought places the continuity of this ecosystem service in jeopardy.

Other pathways by which climate change may affect California rice production are poorly understood. Rice weeds, pests, and pathogens do not show any overall pattern of being benefited or inhibited by warmer temperatures. More research is needed on how this important southwestern crop will fare under future climate.

\section{Small grains}

Barley, oats, and wheat are grown in one-half to two-thirds of southwestern counties, generally on relatively small areas per county. The values reported here for harvested acres and production value represent only barley, oaters, and wheat harvested for grain. This can be a small percentage of the actual total because some small grains are harvested as hay, green-chop forage, or silage for dairies.

Growth and development of barley, oats, and wheat follow similar patterns. Most small grain crops are sown in the autumn and harvested in late spring or early summer. Nitrogen fertilizer is generally used annually on small grain crops to stimulate growth, yield, and protein content. Small grains grown in the Southwest are usually irrigated. In 2012, nearly all the regional durum wheat and about 30-40 percent of northern Utah wheat was irrigated. Water scarcity, along with a reduction in grain filling period, may prove to be the most important factor in future small grain yields.

In the U.S. Great Plains, warming and drought have resulted in decreased wheat production by 33 percent (Tack et al., 2014), with drought attributing to 22 percent of the decline. Other studies have found that with adequate water, winter wheat grain yields increase because of temperature and $\mathrm{CO}_{2}$ effects (Ludwig $\&$ Asseng, 2006; Qiao et al., 2004). Because of the interacting effects of temperature, precipitation, and $\mathrm{CO}_{2}$, determining the effect of climate change on wheat production in the Southwest is complex. In general, temperatures above $88^{\circ} \mathrm{F}$ have been shown to reduce grain yield. Maximum temperatures from 1981 to 2010 across much of the region between May and October exceeded $88^{\circ} \mathrm{F}$. Future projections indicate that these maximum temperatures will increase in spatial and temporal extent, possibly reducing wheat yield. However, sensitivity to high temperature is not presently an issue for many parts of the region. A study of changes in timing of cereal phenology (maize, oats, and wheat) by 2040 showed 1- to 3 -week advancements in sowing date and time of flowering and maturity in northern and central Europe under a changed climate (Olesen et al., 2012). Shifting sowing date may prove an effective adaptation strategy for regional small grain production in the future. 
Although the Midwest is the major production region for U.S. corn, corn is grown in the Southwest for both grain and silage purposes. The production value of Southwest corn was $\$ 362$ million in 2012. Nearly two-thirds of all Southwest counties have some acreage devoted to corn growth. In 2012, 795,000 acres of corn grain and silage were harvested in the Southwest. Nearly 80 percent of Southwest counties that grow corn for grain or silage produce it on fewer than 4,570 acres. California has eight counties with the largest silage corn acreage and some of the largest regional milk and cattle sales. Of the top six counties that produce corn for grain, only Cochise, Arizona, was outside California. Nearly all of the corn grown in the region is irrigated.

Temperature increase and drought stress will likely decrease corn production and yields in the Southwest. Elevated $\mathrm{CO}_{2}$ levels will provide minimal photosynthetic gain for corn. Additionally, corn requires fertilization and may be sensitive to weeds, diseases, and insect pests. The cumulative effects of temperature, drought, and other sensitivities make corn production in the region sensitive to risk given projected climate changes especially near the end of the 21st century (Lee et al., 2011). Along with adaptive management options of earlier planting and adequate irrigation, growers may seek to select drought-tolerant cultivars or, where possible, manage irrigation to ensure enough water is available during and after critical periods such as flowering.

\section{Safflower}

Nationally, the total safflower area harvested in 2012 was 160,100 acres, with nearly half (47 percent) grown in California and Utah, contributing \$29 million to regional revenue. Two regions are particularly important for safflower production; several counties in the northern California Central Valley and two counties in northern Utah (Cache and Box Elder). Safflower is commercially cultivated to produce vegetable oil and birdseed. Some safflower varieties are cultivated for use as livestock feed. Safflower is generally grown on arable dryland following a year in which wheat or barley has been grown. Of the regional acres harvested, most were not irrigated (approximately 11 percent in Utah).

Safflower prefers hot, arid conditions. The deep taproot of safflower allows it to grow well in arid environments. Seeds germinate when soil temperatures are above $40^{\circ} \mathrm{F}$. Safflower produces a higher yield when it has access to water, but it is considered drought resistant due to its deep tap root. Elevated $\mathrm{CO}_{2}$ led to greater safflower growth and less transpiration in safflower plants in a controlled environment (Mohamed et al., 2013). California's Central Valley safflower crop yield is not predicted to decline as long as sufficient water is available (Lee et al., 2011).

\section{Crop-Specific Vulnerabilities and Adaptation Strategies: Hawai'i}

Hawai'i's top crop items by acreage include macadamia nuts, coffee, and vegetables (National Agricultural Statistics Service, 2012); sugar cane for sugar and short-rotation woody crops are also among Hawai' 'i's top crop items, but statistics are withheld from the NASS census report to avoid revealing individual operators. Sugar cane was previously much more important in Hawai ' $i$, reaching peak production in the mid-1960s with 1.2 million tons of raw sugar, but production rapidly dropped in the 1980s and 1990s. Today, Hawai 'i Commercial and Sugar Inc. in Maui, is Hawai' $i$ 's only producer of raw sugar. This section on Hawai' $i$ will use the tree crops, coffee, and macadamia, as examples to illustrate some of the exposure, sensitivities, and adaptive capacities of Hawaiian crops to climate change. Also included here as an example is taro (Colocasia esculenta). Taro
Table 4: Statistics on crop production in the Hawai'i.

\begin{tabular}{|l|r|r|} 
Crop name & \multicolumn{1}{c}{ Acres* } & \multicolumn{1}{c|}{ Value $\dagger$} \\
\hline $\begin{array}{l}\text { Macadamia } \\
\text { nuts }\end{array}$ & 16,000 & 34,800 \\
\hline Coffee & 7,900 & 54,270 \\
\hline Taro & 360 & 1,944 \\
\hline $\begin{array}{l}\text { Sugarcane for } \\
\text { sugar and } \\
\text { seed } \neq\end{array}$ & 18,200 & \\
\hline
\end{tabular}

*Acres are bearing-acres only. $\uparrow$ Values are in $\$ 1,000$ s for 2014. Data are from USDA 2014 State Agriculture Overview (National Agricultural Statistics Service, 2014a). $\$$ The value of sugarcane for sugar and seed does not appear to avoid disclosing data for individual operations. 
(kalo) was introduced to the Hawaiian Islands by Polynesian settlers more than 1,000 years ago and has been cultivated as a staple crop since its introduction. It is grown for its root (corm) and leaves. Taro is of immeasurable importance to indigenous Hawaiians and its cultivation is central to cultural beliefs about creation (Cho et al., 2007).

\section{Tree crops}

Maximum projected increases in annual average temperature push the upper limit of the temperature envelope for many crops in Hawai 'i. Increasing temperatures will affect crop productivity and quality both through the direct effect of heat stress and through increased evaporative demand. Temperatures above $75^{\circ} \mathrm{F}$ reduce photosynthesis and stomatal conductance in coffee trees and accelerate fruit development and ripening. The upper threshold for acceptable macadamia productivity is $86^{\circ} \mathrm{F}$. Prolonged exposure to high temperatures depresses growth and causes physiological abnormalities in tree crops. Potential adaptive responses to prolonged high temperatures could include using shade trees in areas where maximum temperature thresholds are being exceeded. Coffea is a shade-adapted species, and shade-grown cultivation is already practiced by many Kona coffee farmers and is well-suited to the method of cultivation on small farms. Shade will be more challenging to introduce on larger, mechanized coffee farms.

Macadamia is not shade-adapted, and it is possible that if trees receive insufficient light, then yield will decline. An alternative adaptive response is to move orchards to higher elevations. However, there is limited land availability in zones of adequate precipitation. In South Africa, overhead sprinklers have been shown to reduce macadamia canopy temperatures (Allan, 1996), but increased pressure on water resources may not permit this in Hawai' $i$.

Increased evaporative demand when coupled with drought is likely to be one of the most severe challenges that tree crop farmers in Hawai ' $i$ will face. Optimum rainfall for rain-fed coffee cultivation in Hawai ' $\mathrm{i}$ is around 60 to 80 inches. Irrigation is necessary in the drier coffee-raising areas of Kauai, Maui, and Oahu. Coffee usually has a deep root system that permits some drought tolerance, but where trees are rain-fed and planted in shallow, young soils, drought may be a major threat to annual crop production and even to tree survival. The seasonal timing of drought will also be an important determinant of whether drought will damage coffee harvests.

Minimum annual rainfall requirement for macadamia is about 40 inches; on Hawai 'i, a strong correlation exists between productivity and rainfall greater than 80 inches mm per year, but highest productivity is achieved in parts of Kona where annual precipitation averages around 60 inches (Stephenson \& Trochoulias, 1994). Much of the macadamia crop on the Hawaiian Islands depends on precipitation with supplemental irrigation practices in drier areas where precipitation totals less than 50 inches per year (Carr, 2012). Macadamias can tolerate periodic drought stress, but under prolonged conditions of water shortage nut yields are smaller and poorer in quality with lower oil content. Irrigation is a possible means for alleviating some of the water stress caused by drought in coffee and macadamia crops. However, limitations on available water resources during drought conditions may prohibit sufficient irrigation to prevent damage to crop development. Stephenson et al. (2003) show that permitting levels of water stress at certain times in the macadamia growth cycle may help to increase yields. Further research could improve our understanding of the relationship between water stress, irrigation timing, and macadamia nut productivity in Hawai' $i$.

\section{Taro}

Taro is cultivated at various scales in wetland and dryland systems and the method and scale of cultivation is likely to have some bearing on the sensitivity of this crop to rising temperatures. Generally, taro can be grown where daily average temperatures range from $70^{\circ} \mathrm{F}$ to $80^{\circ} \mathrm{F}$, and even where temperatures are up to $95^{\circ} \mathrm{F}$. Physiologically, it is less sensitive to high temperatures than other crops. However, increased temperatures may raise the crop's water requirement in dryland cultivation systems 
and prolonged heat waves could cause damage or crop failure if there is insufficient moisture. Dryland taro cultivation may also be moved to higher elevations, but the logistics of this action will depend on the availability of affordable land with adequate supplies of fresh water for irrigation.

Taro grown in flooded ponds or lo'i, requires cool water (about $80^{\circ} \mathrm{F}$ or lower) flowing over the roots (Gingerich et al., 2007); citing others). Water passes through the ponds and so does not diminish available water supplies. Above $80^{\circ} \mathrm{F}$, wetland taros are more susceptible to fungal disease and rotting. Decreased precipitation may threaten this method of taro cultivation if insufficient streamflow is available to provide a continuous supply of cool water. When grown in dryland areas, taro requires evenly distributed annual average rainfall of at least 60 inches; supplemental irrigation is necessary in drier areas. Restricted growth, increased suckering, and/or reduced quality may occur if plants are water-stressed.

Changing climate conditions may exacerbate outbreaks of taro leaf blight. Taro leaf blight is caused by the oomycete Phytophtora colocasiae, and once a crop is infected, the pathogen can reduce corm yield by up to 50 percent, adversely affect corm quality, and cause leaf losses in susceptible plants as high 95 percent (Nelson et al., 2011; Singh et al., 2012). Increasing wetness, higher relative humidity, or a longer wet seasons may encourage pathogen dispersal and disease spread. Conversely, cooler nighttime temperatures $\left(63-68^{\circ} \mathrm{F}\right)$ can also trigger epidemics because the release of infective zoospores is triggered by cooler temperatures.

Wetland taro production is also threatened by sea-level rise. Rising sea levels will increase salt water intrusion of freshwater surface and groundwater systems and raise the elevation of groundwater. As the freshwater aquifer increases in altitude, it will become necessary to move low-lying lo'i to higher elevations, if land is available.

\subsection{Livestock Systems Overview of Risks, Vulnerabilities, and General Adaptation Strategies}

\section{Effects of Climate Change on Southwestern Animal Agriculture}

Animal agriculture accounts for one-third of the agricultural revenue in the Southwest. In 2012, the market value of livestock and poultry for this six-State region was $\$ 17.6$ billion. Approximately 70 percent of Southwest livestock revenues are from dairy cows, cattle, and calves (U.S. Department of Agriculture, 2013). Unlike poultry and swine, which are most typically housed within structures, cattle, and also goats and sheep, are primarily raised on rangelands and pastures that are susceptible to elevated temperatures facing the Southwest.

Major confined feeding/production operations for beef cattle feedlots, dairies, hogs, and poultry exist throughout the mainland five-State region and total \$15.4 billion per year (NASS, 2013). Although a few dairy, feedlot, hog, and poultry operations exist outside of California, especially along the Wasatch Front (Utah), the Rio Grande River Basin (New Mexico), and the Lower Colorado River (Arizona), the vast majority of these operations exist within central California (Figure 7). Hog and beef cattle feedlot inventories have declined in recent years, although the value of poultry products has risen substantially in the recent decade (NASS, 2013). California and Arizona rank sixth and eighth, respectively, in cattle on feed, but combined they total only about 6 percent of U.S. beef on feed inventories. The top five States, all in the Midwest, total more than 70 percent of annual cattle on feed inventories (Galyean et al., 2011).

Regional Agriculture's Sensitivity to Climate Change and Adaptation Strategies

Page $\mid 28$ 
There are four primary pathways of animal production and welfare outlined in the National Climate Assessment in which climate change will affect animal agriculture in the Southwest: 1) feedgrain production, availability, and price; 2) pastures and forage crop production and quality; 3) animal health, growth, and reproduction; and 4) disease and pest distributions.

\section{Regional Issues for Southwest Animal Agriculture and Rangeland Ecosystems}

The regional setting and associated current conditions will likely shape key vulnerabilities across this region for animal agriculture operations. Some of these vulnerabilities are specific to particular types of animal production systems characteristic within the Southwest, such as rangeland beef cattle, and others are more generic to any animal production system.

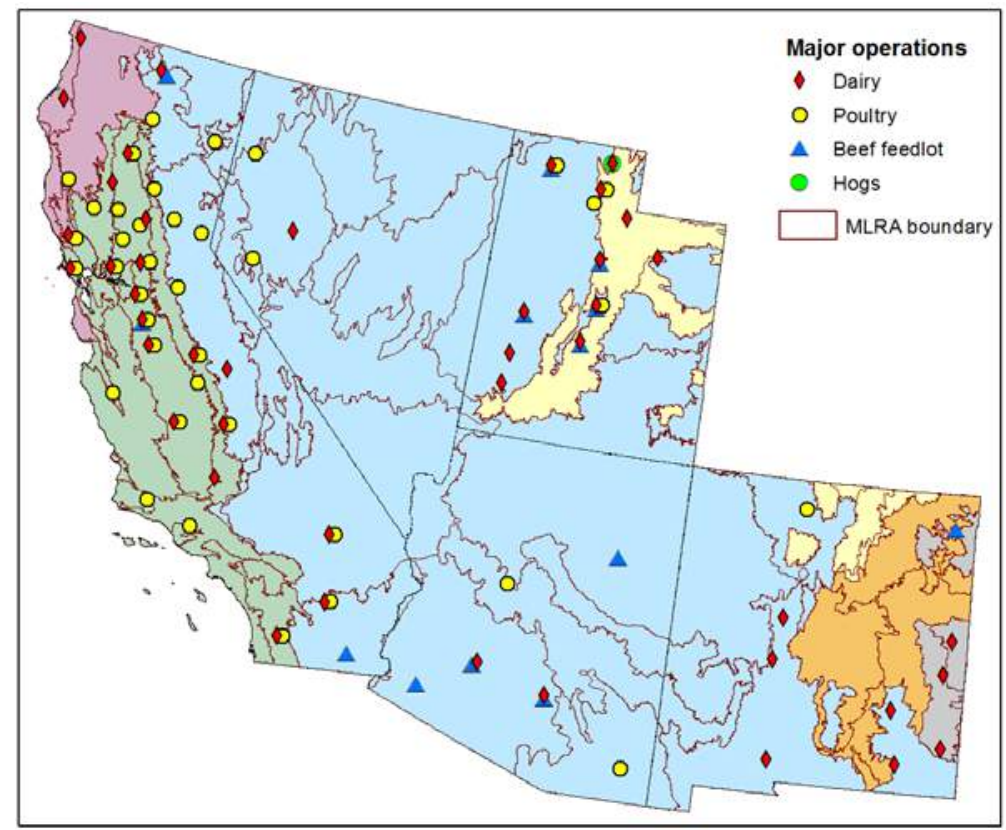

Figure 7: Locations within land resource regions across Arizona, California, Nevada, New Mexico, and Utah of major dairy ( $>700$ head), beef feedlot $(>1,000$ head $), \operatorname{hog}(>5,000$ head), and poultry $(>\$ 100,000$ in annual revenues) operations (NASS, 2013).

\section{Reduced long-term livestock grazing capacities}

Inherently low long-term carrying capacities for rangeland livestock will be further reduced. For example, a common ecological site within MLRA 41 in southeastern Arizona is the Clay Loam Upland site within a 12- to 16-inch precipitation zone. This site has a documented representative primary production level of $\sim 1,075 \mathrm{lbs} /$ acre/year. However, drier, more arid conditions result in primary production of $<500$ lbs/acre/year. This level of reduction in primary production can equal a corresponding reduction of stocking rates of approximately 20 to 40 percent or more (Natural Resources Conservation Service, 2014). Economic costs of livestock grazing operations are directly dependent upon forage production (Brownsey et al., 2013), and reduced long-term average primary production will directly increase economic costs and further reduce inherently low rates of return realized from rangeland livestock operations.

\section{Reduced air and water quality}

Inherently low ground cover will be further reduced and there will be greater site vulnerability to wind and water erosion. For example, a common ecological site within MLRA 30 in California is Granitic Loam, which is dominated by creosote bush and native grasses. Representative annual production is $\sim 400$ lbs/acre/year with low ground cover of approximately 10 to 15 percent inherent to the site. Drier conditions create a site with further reduced ground cover, even below 5 percent, and these sites are extremely susceptible to wind and water erosion (Natural Resources Conservation Service, 2014). A reduction in ground cover from 15 percent to only 5 percent can triple the susceptibility of a site to soil loss by wind and water erosion. Conversely, increase in vegetation cover to above 12 percent in a desert environment in California resulted in a 90 percent decrease in sand flux (i.e., wind erosion losses) (Lancaster \& Baas, 1998). 


\section{Persistently degraded land health}

Degraded positions may become permanent. For example, a common ecological site within MLRA 25 in Utah is Upland Loam, which is dominated by Wyoming Big Sagebrush. This site is susceptible to degradation due to prolonged drought, especially if in combination with fire, overgrazing, or both. If this site degrades to yellow rabbit brush and invasive annuals this situation is self-sustaining and can result in complete loss of site potential. These sites in degraded states have increased intervals of fire frequency and greatly reduced value for livestock grazing as well as wildlife habitat, including for sage grouse. Restoration of these degraded states is highly problematic (Natural Resources Conservation Service, 2014).

\section{Reduced supplies of harvested feeds and pasture forages}

The demand for non-rangeland forages will increase, and overall supplies that are required in support of rangeland beef cow-calf production systems will likely be reduced. The extensive nature of rangeland livestock production across this arid and semiarid region requires periods of supplemented feed and/or pasture forages. Livestock production within this region is highly reliant on harvested forages, especially hay, that augment forage supplies during drought, dormant seasons, or periods of exclusion such as during or after wildfires. The region is extremely reliant on surface freshwater supplies for irrigated crop and pasture production, and the bulk of irrigated production across the region is for livestock feeds. There are $\sim 20$ million acres of pastureland across this five-State region. Only about 5 percent ( $\sim 1$ million acres) of these pasturelands were irrigated in 2012, a decline of about 0.5 million acres since 2007. Southwest rangelands and pastures are primarily rain-fed (nonirrigated) and highly susceptible to projected drought. One of the most likely effects of climate change on Southwest rangelands will be the decrease in net primary productivity (NPP). Warming and drying will synergistically reduce soil water availability and decrease NPP. More frequent droughts may also contribute to a change in vegetation composition and reduction of ground cover, both of which can drastically increase susceptibility of ecological sites to water and wind erosion (Natural Resources Conservation Service, 2014; Polley et al., 2013). Of direct significance will be the likely need to feed livestock longer with estimates ranging from 4 to 16 percent more feed required under increased ambient temperatures (Mader et al., 2009).

\section{Increased heat stress associated with expansion of arid zones}

Arid sites within desert MLRAs (primarily within the Western Range and Irrigated Land Resource Region) may expand with projected changes in aridity and effect on heat stress for animals. Higher ambient air temperatures predicted across this region will directly affect soil moisture and potential evaporation rates that define site aridity. The resulting expansion of aridity is not yet well assessed or predicted, but this is an area of current research. The direct effect of increased temperatures and resulting heat stress on animal performance is well documented (St-Pierre et al., 2003).

\section{Further reduced capacities to sequester carbon}

An arid and semiarid region already seriously limited in its inherent capacities to store carbon may increasingly become a source of atmospheric carbon. Desert regions across the Southwest are typically sources of atmospheric carbon. Uptake of carbon (i.e., sequestration) is restricted to infrequent periods of significant precipitation that promote primary production. However, overall carbon stores are low across this arid region, although they are highly influenced by vegetation type and amount. More arid conditions that lead to more woody species may actually increase carbon sequestration, though degradation resulting in annual grassland vegetation may lower carbon storage in soils and increase atmospheric carbon. Carbon fluxes will continue to be low and volatile (Bradley et al., 2006; Svejcar et al., 2008).

\section{Reduced forage quality}

Both harvested forages and rangeland forages may have increased cellulosic and lignin contents that reduce digestibility by both ruminants and monogastrics. In the Southwest, livestock production will be 
reduced by lower forage quality and quantity and a decrease in voluntary animal intake associated with lower forage quality, higher temperatures, and heat stress. Even in the absence of the effects of increased greenhouse gas concentrations on climate patterns, atmospheric chemistry will increase the vulnerability of livestock operations (Polley et al., 2013). Forage quality (digestibility) will also decrease as a result of increased ambient temperatures (Craine et al., 2010). These declines in forage quality will in turn result in reduced animal intake and lower animal performance. An emerging industry in the southwest, grass-fed beef, is heavily reliant on the ability of producers to manage forage quality for maximum animal performance, and will be increasingly pressured for nutritionally adequate forage supplies.

In Hawai 'i, nearly all beef cattle operations depend on pasture or range grazing systems, where the nonnative warm season C4 grass "Kikuyugrass" (Pennisetum clandestinum) is the primary forage. Depending on the degree of conservative management practiced by ranchers (e.g., rotational grazing, reduced stocking rates), the effects of climate change (increasing temperatures and greater drought persistence) on Hawaiian grazing lands may decrease in pasture quality, thereby increasing the competitiveness of noxious invasives such as fire weed (Senecio madagascariensis) over the forage species.

\section{Reduced options for stocker cattle operations}

The three phases of beef cattle production in the United States are 1) cow-calf operations, in which calves are produced and raised on high-quality pasture and feed; 2) stocker operations, in which weaned calves are pastured on rangeland for an additional one to two seasons; and 3) feedlot operations, in which stocker cattle receive grain and other high-quality feed to quickly bring them to market weight. Beef cattle production in this region is reliant not only on cow-calf operations, but also a declining acreage of pasturelands needed for stocker growth before entering the third phase of U.S. beef production in feedlots.

\section{Pastureland acreage}

Pastureland acreage in the Southwest region has declined by approximately 20 percent between 2007 and 2012 (a reduction of approximately 5 million acres, excluding Arizona), and the amount of irrigated pastureland has been reduced by approximately 35 percent. Stocker inventory varies but has remained around 1.6 million head across the region since 2000 (Figure 8 ), but there has been about a 5 percent decline in annual inventory since 2007. This reflects reduced cow-calf inventories, and further reductions in irrigated pastureland and availability of pastures could further reduce

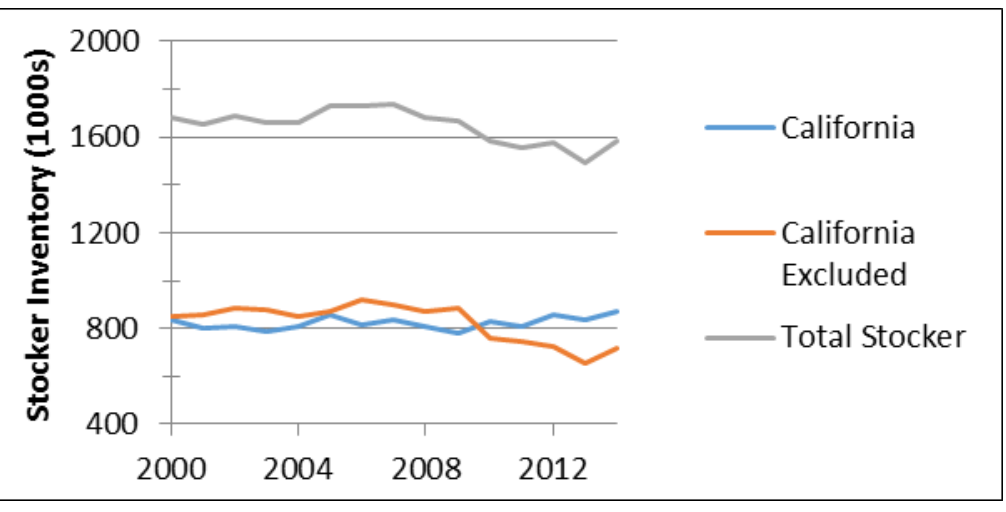

Figure 8: Annual stocker cattle inventory in the five-State region from 2000 to 2013. California consistently provides about 50 percent of forage resources for stocker operations within the region (U.S. Department of Agriculture, 2013).

opportunities for stocker operations and inventories (U.S. Department of Agriculture, 2013).

\section{Constraints on preparedness of ranching communities for arid or drought conditions or rebuilding ranching operations following prolonged drought}

Even in environments where prolonged droughts are common, ranching communities may not be adequately prepared for the financial consequences and management requirements that are expected to result from prolonged drought. A recent survey of Utah ranchers showed that 67 percent were either somewhat prepared or unprepared for the 2009 drought despite having endured a 5-year drought from 1999 to 2004 . The average age of beef producers in the region is $\sim 58$ years. It is well documented that 
rebuilding livestock herds following droughts can be costly and can take years, even for well-prepared ranchers. Recent experiences in response to prolonged droughts in the Midwest indicate older producers may opt to sell out rather than rebuild their ranching operations following destocking in response to drought and persistent arid conditions. This could lead to a generational shift in ranching to younger ranchers who may be more progressive but may also be less experienced (Coppock, 2011). Irrespective of experience, restocking livestock following extensive destocking with prolonged drought is a lengthy, time-consuming, and costly process, as was documented in the Midwest following the drought of 20092011 (Doye et al., 2012).

\section{Further reduction in the utilization of public land for livestock grazing}

Continued increasing demands for ecosystem services other than food and fiber from public lands in the region will likely continue to reduce the use of the available supply.

There is a slight decline in Bureau of Land Management (BLM) Animal Unit Months (AUMs) supplied within the region since 2004, but this decrease continues a constant decline throughout the 20th century. More specifically, for the five States of Arizona, California, Nevada, New Mexico, and Utah, the change in billed BLM AUMs has shown a precipitous decline from a high of 8.9 million AUMs before the 1950s drought to 3.7 million AUMs in 2012 (Figure 99) (Bureau of Land Management, 2014). This trend in reduced use of

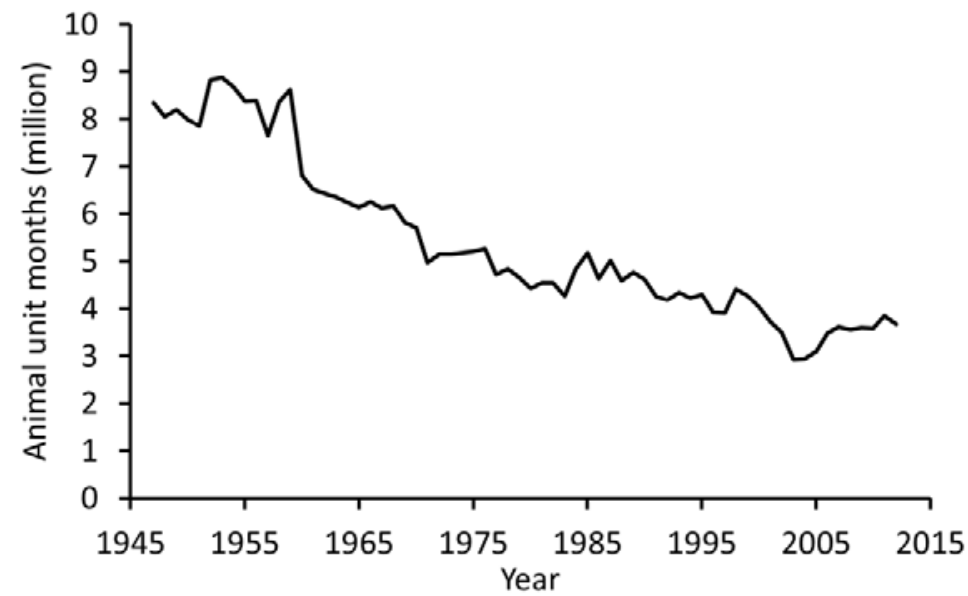
public land for livestock grazing represents an annual decline in forage supply from public land of 30,000-

Figure 9: Change in billed animal unit months from 1947 through 2011 for all BLM-managed lands in Arizona, California, Nevada, New Mexico, and Utah (Bureau of Land Management, 2014).

50,000 AUMs. Conditions of these lands are highly variable, and it is unlikely public lands could supply an increased demand, especially with more arid environmental conditions likely.

\section{Declining export options for Hawaiian cattle operations}

Pasture and rangeland grazing systems are unable to support finishing the number of beef cattle that are born in Hawai ' $i$, therefore after weaning, most are shipped more than 2,500 miles to western States for finishing and slaughter. In 2012, 31,650 head were exported to the mainland, whereas 11,600 were slaughtered locally (with an average live weight of 1,136 pounds). In the future, the cost of shipping and increased feed costs may become prohibitively expensive as oil prices rise. Furthermore, future options for finishing cattle in western States may be affected as environmental and economical stresses increase and drought reduces available water supply on the mainland.

\section{Adaptive Capacities}

The mainland Southwest has supported animal agriculture since the early 17th century when European settlers crossed the Rio Grande River into present day western Texas and southern New Mexico with herds of cattle, sheep, goats, and horses. For the past 400 years this industry has developed management strategies and conservation practices that impart resilience to climatic extremes, especially prolonged droughts, which can seriously affect production from these rangeland-based systems. The ability of livestock production in the mainland Southwest to adapt to higher ambient temperatures will continue to 
rely on these strategies (Joyce et al., 2013) such as reduced stocking rates, proper grazing management practices, erosion control conservation practices, diversified ranch income strategies, alternative forage supplies, practices that moderate housing temperatures and reduce heat stress, and accessing additional range and pasture land. Even though the aging demographics of western ranchers could be a deterrent to implementing various adaptations, examples of creative management coalitions are emerging in the Southwest that can serve as instructive examples (Brunson \& Huntsinger, 2008).

There are additional opportunities for incorporating transformative practices and technologies for sustaining animal agriculture in a warmer environment. For example, increasing reliance on renewable energy sources for climate control of housed animal production systems; using degraded water for irrigation; expanding production of drought-tolerant feeds and forages; employing beef cattle genetics to produce cattle suited to harsh and minimally productive environments; land management partnerships, especially involving public lands, that create emergency supplies of forage during drought periods; development of real-time, site-based information applicable to individual ranches and confined feeding operations; and improvement of readily accessible weather forecasting capacities at temporal and spatial scales directly applicable to individual animal production systems. Some of these transformative strategies are being developed for other regions of the world (Martin \& Magne, 2015; Moore \& Ghahramani, 2014) and could be applicable to the Southwest and Hawai 'i. Animal agriculture has the capacity to adapt and transform as needed to the climatic changes that are now occurring and will continue to occur across this region (Table 5).

Table 5: Types of exposure and resulting sensitivities of animal agricultural and possible adaptive capacities and/or transformative practices and processes to reduce these vulnerabilities to climate change across the Southwest

\begin{tabular}{|c|c|c|}
\hline Exposure & Sensitivity & Adaptive Capacity and/or Transformation \\
\hline $\begin{array}{l}\text { - Elevated maximum } \\
\text { temperature } \\
\text { - Elevated minimum } \\
\text { temperature } \\
\text { - Temperature rise } \\
\text { will be higher in } \\
\text { summer than other } \\
\text { seasons in most of } \\
\text { the region } \\
\text { - Heat waves will } \\
\text { increase in } \\
\text { frequency, intensity, } \\
\text { duration and spatial } \\
\text { extent. } \\
\text { - More intense and } \\
\text { longer-lasting } \\
\text { drought. Based upon } \\
\text { soil moisture, } \\
\text { drought is expected } \\
\text { to intensify in the } \\
\text { dry season. }\end{array}$ & $\begin{array}{l}\text { - Reduced grazing } \\
\text { capacity } \\
\text { - Reduced air/water } \\
\text { qualities } \\
\text { - Persistent land } \\
\text { degradation } \\
\text { - Reduced forage / } \\
\text { pasture quantity / } \\
\text { quality } \\
\text { - Increased heat stress } \\
\text { with expansion of arid } \\
\text { zone } \\
\text { - Reduced capacities to } \\
\text { sequester carbon } \\
\text { - Reduced options for } \\
\text { stocker operations } \\
\text { - Inconsistent } \\
\text { preparedness for } \\
\text { prolonged dry periods } \\
\text { - Decreasing } \\
\text { availability of public } \\
\text { land grazing permits }\end{array}$ & $\begin{array}{l}\text { - Cooperative Extension Service and USDA programs } \\
\text { for ranchers and land managers on climate effective } \\
\text { management and planning } \\
\text { - Reduced stocking rates } \\
\text { - Conservation practices for erosion controls } \\
\text { - Improved feed base and livestock genetics including } \\
\text { heat- and drought-tolerant feeds and forages and } \\
\text { livestock breeds } \\
\text { - Diversification of ranch scale production systems } \\
\text { - Intensification of water re-use for irrigation } \\
\text { - Renewable energy for temperature control in barns } \\
\text { and housed animal structures } \\
\text { - Increasing access to outdoor shade structures or } \\
\text { introduce silvopasture system, where resources } \\
\text { permit (e.g., Hawai'i) } \\
\text { - Expanded use of conservation easements to maintain } \\
\text { rangeland and pasturelands availability } \\
\text { - Increased availability of public land AUMs for grass } \\
\text { banks } \\
\text { - Proper grazing management practices based on } \\
\text { ecological capacities of the land } \\
\text { - Real-time, location specific seasonal weather } \\
\text { forecasting } \\
\text { - Effective climate science programs for K-12 } \\
\text { education in rural and urban areas to prepare the next } \\
\text { generation of animal agriculturalists }\end{array}$ \\
\hline
\end{tabular}




\section{Forest Systems Overview of Risks, Vulnerabilities, and General Adaptation Strategies}

The first part of chapter 3 examines the climate change vulnerability of the forests in the Southwest (Arizona, California, Nevada, New Mexico, and Utah), exclusive of Hawai 'i. Hawai 'i's tropical forests are very different from those on the mainland and are reviewed separately in summary form in the second part of this chapter. The Southwest has a wide variety of forest types that are economically and ecologically important. Effects of climate change are already being observed in some southwestern forests, and these effects are expected to expand and intensify in the coming decades. Assessing which forest systems are most vulnerable, and what adaptation actions are possible, will be essential to preserving ecosystem function and maintaining the well-being of forest landowners.

\subsection{Effects of Climate Change on Southwestern Forests}

Robert Whittaker (1975) described the global distribution of biome types on the basis of mean annual temperature and mean annual precipitation. Since that time, the observation that forests are restricted to particular combinations of annual temperature and precipitation has been reaffirmed and refined using remotely sensed imagery. We used this approach and downscaled it to the forest types of the Southwest using a bioclimatic envelope model (Heikkinen et al., 2006) to examine exposure of forests to change. We aggregated LANDFIRE cover classes (www.landfire.gov) into broader categories that roughly correspond with the Society of American Foresters forest types. The aggregated types include pinyon-juniper, midmontane mixed conifer, oak woodlands, aspen, ponderosa pine, subalpine conifers, riparian woodland, red fir, Douglas-fir, and redwood. Each aggregated forest type was then related to 19 bioclimatic variables from WorldClim data (Hijmans et al., 2005). We used principal components analysis to reduce the dimensionality of the data set; these first two principal components explained 74 percent of the climatic variation in the data across the models that we used.

To quantify exposure to change, we needed to describe the degree to which a particular location, in a particular time window, was marginal (i.e., external) to the current bioclimatic envelope. To do this, we first used a two-dimensional density kernel estimator to draw a 99 percent probability envelope around the current bioclimatic distribution of a forest type in principal components climate space. We then plotted these same locations on this climate surface for two summarized future time periods, 2041-2060 and 2061-2080, which we refer to as mid- and late-century projections.

We used two global climate models (GCMs) to provide estimates of future changes in climate: 1 ) the MRI-CGCM3 model projects the least warm and wettest combined projected change by the end of the century under the highest GHG emission pathway (RCP 8.5; IPCC 2013); and 2) the MIROC-ESMCHEM model projects the warmest and driest projections under RCP 8.5 at the end of the century for the southwestern United States. These two models bracket from the lowest to the highest potential for climate to act as a driver of vegetation change through temperature and precipitation shifts. We then modeled the worst-case climate scenario as the model with the higher temperature change and drier future projections with the highest emissions pathway (RCP 8.5) and the best-case climate scenario with the less warm and wetter model (MRI-CGCM3) with a moderate emissions pathway (RCP 4.5).

We then classified each location in each future climate projection relative to the probability contour interval on the basis of current distributions. Finally, we characterized fractions of forest types that are at risk of change by assessing which fraction of a particular type falls outside the 99th percentile of the climate space for current representatives of that type.

In this assessment, if a location is projected to be highly exposed by the end of the century, we mean that the climate of that location, using the best-case or worst-case model, is projected to fall outside the climatic attributes that describe 99 percent of current locations for that forest type. By color coding the

Forest Systems Overview of Risks, Vulnerabilities, and General Adaptation Strategies Page $\mid 34$ 
degree of marginality with respect to current distributions, we can map climate change exposure and depict where on the landscape, for the mid and late 21 st century, we expect forests to be secure and fall within the center of their climatic envelopes, and where they are exposed to change by falling outside their climatic envelopes.

Our analysis does not predict the sensitivity of these forest types to drivers of forest cover change (e.g., stress-related mortality, fire, disease), nor does it assess the adaptive capacity of forest types. We do not predict particular outcomes for the constituent species within communities, nor do we predict what kinds of vegetation would replace the existing vegetation were a change in cover type to occur. These projected changes in climate do not necessarily mean that current forests will disappear in locations anticipated to be outside the current climatic envelope. Forest trees are long-lived organisms, and changes in vegetation will be governed by a number of factors such as fire and drought in addition to climate. These projections merely describe when and where different forest types are predicted to be at risk to change as a consequence of climate stressors.

\section{Future Outlook for Southwest Forests}

Model projections of forest response to climate change suggest the forests in the Southwest will be less abundant (Figure 10, Table 6). As the climate becomes warmer and drier, the areas suitable to support temperate and montane forests will shift northward and upward in elevation. There will be an expansion of climates typical of deserts and shrublands (Bachelet et al., 2001; Lenihan et al., 2003; Rehfeldt et al., 2012). Increasing temperatures and moisture stress are likely to result in changes in forest composition even among locations that remain forested. Many California forest types may shift from conifer dominance toward slower growing, hardwood dominance (Shaw et al., 2011). Only at higher elevation sites are forest changes expected to entail conifers replacing other conifers. Pinyon and juniper species may replace montane conifer species. The consequence of a changing climate will result in changes in the recreational, aesthetic, and wildlife values of forested lands, and potentially declining timber values. The response of forest species to a warming environment will depend on the rate and magnitude of climate change, the capacity of individual species to disperse to establish in newly suitable areas, and their interactions with ecological stressors.
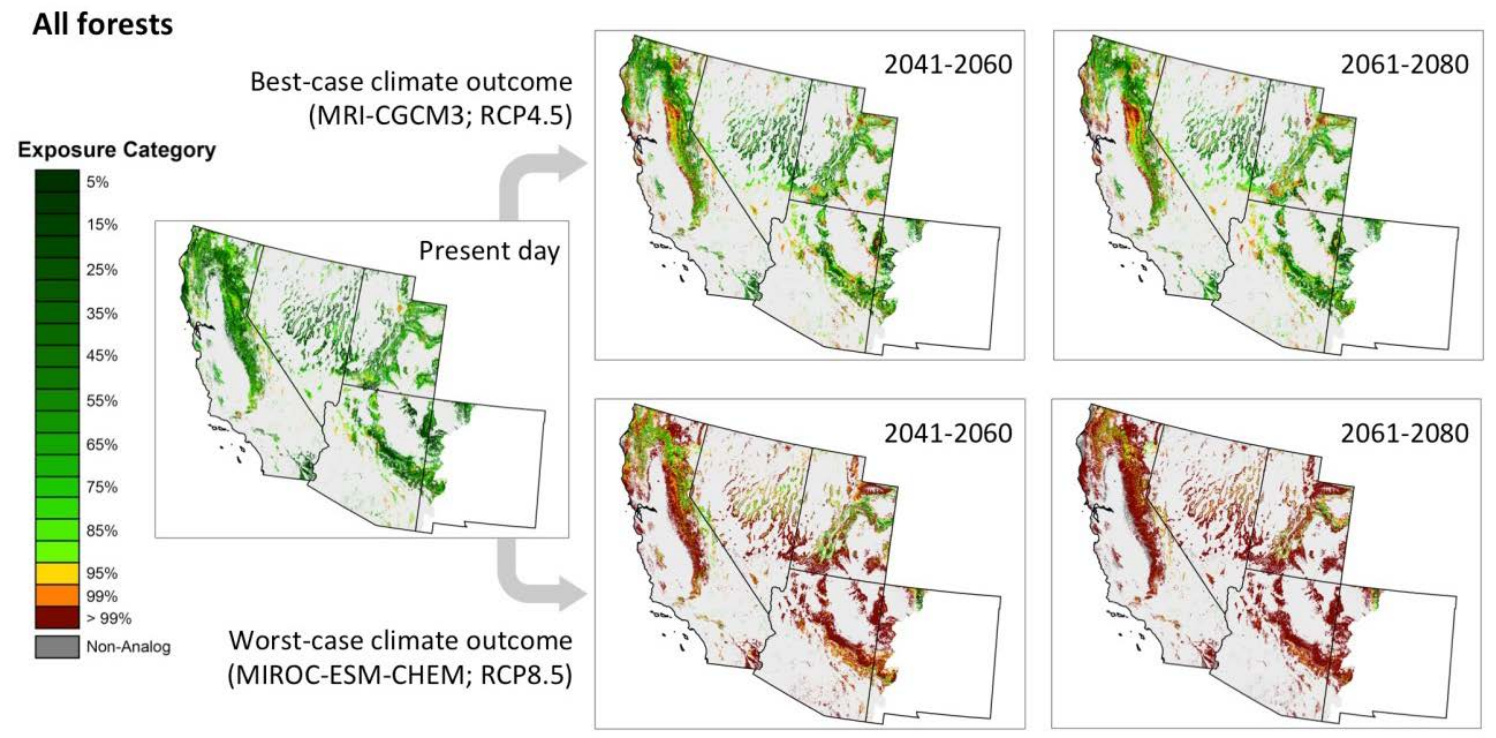

Figure 10: Exposure map for all forest types combined. 
Table 6: Current spatial extent and future climate exposure of the forest types used in this assessment.

\begin{tabular}{|c|c|c|c|c|c|}
\hline \multirow{2}{*}{ Type } & \multirow{2}{*}{ Area, $\mathbf{k m}^{2}$} & \multicolumn{2}{|c|}{ Best Case * } & \multicolumn{2}{|c|}{ Worst Case * } \\
\hline & & $2040-2060$ & $2061-2080$ & $2040-2060$ & $2061-2080$ \\
\hline Pinyon-Juniper & 135,775 & 4.4 & 3.5 & 52.0 & 72.3 \\
\hline Mixed Montane forests & 54,149 & 8.7 & 11.5 & 45.1 & 70.6 \\
\hline Douglas-fir & 33,621 & 9.4 & 11.7 & 50.6 & 77.0 \\
\hline Ponderosa/Jeffrey Pine & 35,367 & 11.3 & 7.5 & 71.1 & 88.4 \\
\hline Oak woodland & 20,143 & 28.0 & 65.8 & 76.4 & 100.0 \\
\hline Aspen & 16,495 & 7.9 & 9.5 & 39.0 & 63.2 \\
\hline Riparian forest & 13,465 & 4.5 & 5.4 & 68.4 & 79.6 \\
\hline Red fir & 11,159 & 15.0 & 15.7 & 75.9 & 96.3 \\
\hline Coastal redwood & 8,126 & 35.3 & 59.5 & 61.4 & 99.5 \\
\hline Subalpine & 9,913 & 14.7 & 18.9 & 76.2 & 93.8 \\
\hline
\end{tabular}

*The fraction of the type exposed to change includes both cells that fall outside the 99 percent probability envelope and cells that fall outside the overall climatic envelop and are projected to be in non-analog climate space.

Some forest types stood out as being particularly vulnerable to climate change in the analysis. By 20612080, oak woodland was projected to be between 67 percent and 100 percent exposed, depending on the climate model and scenario. The large area and economic importance of oak woodlands (as rangeland) make them a priority area on which to focus. Also of concern is coastal redwood (60 to 99 percent exposed), a unique and valuable forest type. Exposure results for red fir (15 to 96 percent exposed) and subalpine conifers (15 to 94 percent exposed) are more uncertain but still warrant concern. The forest types least exposed to climate change in our analysis were aspen ( 9 to 63 percent exposed) and pinyonjuniper woodlands ( 3 to 72 percent exposed), but their possible vulnerability is still significant.

\section{Regional Issues for Southwest Forest Systems}

Exposure to change is spatially heterogeneous, but areas that appear most vulnerable to the effects of climate change follow expected temperature and precipitation gradients. These include higher exposure along the southern and western edges of the forest distributions, and lower exposure in the northern and eastern populations and upper elevations of community-type distributions.

Drought coupled with bark beetle infestations may result in regional-scale die-off of pinyon and juniper species. Recent drought-provoked infestations in Arizona, Nevada, and New Mexico have killed as much as 90 percent of the dominant overstory pinyon species (Breshears et al., 2005; Greenwood \& Weisberg, 2008).

For oak woodlands, extremely low rates of recruitment (i.e., adding new seedlings to the population) observed over most portions of the range are likely to worsen with increased moisture stress from climate change and losses of adult oaks resulting in slowly declining abundance except in the most resilient microclimates (e.g., riparian zones).

The most extensive sudden decline in aspen is expected to occur in the hottest and driest areas-lowlying, south-facing slopes. The pattern suggests that the region's extreme drought and high temperatures - both possible symptoms of global warming - have weakened the trees, allowing more disease and insect attacks (Worrall et al., 2010).

For riparian woodlands, invasive forest species that are tolerant of saline conditions and decreased soil water availability such as salt cedar (Tamarix spp.) and Russian olive (Elaeagnus angustifolia), are likely to increase (e.g., Kerns et al., 2009) as a consequence of increased aridity. 
Climate change is already having notable effects on red fir forests, particularly as a result of declining levels of snowpack over most regions of the Southwest. Most climate models predict strongly declining snowpack through the 21 st century, which is likely to have strong effects on the distribution for many montane forest types.

Trends in coastal upwelling suggest uncertainty for the future of the coastal fog zone. Fully understanding the future of California coastal redwood depends strongly on how changing climates might affect summer fog. Uncertainty in future summer fog projections confounds vulnerability assessment.

Even for species not directly threatened by exposure, such as many subalpine conifer species, increased diseases and fires may speed transitions. A major uncertainty is the degree to which these species will be displaced by those from lower elevations.

Increasing temperatures and moisture stress are likely to result in changes in forest composition even among locations that remain forested. For example, many California forest types may shift from conifer dominance toward slower growing, hardwood dominance (Shaw et al., 2011). The consequence of a changing climate will result in changes in the recreational, aesthetic, and wildlife values of forested lands, and potentially declining timber values.

Successful forest management for climate change adaptation needs to take into account multiple stressors and their interactions, as well as accounting for tradeoffs between the costs, benefits, and risks of different management options (Bierbaum et al., 2014).

\section{Adaptation Strategies}

Forests are under considerable duress in much of the Southwest (e.g., (Breshears et al., 2005; McKenzie et al., 2009). Recent droughts have triggered massive die-off in pinyon-juniper systems in Arizona and New Mexico (Koepke et al., 2010) and aspen forests in Colorado (Huang \& Anderegg, 2012); bark beetle outbreaks associated with drought are spreading across western forests (Bentz et al., 2010), and some of the largest fires in many decades are affecting the region (Holden et al., 2009; Westerling et al., 2006).

Model projections of forest response to climate change suggest a generally reduced abundance of forest in the Southwest. As the climate becomes warmer and drier, the areas suitable to support temperate and montane forests will shift northward and upward in elevation. In general, there will be an expansion of climates typical of deserts and shrublands (Bachelet et al., 2001; Lenihan et al., 2003; Rehfeldt et al., 2012). The response of forest species to a warming environment will depend on the rate and magnitude of climate change, the capacity of individual species to disperse to establish in newly suitable areas, and their interactions with ecological stressors.

Increasing temperatures and moisture stress are likely to result in changes in forest composition even among locations that remain forested. For example, many California forest types may shift from conifer dominance toward slower growing, hardwood dominance (Shaw et al., 2011). Only at higher-elevation sites are forest changes expected to entail conifers replacing other conifers. For example, pinyon and juniper species may replace montane conifer species. The consequence of a changing climate will be changes in the recreational, aesthetic, and wildlife values of forested lands, and potentially declining timber values.

Stephens et al. (2010) suggest a set of resilience, resistance, response, and realignment options to promote resilient forested ecosystems under future climate scenarios. They also stress the importance of managing species persistence at the scale of the ecoregion. The option that offers the most broad-scale promise is the promotion of resilience. Resilient forests accommodate gradual changes in climate and also have the ability to return toward a prior condition after disturbance either naturally or with management assistance. Promoting resilience is the most commonly suggested adaptive option discussed in a climate change context (Hansen et al., 2003). 
Stephens et al. (2010) describe evidence from one of the most drought-stressed conifer forests in North America, the Sierra San Pedro Martir in Baja California, which suggests that managing for resilience is a pragmatic option for coping with climate change. A wildfire occurred in this forest in 2003 immediately after a severe drought from 1999 to 2002 . However, the effects of the fire were surprisingly moderate, with 80 percent of trees (including a large fraction of seedlings) surviving. Stephens et al. concluded that the high spatial variability in the structure of this forest allowed it to quickly return to its predisturbance state even after the stresses of drought and fire.

Restoring resilience has become the driving force behind current forest management efforts throughout the conifer forests of much of the western United States (North et al., 2009; Stine et al., 2014). The basic approach, applied in many different ways depending on site-specific conditions, follows the U.S. Forest Service definition of restoration. The focus of vegetation management to achieve restoration goals includes "a focus on re-establishing the composition, structure, pattern, and ecological processes" (U.S. Forest Service, 2014).

In some special circumstances, it may be necessary or desirable to manage forests to resist the influence of climate change or ensure that any changes take place as slowly as possible (Parker et al., 2000). An example given in Stephens et al. (2010) is the application of mechanical fuel treatments by the U.S. Forest Service in the Northern Sierra Nevada to increase resistance to wildfire. The goal of the response option is to smooth the transition to changed conditions and avoid abrupt threshold responses. Response adaptation includes facilitating "ongoing natural adaptive processes" such as species migration, mortality, colonization, changes in community composition, and changes in disturbance regimes (Stephens et al., 2010). Realignment involves modifying forests to current or future conditions; options include reintroducing structural heterogeneity to forests. For example, past management activities have altered the vertical and horizontal structure of much of California's forests (Stephens et al., 2010).

The National Climate Assessment (2014) offers a consistent and compatible foundation for these local adaptation strategies. (Millar et al., 2006) state that solutions for individual sites will be "wrought from collaborative discussion among colleagues—scientists, resource managers, planners, and the public —and they will be case-, location-, and project-specific. While general principles will emerge, the best preparation is for managers and planners to remain informed about the emerging climate, vegetation, and fire science in their region and to use that knowledge to shape effective local solutions."

Managing for species persistence with sufficient abundance to maintain viable populations at the broad ecoregion scale is an appropriate goal when considering the effects of changing climates in this century (Bierbaum et al., 2014). Specific management practices that may aid this goal include assisting species migrations, maintaining connectivity with matrix landscapes, and increasing intrapopulation genetic diversity in planting mixes (Stephens et al., 2010).

It is useful to note that climate change adaptation actions also often fulfill other societal goals such as sustainable development, disaster risk reduction, or improving the quality of life, and can therefore be incorporated into existing decision-making processes. Exposure to climate change is exacerbated by other stresses such as fire, insects, disease, pollution, habitat fragmentation, and poverty. Bierbaum et al. (2014) argue that "adaptation to multiple stresses requires assessment of the composite threats as well as tradeoffs among costs, benefits, and risks of available options."

\section{Restoring Sustainable Forest Structure}

Adaptation approaches for forests focus on steps that managers can take to change forest structure. This is critical in light of the changes in forests due to a century of fire exclusion and selective and wide-scale logging. Techniques have been developed to provide silvicultural strategies for restoring resilient forest structure. These vary from making minor adjustments to current management practices to major

Forest Systems Overview of Risks, Vulnerabilities, and General Adaptation Strategies Page $\mid 38$ 
deviations from current practice. Use of these various strategies depends on the degree to which climate continues to change, and how forests respond to these additional stressors.

\section{Increasing forest heterogeneity and decreasing stand density}

North et al. (2009) recommend enhancing forest resilience by increasing the physical diversity within a forest. For example, managers can promote higher density and canopy cover in local cool/moist areas, whereas on southern slopes they should encourage lower densities of fire-resistant trees. Additionally, thinning should occur on the basis of crown strata or age/species cohorts to facilitate the structural heterogeneity of the forest stand. Lydersen et al. (2013) demonstrate that the contemporary forest is more homogeneous than it was historically, and the historical variability that likely provided diverse microclimate and habitat conditions and fostered resilience to a variety of stressors and disturbances such as fire, insects, and drought has been lost. The suite of contemporary management objectives, including resilience to climate change, will benefit from restoring these structural components. For example, Knapp et al. (2012) used variable density thinning, which made it easier to respond to differing topography and forest conditions. This work is among a growing body of efforts that demonstrate that it is not only desirable but feasible to achieve these changes in forest conditions at multiple scales.

\section{Altering genetic and species composition}

A generalized response to changing climate would be to alter the composition of stands to accommodate changing conditions. This could entail planting different mixtures of species to reflect changing climates or planting genotypes from warmer and drier locations in order to adapt systems to warmer future conditions (Bower et al., 2014; Hamann et al., 2011; O'Neill et al., 2014; Tepe \& Meretsky, 2011).

Planting a species outside its current distribution in anticipation of climate change and a failure of selfdispersal is called assisted migration (McLachlan et al., 2007). Because forests are long-lived, there have been several instances of forest managers planting species outside their historical distributions (IsaacRenton et al., 2014; Pedlar et al., 2011; Williams \& Dumroese, 2013). Although this is a controversial approach, forest managers may soon face the choice of planting genotypes or even species outside their historic distributions to create future forests on the basis of predicted future distributions. At present, it is more likely that forest managers may gradually add species or genotypes to existing planting mixtures to create more heterogeneity in preparation for future conditions.

\subsection{Effects of Climate Change on Hawai'i's Forests}

Hawai'i's diversity of climate zones, ranging from lowland tropical to alpine desert, supports multiple different types of native forest ecosystems, mixed native and alien ecosystems, and forests of predominantly alien trees. Although there is great diversity in ecosystem types, the composition of native Hawaiian forests is dominated by two cosmopolitan species: ohia lehua (Metrosideros polymorpha) and koa (Acacia koa). Both species are of significant cultural value and occur in dry, mesic, and wet environments. Hawaiian forests are facing multiple pressures, of which climate change is just one. Hawai 'i's forest ecosystems are exposed to the threats of changing temperature, precipitation, and fire regimes, but the direct effects of climate change are entwined with the effects of nonclimatic disturbance such as highly invasive nonnative plant species, herbivory, and disease that leave native Hawaiian forest species particularly exposed to the threats of rising temperature and changed precipitation (Giardina, 2012).

The sensitivity of Hawaiian forests to the effects of climate change will depend on the type of forest ecosystem and its constituent species, its location with respect to rainfall and elevation, the size of forest patch remaining, and the effects of past and ongoing disturbances. Temperature increases may favor nonnative and invasive species, putting Hawai'i's native forests at more risk than at present. If rising temperatures exceed the physiological maximum threshold for native species, this is likely to result in 
reduced resilience against pests, disease, and interspecies competition with nonnatives. Even without interspecies competition, temperatures could become too warm for some native forest species, particularly at lower elevations. The level of uncertainty in projected precipitation means that the effects of changing rainfall and fog patterns are difficult to predict, especially in the context of complex topography and its effect on rainfall distribution over the islands.

Tropical dry forests are among the world's most threatened ecosystems, and Hawai 'i's dry forest ecosystems are no exception. The koa- and ohia-dominated dryland forests are usually of open canopy and are found at elevations ranging from 650 to 300 feet on the leeward side of the islands (Sohmer \& Gustafson, 1994). Species associated with dry forests have higher vulnerability to the effects of climate change than species from any other habitat type (Fortini et al., 2013). The limited extent of the dry forest in Hawai' $i$ also increases its sensitivity to disturbances such as climate change. It is believed that more than 90 percent of Hawai 'i's native dry forests have been removed, and what remains is highly fragmented (Bruegman, 1996). Invasive species such as fountain grass (Pennisetum setaceum) are likely to increase the sensitivity of dry forest ecosystems to the effects of increasing temperatures and drought. Fountain grass completely alters the fire regime of the ecosystem, fueling large, intense fires that kill native trees, reducing the woody component of the ecosystem and favoring increased growth of more fountain grass (Cabin et al., 2002; Cordell et al., 2002).

What remains of mixed mesic forests is found mostly between 2,500 to 4,100 feet in elevation. There are small fragments of coastal mesic forests below 2,500 feet. Mixed mesic forests growing at higher elevations are often open-canopy and dominated by ohia and koa, and like the dry forest ecosystems, they are widely degraded. Much of the area previously covered with this ecosystem was harvested for timber and subsequently converted to pasture of Kikuyugrass. Logging of old growth koa combined with ungulate browsing has replaced old growth forest with patches of small, slow-growing saplings (Denslow et al., 2006)citing others). Remnant forest patches are invaded with nonnative grasses, which reduce woody seedling establishment (Denslow et al., 2006). The mesic forests face similar threats as the dry forests, including greater competition from nonnative invasive species and altered fire regimes.

High rainfall typifies the areas where remnants of Hawaiian wet forests are located; annual precipitation ranges from around 120 to 300 inches. These forests occur at 1,500 to 6,200 feet and are usually dominated by ohia, with koa as a codominant or subdominant (Sohmer \& Gustafson, 1994). One of the most important modifiers of the vegetation in Hawaiian forests is feral pigs, and they are considered to be the current primary threat to Hawaiian wet forests (Cole et al., 2012). The rooting and foraging behavior of the pigs can disturb large areas of forest soils and spread the seeds of invasive species such as strawberry guava (Psidium cattleanium). Combined, the effects of declining precipitation, increasing temperature, disturbance from ungulates, and competition with nonnative species mean that like other forest types, Hawai 'i's wet forests are threatened on multiple fronts.

The effects of climate change are predicted to be more severe at higher elevations (Giambelluca et al., 2008); therefore, high mountain cloud forest ecosystems between 3,300 and 6,200 feet are very exposed to warming temperatures and altered precipitation patterns. Although ohia is one of the dominant tree species in cloud forests, many other species growing within the forest do not have a broad geographic range, which means the composition and dynamics of the forest may alter significantly with climate change. In particular, the position of these forests is strongly influenced by the trade wind inversion (TWI), and if climate change causes the base elevation of the TWI to drop, then the ecotone between cloud forests and subalpine shrublands will likewise move to lower elevations.

Mamane-naio dry forests grow above the TWI in the subalpine zone at higher elevations between 6,000 and 10,000 feet. Temperatures range from highs of $68^{\circ} \mathrm{F}$ to near freezing, and precipitation tends to be seasonal, varying between 27 inches at the treeline to 63 inches at lower elevations (Reddy et al., 2012). These ecosystems are dominated by mamane (Sophora chrysophylla) and naio (Myoporum sandwicense), and they are mostly found on Hawai'i Island, circling Mauna Kea, with some populations on the slopes of 
Mauna Loa. Like the lower-elevation dry forest, the original extent of mamane-naio forests has been depleted by livestock, through competition with invasive species and exposure to disease, and through changes in the fire regime. Exotic, invasive grasses flourish in the mamane-naio understory and have been shown to suppress the germination of mamane (Hess et al., 1999); citing others). Future exposure to increased temperatures and severe, prolonged drought is likely to further reduce tree cover, increase grass cover, and heighten the risk of devastating fires. The remaining mamane-naio forests are not as extensive as the dry forests dominated by koa or ohia, but they are of immeasurable conservation value by providing the only habitat for the palila or Hawaiian Honeycreeper (Loxioides bailleui) as well as supporting other native Hawaiian birds. There are active efforts to restore areas of mamane-naio dry forests, including replanting of native species and eradication of remaining feral sheep. Since the palila was listed as an endangered species in 1967, around 60,000 acres of critical habitat was established in 1977, and additional habitat was added in 2006.

The adaptive capacity to reduce exposure or sensitivity of Hawaiian forests to the effects of climate change also comes from forest management. The importance of Hawaiian forests is widely recognized by government, planners, academics, and stakeholders, and there are many efforts driving toward extending restorations and replanting of forests. Giardina (2012) lists several initiatives that are addressing management options for the effects of climate change on Hawaiian forests, including the Hawai ' $\mathrm{i}$ Department of Land and Natural Resources Watershed Initiative, the U.S. Fish and Wildlife Service Pacific Island Climate Change Cooperative, the Hawai' $i$ Restoration and Conservation Initiative, and the Hawai'i Conservation Alliance Effective Conservation Program. Another example is the Forest Stewardship Program run by the State of Hawai'i Division of Forestry and Wildlife (Giardina, 2012). Along with innovative new tax codes in Hawai ' $i$ and Kauai counties, this program is intended to encourage owners of pastureland and former sugar plantations to pursue forestry as an alternative, potentially more profitable land use. In addition, Federal landowner assistance programs such as the Wildlife Habitat Incentives, the Forestry Incentives, and the Environmental Quality Incentives Programs currently encourage private landowners through cost-share assistance to improve and manage their forest resources. 


\section{Greenhouse Gas Emissions Profile from Agriculture and Forests, and Mitigation Opportunities within the Southwest Region}

Agriculture in the Southwest region (including crop, animal, and forestry production) has net greenhouse gas (GHG) emissions of approximately -45.8 teragrams ${ }^{2}$ carbon dioxide equivalent $\left(\mathrm{Tg} \mathrm{CO}_{2}\right.$ eq.) (i.e., a net storage of $\mathrm{GHG}$ emissions). In the region, crop-related nitrous oxide $\left(\mathrm{N}_{2} \mathrm{O}\right)$ emissions at $17 \mathrm{Tg} \mathrm{CO}_{2}$ eq. are the largest contributor to GHGs, followed by methane $\left(\mathrm{CH}_{4}\right)$ from enteric fermentation $(16 \mathrm{Tg} \mathrm{CO}$ eq.), manure management (12 $\mathrm{Tg} \mathrm{CO}_{2}$ eq.), and soil carbon stock changes ( $2 \mathrm{Tg} \mathrm{CO}_{2}$ eq.). Forestry is the largest contributor to net carbon storage at $-93 \mathrm{Tg} \mathrm{CO}_{2}$ eq. $^{3}$

\subsection{Soil Carbon Stock Changes}

Carbon stock changes of major land use and management types for both organic and mineral soil types resulted in net emissions of $2.41 \mathrm{Tg} \mathrm{CO}_{2}$ eq. in 2008 (Table 7).

Specifically, cropland production changes on mineral soils sequestered ${ }^{4} 0.16 \mathrm{Tg} \mathrm{CO}_{2}$ eq. and land removed from agriculture and enrolled in the Conservation Reserve Program sequestered $0.25 \mathrm{Tg} \mathrm{CO}_{2}$ eq. In contrast, agricultural production on organic soils (which have a much higher organic carbon content than mineral soils) produced emissions of 2.56 $\mathrm{Tg} \mathrm{CO} 2$ eq., and changes in hay production resulted in emissions of $0.26 \mathrm{Tg} \mathrm{CO}_{2}$ eq. Tillage practices contribute to soil carbon stock changes. Table 8 shows the tillage practices by type of crop for the Southwest Regional Climate Hub. Management practices that utilize reduced till or no till can contribute to increased carbon storage over time depending on site-specific conditions.

\subsection{Nitrous Oxide Emissions in the Southwest Region}

In 2008, $\mathrm{N}_{2} \mathrm{O}$ emissions were approximately $17 \mathrm{Tg} \mathrm{CO}_{2}$ eq. Of these emissions, $9 \mathrm{Tg} \mathrm{CO}_{2}$ eq. came from croplands and $8 \mathrm{Tg} \mathrm{CO}_{2}$ eq. came from grasslands. ${ }^{5}$ Most crop-related $\mathrm{N}_{2} \mathrm{O}$ emissions in the region are from the minor crops (Table 9). The quantity and timing of nitrogen-based fertilizer affects the rate of

\footnotetext{
${ }^{2}$ A teragram (Johnson et al., 2010) is $10^{12}$ grams, which is equivalent to $10^{9}$ kilograms or 1 million metric tons.

${ }^{3}$ Net carbon storage is the balance between the release and uptake of carbon by an ecosystem. A negative sign indicates that more carbon was sequestered than greenhouse gases emitted.

${ }^{4}$ Sequestration of carbon is subtracted from the regional $\mathrm{CO}_{2}$ eq. emissions.

${ }^{5}$ Including both direct and indirect emissions;

Table 9 includes only direct emissions from crops.
}

Greenhouse Gas Emissions Profile from Agriculture and Forests, and Mitigation Opportunities within the Southwest Region Page $\mid 42$ 
both direct and indirect $\mathrm{N}_{2} \mathrm{O}$ emissions. ${ }^{6}$ Table 10 gives the percent of national acres that did not meet the best practice rate or timing criteria as defined by Ribaudo et al. (2011) and therefore represent opportunities for GHG mitigation. Best practice rate criterion is defined as applying no more nitrogen (commercial and manure) than 40 percent more than that removed with the crop at harvest, on the basis of a given yield goal, including any carryover from the previous crop. Best practice timing criterion is defined as not applying nitrogen in the fall for a crop planted in the spring (Ribaudo et al., 2011).

Table 7: Estimates of annual soil carbon stock changes by major land use and management type in the Southwest region, 2008.

\begin{tabular}{|l|c|}
\multicolumn{1}{|c|}{ Land Uses } & \multicolumn{1}{c|}{$\begin{array}{c}\text { Emissions } \\
\text { (Tg CO }\end{array}$ eq.) } \\
\hline Net change, cropland* & -0.16 \\
\hline Net change, hay & 0.26 \\
\hline $\begin{array}{l}\text { Conservation Reserve } \\
\text { Program }\end{array}$ & -0.25 \\
\hline $\begin{array}{l}\text { Ag. land on organic } \\
\text { soils }\end{array}$ & 2.56 \\
\hline Total $\dagger$ & 2.41 \\
\hline
\end{tabular}

Table 8: Tillage practices by crop type in the Southwest region.*

\begin{tabular}{|c|c|c|c|c|c|}
\hline $\begin{array}{l}\text { Crop } \\
\text { Type }\end{array}$ & Acres $\dagger$ & $\begin{array}{l}\text { No } \\
\text { Tillt: }\end{array}$ & $\begin{array}{l}\text { Reduced } \\
\text { Till: }\end{array}$ & $\begin{array}{c}\text { Conventiona } \\
\text { I Till: }\end{array}$ & $\begin{array}{c}\text { Other } \\
\text { Conservatio } \\
\text { n Tillage: }\end{array}$ \\
\hline Corn & 867,673 & $37 \%$ & $12 \%$ & $36 \%$ & $15 \%$ \\
\hline Cotton & 434,237 & $8 \%$ & $13 \%$ & $79 \%$ & \\
\hline Sorghum & 103,580 & $22 \%$ & $13 \%$ & $45 \%$ & $21 \%$ \\
\hline Wheat & 630,289 & $6 \%$ & $34 \%$ & $50 \%$ & $10 \%$ \\
\hline Total & $2,035,778$ & & & & \\
\hline
\end{tabular}

Source: (U.S. Department of Agriculture, 2011).

*Annual cropping systems on mineral soils (e.g., corn, sorghum, and wheat).

$\dagger$ Total does not include change in soil organic carbon storage on Federal lands, including those that were previously under private ownership, and does not include carbon storage due to sewage sludge applications.

Table 9: Direct nitrous oxide emissions by crop type.

\begin{tabular}{|c|c|c|} 
Crop Type & $\begin{array}{c}\text { Direct } \mathbf{N}_{2} \mathrm{O} \\
\text { Emissions } \\
(\mathrm{Tg} \mathrm{CO} \text { eq. }\end{array}$ & $\begin{array}{c}\text { \% of } \\
\text { Region's } \\
\text { Cropland } \\
\mathbf{N}_{2} \mathbf{O} \\
\text { Emissions }\end{array}$ \\
\hline Hay & 1.48 & $22.3 \%$ \\
\hline Corn & 0.45 & $6.8 \%$ \\
\hline Cotton & 0.19 & $2.8 \%$ \\
\hline Wheat & 0.09 & $1.4 \%$ \\
\hline Sorghum & 0.02 & $0.3 \%$ \\
\hline Minor Crops & 4.41 & $66.5 \%$ \\
\hline Total & $\mathbf{6 . 6 4}$ & $\mathbf{1 0 0 . 0 \%}$ \\
\hline
\end{tabular}

Source: USDA, (2011).
Table 10: National percent of acres not meeting rate and timing criteria (percent of acres).

\begin{tabular}{|c|c|c|}
\hline Crop & $\begin{array}{c}\text { Not Meeting } \\
\text { Rate }\end{array}$ & $\begin{array}{c}\text { Not Meeting } \\
\text { Timing }\end{array}$ \\
\hline Corn & $35 \%$ & $34 \%$ \\
\hline Sorghum & $24 \%$ & $16 \%$ \\
\hline Soybeans & $3 \%$ & $28 \%$ \\
\hline Wheat & $34 \%$ & $11 \%$ \\
\hline
\end{tabular}

Source: (Ribaudo et al., 2011).

\subsection{Livestock GHG Profile}

Livestock systems in the Southwest focus primarily on the production of swine, beef, and dairy cattle, sheep, poultry, and horses. In 2008, the region had more than 54 million poultry animals, 10 million beef and dairy cattle, and more than 1 million swine (U.S. Department of Agriculture, 2011). Nearly 66

${ }^{6}$ Direct $\mathrm{N}_{2} \mathrm{O}$ emissions are emitted directly from agricultural fields and indirect $\mathrm{N}_{2} \mathrm{O}$ emissions are emissions associated with nitrogen losses from volatilization of nitrogen as ammonia $\left(\mathrm{NH}_{3}\right)$, nitrogen oxides $(\mathrm{NOx})$, and leaching and runoff.

Greenhouse Gas Emissions Profile from Agriculture and Forests, and Mitigation Opportunities within the Southwest Region

Page $\mid 43$ 
percent of the cattle population is beef cattle. The primary source of GHGs from livestock is from enteric fermentation, digestive processes that result in the production of methane $\left(\mathrm{CH}_{4}\right)$ (referred to as enteric $\mathrm{CH}_{4}$ ). In 2008, Southwest livestock produced $16.12 \mathrm{Tg} \mathrm{CO}_{2}$ eq. of enteric $\mathrm{CH}_{4}{ }^{7}$ Most of the remaining livestock-related GHG emissions are from manure management practices-which produce both $\mathrm{CH}_{4}$ and $\mathrm{N}_{2} \mathrm{O} .{ }^{8}$ In 2008, manure management in the Southwest region resulted in $12.2 \mathrm{Tg} \mathrm{CO}_{2}$ eq., considering both $\mathrm{CH}_{4}$ and $\mathrm{N}_{2} \mathrm{O}$, with the majority attributed to $\mathrm{CH}_{4}$ (U.S. Department of Agriculture, 2011).

\section{Enteric fermentation}

The primary emitters of enteric $\mathrm{CH}_{4}$ are ruminants (e.g., cattle and sheep). Per-head emissions of enteric $\mathrm{CH}_{4}$ from dairy cattle are 40 to 50 percent greater than for beef cattle primarily due to their greater body weight and energy requirements for extended periods of lactation (U.S. Environmental Protection Agency, 2014). Even though the population of beef cattle is almost twice that of dairy cattle in the Southwest, the overall contribution to enteric $\mathrm{CH}_{4}$ emissions from dairy cattle is slightly higher than for beef cattle (U.S. Department of Agriculture, 2011). Table 11 provides $\mathrm{CH}_{4}$ emissions by animal types for 2008.
Table 11: Emissions from enteric fermentation in the Southwest.

\begin{tabular}{|l|c|c|}
\multicolumn{2}{c}{$\begin{array}{c}\text { Animal } \\
\text { Category }\end{array}$} & Tg CO \\
& & $\begin{array}{c}\text { Percent of Region's } \\
\mathrm{CH}_{4} \text { Enteric } \\
\text { Emissions }\end{array}$ \\
\hline Beef cattle* & 7.04 & 43.7 \\
\hline Dairy cattle* & 8.97 & 55.7 \\
\hline Goats $\dagger$ & 0.01 & 0.0 \\
\hline Horses $\dagger$ & 0.03 & 0.2 \\
\hline Sheep $\dagger$ & 0.04 & 0.2 \\
\hline Swine $\dagger$ & 0.03 & 0.2 \\
\hline Total & 16.12 & 100.0 \\
\hline
\end{tabular}

*Source: (U.S. Department of Agriculture, 2011).

$\uparrow$ Source: Based on animal population from USDA (2011) and emission factors as provided in IPCC (2006).

\section{Emissions from manure management systems}

Manure management in the Southwest yielded emissions of $10.1 \mathrm{Tg} \mathrm{CO}_{2}$ eq. of $\mathrm{CH}_{4}$ and $2.1 \mathrm{Tg} \mathrm{CO}_{2}$ eq. of $\mathrm{N}_{2} \mathrm{O}$ in 2008. Table 12 summarizes $\mathrm{CH}_{4}$ and $\mathrm{N}_{2} \mathrm{O}$ emissions by animal category. Dairy cattle waste accounts for the majority of manure-related emissions, emitting 93 percent of the region's agricultural $\mathrm{CH}_{4}$ and 70 percent of its $\mathrm{N}_{2} \mathrm{O}$.

The distribution of animal population among different farm sizes varies across animal categories. In the Southwest, 43 percent of dairy cattle are managed by farms with more than 2,500 head; 95 percent of swine are managed by farms with more than 5,000 head. Mitigation technologies such as anaerobic digesters ${ }^{9}$ are more economically feasible on large farm operations such as these due to economies of scale. Figure 11 summarizes $\mathrm{CH}_{4}$ and $\mathrm{N}_{2} \mathrm{O}$ emissions by animal category and

\footnotetext{
${ }^{7}$ The enteric $\mathrm{CH}_{4}$ emissions total for the region includes cattle and non-cattle.

${ }^{8}$ Livestock respiration also produces carbon dioxide $\left(\mathrm{CO}_{2}\right)$, but the effects of ingesting carbon-based plants and expelling $\mathrm{CO}_{2}$ result in zero-net emissions.

${ }^{9}$ Anaerobic digesters are lagoons and tanks that maintain anaerobic conditions and can produce and capture methane-containing biogas. This biogas can be used for electricity and/or heat, or can be flared. In general, anaerobic digesters are categorized into three types: covered lagoon, complete mix, and plug flow digesters.
}

Greenhouse Gas Emissions Profile from Agriculture and Forests, and Mitigation Opportunities within the Southwest Region Page $\mid 44$ 
baseline manure management practices. ${ }^{10}$ The largest sources of agricultural $\mathrm{CH}_{4}$ are dairy anaerobic lagoons and deep pits. The largest sources of $\mathrm{N}_{2} \mathrm{O}$ are dairy and beef dry lots. Figure 12 displays the proportion of beef cattle, dairy cattle, and swine raised in various manure management systems. Most beef cattle waste is deposited on pasture, whereas dairy and swine waste is managed using a variety of systems, including anaerobic lagoons, deep pits, dry lots, and liquid/slurry systems.

Figure 11: $2008 \mathrm{CH}_{4}$ and $\mathrm{N}_{2} \mathrm{O}$ emissions from the Southwest by animal category and management system ( $\mathrm{Tg}$ of $\mathrm{CO}_{2} \mathrm{eq}$. ).

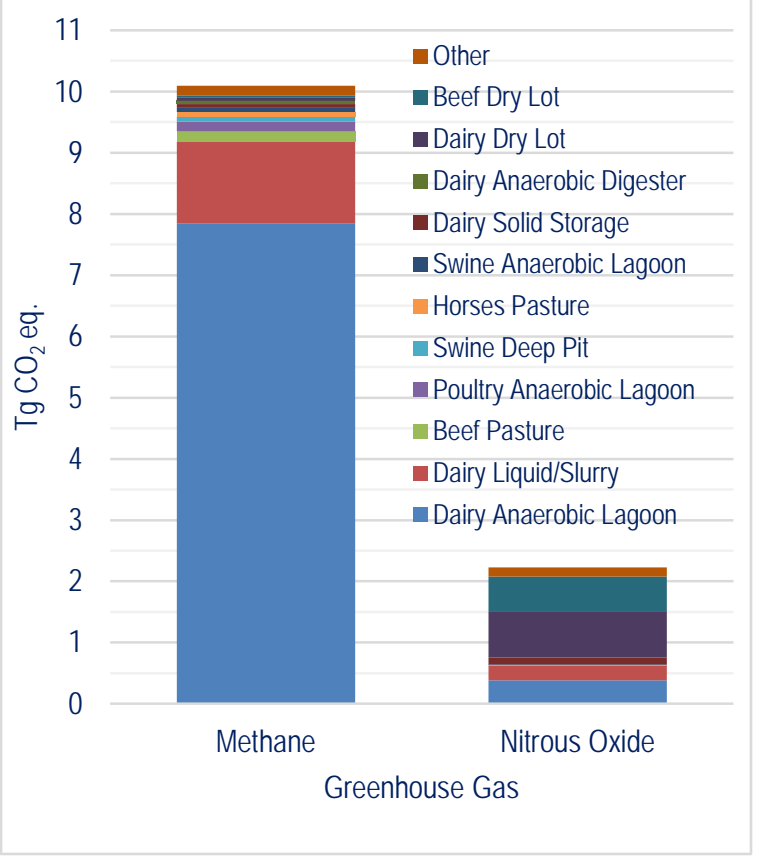

Figure 12: Proportion of beef cattle, dairy cattle, and swine managed with each manure management system in the Southwest.

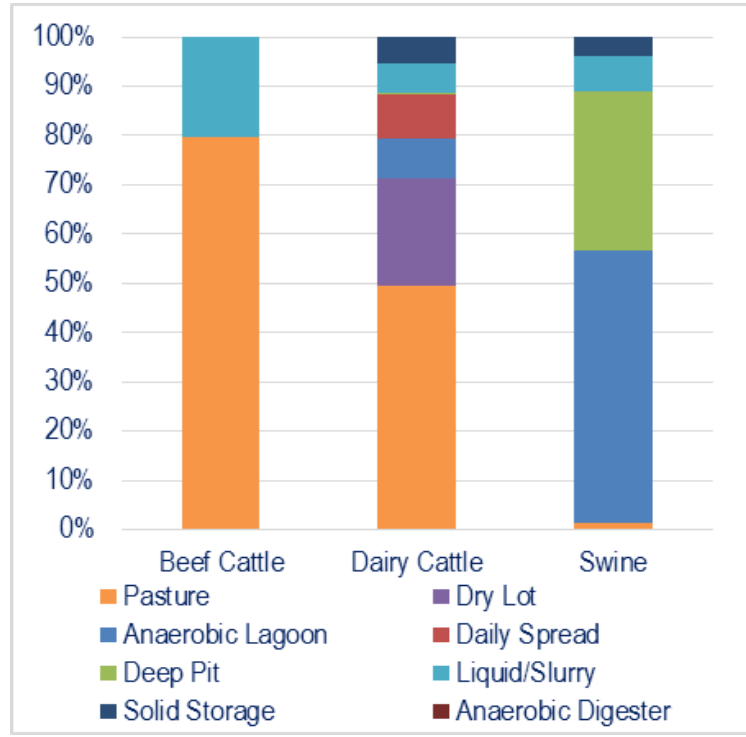

\subsection{Forest Carbon Stocks and Stock Changes}

In the 2008 GHG inventory reported by the USDA, forests and harvested wood products from forests sequester $93 \mathrm{Tg} \mathrm{CO}_{2}$ eq. per year in the Southwest; in addition, the 98,061 thousand acres of forest land in the Southwest maintain 18,295 $\mathrm{Tg} \mathrm{CO}_{2}$ eq. in forest carbon stocks. ${ }^{11}$ Managed forest systems in the Southwest produce softwood timber and serve as reserved forest land. Forestry activities present significant opportunities for managing GHGs. Forest managers in the Southwest use a wide variety of silvicultural techniques to achieve management objectives, most of which will have effects on carbon dynamics. Silvicultural techniques include enhancement of forest growth (which increases the rate of carbon sequestration) and forest harvesting practices (which transfers carbon from standing trees into harvested wood products and residues, which eventually decay or are burned as firewood or pellets). Other forest management activities will result in accelerated loss of forest carbon, such as when soil disturbance increases the oxidation of soil organic matter, or when prescribed burning releases $\mathrm{CO}_{2}\left(\mathrm{~N}_{2} \mathrm{O}\right.$ and $\mathrm{CH}_{4}$ ).

\footnotetext{
${ }^{10}$ Definitions for manure management practices can be found in Appendix 3-B of (ICF International, 2013).

${ }^{11}$ Other GHGs such as $\mathrm{N}_{2} \mathrm{O}$ and $\mathrm{CH}_{4}$ are also exchanged by forest ecosystems. $\mathrm{N}_{2} \mathrm{O}$ may be emitted from soils under wet conditions or after nitrogen fertilization; it is also released when forest biomass is burned. $\mathrm{CH}_{4}$ is often absorbed by the microbial community in forest soils but may also be emitted by wetland forest soils. When biomass is burned in either a prescribed fire/control burn or in a wildfire, precursor pollutants are emitted, which can contribute to ozone and other short-lived climate forcers. $\mathrm{CH}_{4}$ is also emitted (U.S. Department of Agriculture, 2014).
}

Greenhouse Gas Emissions Profile from Agriculture and Forests, and Mitigation Opportunities within the Southwest Region

Page 45 
Southwest Region and California Sub Hub

Forest management activities and their effects on carbon storage vary widely across the Southwest with different forest types, ownership objectives, and forest stand conditions. However, some commonly used silvicultural prescriptions exist for Southwest forest types. For example, the USDA's Quantifying Greenhouse Gas Fluxes in Agriculture and Forestry: Methods for EntityScale Inventory Technical Bulletin (U.S. Department of Agriculture, 2014) provides this information for regions overlapping with the Southwest (the Rocky Mountain South and Pacific Southwest regions.

Table 13: Southwest forest carbon stock and stock changes.

\begin{tabular}{|c|c|c|}
\hline Source & Units & Southwest \\
\hline Net area change & $1,000 \mathrm{ha} \mathrm{yr}^{-1}$ & 167 \\
\hline Non-soil stocks & $\mathrm{Tg} \mathrm{CO}$ eq. & 14,137 \\
\hline SOC & $\mathrm{Tg} \mathrm{CO} \mathrm{CO}_{2}$ eq. & 4,158 \\
\hline Non-soil change & $\underset{\mathrm{yr}^{-1}}{\mathrm{Tg} \mathrm{CO}}$ & $-89^{2}$ \\
\hline $\begin{array}{l}\text { Harvested wood products } \\
\text { change }\end{array}$ & $\underset{\mathrm{yr}^{-1}}{\mathrm{Tg} \mathrm{C}}$ & $-4^{2}$ \\
\hline \multicolumn{3}{|c|}{ Forest carbon stock summary ( $\mathrm{Tg} \mathrm{CO}_{2}$ eq.) } \\
\hline Non-soil stocks + SOC & & 18,295 \\
\hline \multicolumn{3}{|c|}{ Forest carbon stock change summary ( $\mathrm{Tg}_{\mathrm{CO}}$ eq. yr $\left.{ }^{-1}\right)$} \\
\hline Forest carbon stock change & & -93 \\
\hline
\end{tabular}

The USDA's Forest Service 2010 Resources Planning Act Assessment (RPA) General Technical Report (2012) describes future projections of forest carbon stocks in the United States resulting from various climate change effects (e.g., less-than-normal precipitation, above-normal temperature) and other stressors (e.g., urbanization, other land development, demand for fuel and fiber). The RPA projects that "declining forest area, coupled with climate change and harvesting, will alter forest-type composition in all regions." For the Pacific Coast, the rate of urban growth is third highest in the country, and the Hemlock-Sitka spruce area is projected to decline, whereas Douglas-fir forest area is projected to increase.

\subsection{Mitigation Opportunities}

Figure 13 shows the mitigation potential of GHG emissions by sector for the Southwest region. Each bar represents the GHG potential below a break-even price of $\$ 100 /$ metric ton $\mathrm{CO}_{2}$ eq. ${ }^{12} \mathrm{~A}$ break-even price is the payment level (or carbon price) at which a farm will view the economic benefits and the economic costs associated with adoption as equal. A positive break-even price represents the minimum incentive level needed to make adoption economically rational. A negative break-even price suggests that 1 ) no additional incentive should be required to make adoption cost-effective; or 2) there are nonpecuniary factors (such as risk or a required learning curve) that discourage adoption (Bonfils et al., 2012). The break-even price is determined through a discounted cash-flow analysis such that the revenues or cost savings are equal to the costs. ${ }^{13}$ The left two bars represent reductions from changes in management practices that mitigate GHGs. The right three bars represent increased carbon storage from changes in management practices. A total of $6.6 \mathrm{Tg} \mathrm{CO}$ eq. can be mitigated at a break-even price below $\$ 100 /$ metric tons $\mathrm{CO}_{2}$ eq. Changes in land management practices can increase carbon storage by $4.4 \mathrm{Tg}$ $\mathrm{CO}_{2}$ eq. at a break-even price below $\$ 100 /$ metric tons $\mathrm{CO}_{2}$ eq. The color shading within a bar represents the mitigation potential or the potential increased carbon storage below different break-even prices indicated in the legend. For example, changes in land retirement practices have the potential to contribute to more than $1 \mathrm{TgCO}_{2}$ eq. of increased carbon storage for less than $\$ 20 /$ metric ton $\mathrm{CO}_{2}$ eq. (i.e., light blue and light green bars).

- Most of the opportunity for reducing net GHG emissions will be from changes in manure management practices.

- The next largest opportunities are by increasing carbon stock is interseeding legumes on rangeland areas grazed by cattle (by preventing erosion and increasing carbon sequestration) and land retirement practices, such as retiring cultivated organic and marginal mineral soils.

\footnotetext{
${ }^{12}$ Break-even prices are typically expressed in dollars per metric ton of $\mathrm{CO}_{2}$ eq.

${ }^{13}$ See ICF International (2013) for additional details.
}

Greenhouse Gas Emissions Profile from Agriculture and Forests, and Mitigation Opportunities within the Southwest Region Page $\mid 46$ 
- The highest reductions in emissions from manure management are from installing complete mix digesters or lagoon digesters at swine and dairy farms, and installing improved separators at dairy farms with anaerobic lagoons. ${ }^{14}$

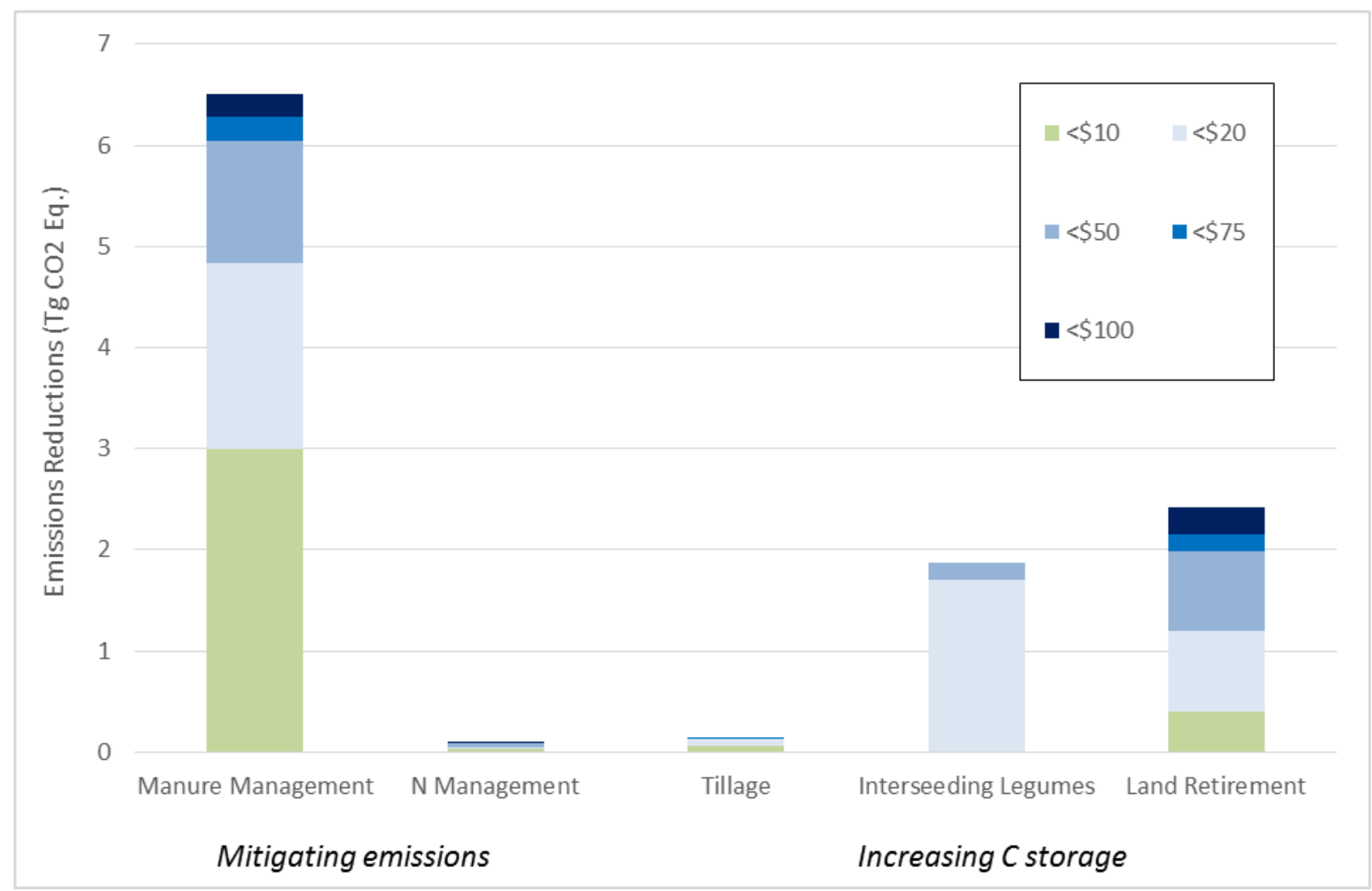

Figure 13: Mitigation potential in the Southwest, by sector. See the text in section 4.4 for an explanation of colors.

\section{Agricultural Soils}

For farms larger than 250 acres, variable rate technology is a relatively low-cost option for reducing $\mathrm{N}_{2} \mathrm{O}$ emissions from fertilizer application. ${ }^{15}$ Reducing nitrogen application can be a relatively low-cost option for all farm sizes. Transitioning from conventional tillage to continuous no-tillage or reduced tillage to continuous no-tillage field management practices boosts potential for carbon storage at low cost (i.e., the magnitude of the carbon storage potential is orders of magnitude higher than the potential to reduce $\mathrm{N}_{2} \mathrm{O}$ emissions). Carbon gains can be realized only if no-till is adopted permanently, otherwise gains will be reversed.

\section{Land Retirement}

This category includes retiring marginal croplands and establishing conservation cover, restoring wetlands, establishing windbreaks, and restoring riparian forest buffers. Retiring marginal soil and restoring forested wetlands provide the most opportunities for increasing carbon storage.

\section{Manure Management}

\footnotetext{
${ }^{14}$ The emission reduction excludes indirect emission reductions from the reduced use of fossil fuels to supply the electricity for on farm use (i.e., the emission reductions only account for emissions within the farm boundaries).

${ }^{15}$ Variable rate technology (VRT), a subset of precision agriculture, allows farmers to more precisely control the rate of crop inputs to account for differing conditions within a given field. VRT uses adjustable rate controls on application equipment to apply different amounts of inputs on specific sites at specific times (Alabama Precision Ag Extension, 2011).
}

Greenhouse Gas Emissions Profile from Agriculture and Forests, and Mitigation Opportunities within the Southwest Region

Page $\mid 47$ 
The total $\mathrm{CH}_{4}$ mitigation potential for livestock waste in the Southwest is $6.5 \mathrm{Tg} \mathrm{CO}_{2}$ eq. under $\$ 100 /$ metric tons $\mathrm{CO}_{2}$ eq. Lower-cost GHG mitigation opportunities for manure management are primarily for large swine and dairy operations. The relatively higher $\mathrm{CH}_{4}$ reductions can be achieved on dairy operations by transitioning from anaerobic lagoons to improved solids separators, a covered anaerobic lagoon, a covered lagoon digester, or a complete mix digester. For large swine operations, the relatively higher mitigation measures are to transition from anaerobic lagoons, deep pits, or liquid/slurry systems to complete mix digesters, covered lagoon digester, or to covering an existing lagoon.

\section{Enteric Fermentation}

Emissions from enteric fermentation are highly variable and are dependent on livestock type, life stage, activity, and feeding situation (e.g., grazing, feedlot). Several practices show potential for efficacy in reducing emissions from enteric fermentation. Diet modification (e.g., increasing fat and/or protein content, providing higher quality forage) and providing supplements (e.g., monensin, bovine somatotropin $[\mathrm{bST}]$ ) have been evaluated for mitigation potential, the effectiveness of each option is not conclusive.

\section{USDA Programs}

The recently published USDA Climate Change Adaptation Plan ${ }^{16}$ presents strategies and actions to address the effects of climate change on key mission areas including agricultural production, food security, rural development, forestry, and natural resources conservation. USDA programs administered through the Agricultural Research Service (ARS), Natural Resources Conservation Service (NRCS), U.S. Forest Service, Farm Service Agency (FSA), Rural Development (RD), Risk Management Agency (RMA), and Animal and Plant Health Inspection Service (APHIS) have been and will continue to play a vital role in sustaining working lands in a variable climate and are key partner agencies with the USDA Climate Hubs.

\subsection{Natural Resources Conservation Service}

NRCS, along with other USDA service center agencies and the Cooperative Extension System, will connect farmers, ranchers, nonindustrial private forest landowners, and others in the agricultural, conservation, and environmental sectors to advance climate change research and applications. Much of this assistance focuses on developing conservation practices that can mitigate climate change through reduced greenhouse gas emissions or increased carbon sequestration and have been developed through Conservation Innovation Grants. Application of conservation practices builds greater resiliency to variability in climate and weather. NRCS continues to enhance delivery of conservation programs and assistance to working lands using advances in information and techniques made more readily available through the Hub network.

Climate vulnerabilities suggest increasing temperatures; increase in precipitation; longer temperate seasons; more frequent flooding; and other extreme weather events such as high wind, ice storms, extended periods of wet weather, and drought conditions. These anticipated changes are expected to have a direct effect on agriculture in the Southwest. Additionally, in light of the Hawaiian or Pacific Islands being a part of the geographic extent of the Southwest Regional Climate Hub, subsequent change in sea level is also an environmental effect of great concern.

GHG generation or suppression is thought to have an effect on climate patterns. To meet the rising demands for meat and poultry, livestock operations continue to grow and concentrate in various regions

\footnotetext{
${ }^{16}$ The 2014 USDA Climate Change Adaptation Plan includes input from 11 USDA agencies and offices. It provides a detailed vulnerability assessment, reviews the elements of USDA's mission that are at risk from climate change, and provides specific actions and steps being taken to build resilience to climate change. Find more here: http://www.usda.gov/oce/climate_change/adaptation/adaptation_plan.htm.
}

USDA Programs

Page $\mid 48$ 
around the country. This can lead to increased methane production, which can affect air quality. Manure storage and treatment facilities may also contribute to GHG emissions unless they are properly designed.

Livestock operations will likely need to adapt to increased intensity and frequency of summer heat stress, which could decrease production and increase the effect of pathogens and parasites. These conditions would likely affect livestock health and increase mortality. Data suggest that pastures are overgrazed with a continuous grazing method and are more vulnerable to further climate-induced disturbances.

Crop and forage production could face heat and ozone stress, drought conditions, effects of water inundation on fields, and invasive weed, pest, and pathogen outbreaks. Excessive rainfall in the other seasons could lead to flooding and delay springtime planting and result in lower crop yields.

Supporting long-term habitat for wildlife, including threatened and endangered species, may require development of adaptation strategies to address shifts in plant and animal distribution, changes in plant phenology, disruption in interactions that have coevolved such as plant-pollinator relationships, range restriction of plants, and increased spread of invasive and nonnative plants.

Another major vulnerability stems from drought and its effect on surface and ground water supplies.

\section{Role of NRCS in the Southwest}

NRCS can participate in determining important research directions and activities in areas supported by the Southwest Hub and California Sub Hub by evaluating production systems under credible climate change scenarios. With practical understanding gained by evaluation of conservation and production success accompanied by feedback from producers, NRCS can provide input within the Hub network to agencies, universities, and organizations conducting foundational and applied research.

NRCS has major technical and financial assistance programs focusing on soil erosion, water quantity, water quality, confined animal facilities, ecosystem restoration, rangeland and woodland that can be grazed, forest health, specialty crop production, and air quality. The Bay-Delta is one of eight Presidential ecosystem landscape initiatives and is a Secretarial Critical Conservation Area. NRCS also works with a large number of historically underserved producers and with many small producers and limited-resource producers, along with providing conservation technical and financial assistance to Tribes.

NRCS participates in and offers conservation technical and financial assistance to producers through various Environmental Quality Incentive Program (EQIP) offerings and numerous locally led conservation programs at the county level. Each of these programs provides producers the flexibility to address emerging issues related to climate change as it relates to their personal circumstances.

NRCS has many conservation practices and programs that can provide technical and financial assistance to help producers adapt to climate change effects. Conservation practices include cover crops, conservation tillage, and conservation crop rotation to increase soil resilience on cropland; prescribed grazing to improve pastures; reduction of GHGs from confined livestock operations by manure management; sequestration of carbon through tree planting; and control of excessive runoff through water management.

Programs that support and promote the adoption of these practices through financial assistance include EQIP, the Conservation Stewardship Program (CSP), Agricultural Conservation Easement Program (ACEP), and the Regional Conservation Partnership Program (RCPP).

NRCS can further help farmers and other technical service providers with products that help assess and measure the effects associated with climate change and the ability to adapt to them. NRCS maintains many databases, techniques, and assessments that could be used directly or in conjunction with other climate-related tools. 


\section{NRCS California}

California Natural Resources Conservation Service (CA NRCS) has 55 field offices providing conservation technical and financial assistance on private agricultural and forest lands throughout California. CA NRCS has a primary role in the delivery of products of the Southwest Hub and California Sub Hub network. CA NRCS, along with other the USDA Service Center agencies and the Cooperative Extension System, will connect farmers, ranchers, nonindustrial private forest landowners, California's approximately 92 Resource Conservation Districts, 108 Tribes, and other agricultural and conservation and environmental sectors to advances in climate change research and applications.

CA NRCS is already addressing potential effects of climate change through ongoing conservation programs and technical assistance activities that take steps to conserve and improve natural resources and to assist farmers and ranchers as stewards of the land. Much of this assistance focuses on developing conservation practices that can mitigate climate change through reduced GHG emissions or increased carbon sequestration and have been developed through Conservation Innovation Grants conducted primarily in California. Application of these conservation practices builds greater resiliency to variability in climate and weather. Another example is launch of the Soil Health Initiative in California, which provided education and training sessions for all CA NRCS field employees and producers on the advantages and methods for improving the condition and resiliency of working lands soils. CA NRCS will continue to enhance its delivery of conservation programs and assistance to working lands using advances in information and tools made more readily available through the Hub network.

In addition to technology transfer, CA NRCS can participate in determining important research directions and activities in areas supported by the Southwest Hub and California Sub Hub by evaluating production systems under credible climate change scenarios, and by identifying resource management systems and conservation priorities and practices necessary to protect natural resources and agricultural productivity in the face of climate change. With this practical understanding gained by evaluation of conservation and production success accompanied by feedback from producers, CA NRCS can provide input within the Hub network to agencies, universities, and organizations conducting foundational and applied research (including some applied research facilitated by NRCS through Conservation Innovation Grants).

\section{Role of CA NRCS}

CA NRCS has major technical and financial assistance programs focusing on soil erosion (both water related and windblown), water quantity (drought and water management), water quality (sediment, nutrients, and pesticides), confined animal facilities (dairy water quality and nutrient management planning, expanding use of digesters), ecosystem restoration (anadromous fish, mountain meadows, riparian and aquatic habitat, coastal estuaries, wetland habitat for migratory birds), rangeland and grazeable woodland (livestock water, grazing management and water quality), forest health (reducing catastrophic fire and associated runoff and sedimentation), specialty crop production (more than 400 crops on land varying from very steep to flat, peat soils to desert soils, in 16 Multiple Land Resource Areas), and air quality (highly erosive soils subject to severe wind, nonattainment area for air quality with increased regulation). The Bay-Delta is one of eight Presidential ecosystem landscape initiatives and is a Secretarial Critical Conservation Area. CA NRCS is an active participant in an 11-State Sage Grouse Habitat Initiative.

CA NRCS also works with a large number of historically underserved producers and with many small producers and limited-resource producers, along with providing conservation technical and financial assistance to Tribes.

California NRCS participates in and offers conservation technical and financial assistance to producers through various EQIP offerings: the National Air Quality Initiative, the National Water Quality Initiative, the Bay Delta Initiative, and numerous locally led conservation programs at the county level. Preservation

USDA Programs

Page $\mid 50$ 
of prime farmland and ranchland, preservation of wetlands, and restoration of wetlands are addressed through the Agricultural Conservation Easement Program. Each program gives producers the flexibility to address emerging issues related to climate change as it relates to their personal circumstances. In addition, the Lockeford Plant Materials Center offers technical assistance in evaluating plant materials and plant production methods that are most effective for erosion control, streambank stabilization, native plant materials, and other conservation uses.

\subsection{U.S. Forest Service}

The Forest Service is involved in research, translation, and delivery of information and technical tools for the public and private forestry sector. Forest and rangelands are key sinks of carbon, and carbon sequestration is increasingly an important management objective. Research in this area provides baseline carbon data at various scales to managers and provides methods to assess carbon in the forests and forest products, and provides management strategies to consider carbon in management strategies. The Research and Development branch is the principal in-house forestry and natural resource research arm of USDA. . The State and Private Forestry (S\&PF) branch is the Federal leader in providing technical and financial assistance to landowners and resource managers to help sustain the Nation's forests and protect communities and the environment from wildland fires.

\section{National Forest System}

The National Forest system manages 193 million acres and is often the "front line" when communicating with the public. The National Forest system consists of 154 national forests and 20 grasslands organized into 9 regions. It contains 439 wilderness areas that total more than 36 million acres of land that range in size from 372 acres in the Allegheny Islands Wilderness in Pennsylvania to 2,356,934 acres in the Frank Church-River of No Return Wilderness, which spans five national forests in Idaho. There are also 20 national recreation areas, 6 national scenic areas, 6 national monument areas, 2 national volcanic monument areas, and 2 national historic areas. The Forest Service works in partnership with public agencies, private organizations, Tribes, watershed groups, volunteer organizations, nonprofit organizations, schools, and individuals to manage national forest resources. These include water, fish, trees, soil, recreation facilities, trails, roads, terrestrial habitats, invasive weeds, and many more. These National Forests and Grasslands are often the front line interacting with the public on natural resource management.

\section{Research and Development}

$R \& D$ staff members translate climate projections into potential effects on forest, rangeland, and urban ecosystems. These effects include changes in species composition, appearance, and function. This "translation" requires that climate change be considered as one of many stressors that affect forest, rangeland, and urban ecosystems; these stressors include invasive plants, insect outbreaks, pathogens, fire, and fragmentation. The resulting information is used to perform vulnerability assessments, and then to devise management strategies that will keep these ecosystems healthy, resilient, and productive. Forest Service Research Stations assist land managers with vulnerability assessments, often directly, but also indirectly by providing models and tools (many available on the web, http://www.fs.fed.us/ccrc). Such efforts are underway throughout the country. The research is often (but not always) regional in nature because ecosystems differ across the regions of this country.

\section{Regional Stations}

The five Forest Service research stations, the International Institute of Tropical Forestry, and the two threat assessment centers serve as regional hubs that provide key information to decision makers. In addition, there is also national-level expertise throughout the stations that enables the agency to carry out national assessments of the effects of climate change; an example being the Resources Planning Act 
(RPA) Assessment, which reports on the status and trends of the Nation's renewable resources on all forest and rangelands (http://www.fs.fed.us/research/rpa/). The stations utilize multiple approaches to climate change technology transfer that range from having a dedicated team to depending on individual scientists to move their results to the field. Each station has a cadre of scientists and professional support staff who are advancing our knowledge of the effects from a changing climate. The Forest Service has a web portal that provides climate change information and tools in a user-friendly format for government land managers at the Climate Change Resource Center (http://www.fs.fed.us/ccrc/).

\section{Forest Service Cooperative Forestry Program}

The Forest Service Cooperative Forestry program works with States, private landowners, and other partners to promote healthy forests and livable communities throughout the United States. In partnership with State forestry agencies, Cooperative Forestry currently manages a number of programs, including the Forest Stewardship Program (FSP). This program helps private forest landowners develop plans for the sustainable management of their forests. The FSP mission is to protect and improve the health of America's rural, wildland, and urban forests. Forest Health Protection provides technical assistance on forest health-related matters, particularly those related to disturbance agents such as native and non-native insects, pathogens, and invasive plants. In addition, Forest Health Protection provides forest insect, disease, and invasive plant survey and monitoring information, and technical and financial assistance to prevent, suppress, and control outbreaks threatening forest resources. More than 250 specialists in the areas of forest entomology, forest pathology, invasive plants, pesticide use, survey and monitoring, suppression and control, technology development, and other forest health-related services provide expertise to forestland managers throughout the Nation. The Urban and Community Forestry Program encourages States, Federally recognized Tribes, and other partners to focus financial, educational, and technical assistance on helping localities improve the resilience of their urban and community forests in response to climate-related stressors.

\section{National Agroforestry Center}

The USDA National Agroforestry Center (NAC) is a partnership between the Forest Service and NRCS to accelerate the application of agroforestry through a national network of partners. NAC conducts research, develops technologies and tools, coordinates demonstrations and training, and provides useful information to natural resource professionals (http://nac.unl.edu/).

\section{Role of the Forest Service in the Region}

Climate change is already affecting the forests in the Pacific Southwest region. Changes are resulting in shifts in ecological patterns and processes throughout California. Perhaps the most significant for the Forest Service are trends in hydrology and fire. Although precipitation has remained steady or increased over much of northern and central California, the balance between rain and snow has shifted strongly toward rain, and mean annual snowpack depths have been decreasing over the last 50 years. Peak stream flow has shifted earlier in the season by 3 or more weeks, and there is higher interannual variability in stream flow as well, with lower low flows and higher high flows. Forest fire frequency, size, and total annual burned area are all rising (as they are across the West); in some forest types (mostly low- to middle-elevation conifers) fire severity is also rising. Evidence also suggests that the interaction between rising temperatures and more profound summer drought is leading to higher mortality of forest trees. Scientific studies indicate that the geographic distributions of many plant and animal species in California are changing (mostly moving uphill or to otherwise cooler locations) to track changing climates; this includes forest pests such as mountain and western pine beetles.

In response to these changes, the Forest Service is focusing on three actions: 1) assessing current risks, vulnerabilities, policies, and gaps in knowledge; 2) engaging internal and external partners; and 3) 
managing for resilience in ecosystems and human communities through adaptation, mitigation, and sustainable consumption strategies.

To implement robust management actions today that will sustain Sierra Nevada resources into the future, it is important that climate change be considered explicitly in management plans and practices. The Pacific Southwest region is implementing several programs to help ecosystems adapt.

The Sierra Nevada Climate Change Vulnerability Assessment and Adaptation Strategy project (SNVAAS) was a cooperative venture funded primarily by the California Landscape Conservation Cooperative, in partnership with EcoAdapt (a climate science nongovernmental organization), that identified management actions to aid regionally important ecosystems and species in adapting to changing climate conditions. Key products include 1 ) vulnerability assessment findings for 8 ecosystems and 15 species; 2) climate change adaptation strategies; and 3) down-scaled climate data and maps for the Sierra Nevada, including future climate projections for temperature, precipitation, snowpack, runoff, recharge, soil moisture, wildfire, and vegetation change. Products and information from the project are available on the EcoAdapt website (http://ecoadapt.org/programs/adaptation-consultations/calcc). In fiscal year 2015, Region 5 of the Forest Service is expanding the effort to include the four forests in southern California.

National Forest managers have been responding annually to the agency's Climate Change Scorecard since 2011. The scorecard is a tool for forest managers to improve organizational capacity and readiness to respond to climate change while creating a balanced approach that also includes mitigating climate change, building partnerships across boundaries, and preparing Forest Service employees to respond to climate-related issues by understanding and applying emerging science. The scorecard consists of 10 YesNo questions related to capacity building, adaptation to climate change, engagement with partners, and mitigation and sustainable operations. The Forest Service's goal is for all National Forests to respond Yes to at least 7 of the 10 questions by the end of fiscal year 2015. Region 5 (consisting of 18 National Forests in California) is presently leading the agency in this effort, and is on track to meet the national goal.

\subsection{Farm Service Agency}

In the Southwest region, the major FSA activities focus on providing assistance after disasters such as prolonged, catastrophic droughts. Drought in the Southwest has been an issue particularly over the last 10 years, which have been some of the driest on record. During these times FSA must re-focus its priorities and resources to assist farmers and ranchers with benefits to mitigate losses during years of drought. As a result of these drought events, numerous other disaster events have occurred that require FSA to re-direct its resources. Catastrophic wild land fires and flash flooding typically occur during prolonged periods of drought. Although monsoonal rains are a normal occurrence throughout the year, the effects can be disastrous when the soil cannot retain the moisture or when burn scars from a devastating wildfire causes flash flooding - all due to drought. FSA resources must be shifted to address these natural disasters that affect farmers and ranchers. Additionally, resource concerns may change as it pertains to FSA conservation efforts. For example, wildlife may be affected during times of prolonged drought, which in turn may necessitate FSA to address habitat concerns through specific initiatives that meet the needs of specific, affected species.

The 2014 Farm Bill, in addition to other legislation, authorizes several different programs that FSA can utilize to address the vulnerabilities and effects caused by climate changes. During times of flooding, the Emergency Conservation Program can be used to rehabilitate land that has been affected by flooding. The Conservation Reserve Program can be implemented to address wildlife concerns that have a direct correlation to climate change events. FSA's Livestock Disaster Assistance Program, Livestock Indemnity Program, and Noninsured Assistance Program are resources that are available to farmers and ranchers to mitigate losses caused by natural disaster. All of these programs are available as risk management tools to address the vulnerabilities that agriculture producers face.

USDA Programs

Page $\mid 53$ 


\subsection{Rural Development}

Rural Development supports rural communities through loans, loan guarantees, and grants. Climate change represents a risk to the agency assets and the communities they serve. Rural Development administers services through Rural Housing Service (RHS), Rural Business-Cooperative Service (RBS), and Rural Utilities Service (RUS).

Within the Southwest region the occurrence of drought, warmer temperatures, more wildfires, insect outbursts, flooding, erosion, and rising sea level are anticipated to cause 1 ) disruption of electric and other energy supplies, 2) increased damage to structures/infrastructure from flooding, and 3) increased demand on water supplies.

\section{Rural Housing Service}

RHS administers programs that provide financial assistance (loans and grants) for quality housing and community facilities for rural residents throughout the United States.

RHS will implement the prevention measures outlined below in an effort to reduce the effects of climate change and become more resilient to adverse effects predicted to be incurred by flooding, storm surges, hurricanes, tropical storms, and other severe weather patterns that could adversely affect structures funded through RHS programs.

1. RHS will continue to provide training to staff on proper siting of facilities/infrastructure for the life of a structure (30 to 50 years in some cases) in locations where the effects from climate change will not adversely affect the facility or the surrounding environment.

2. RHS will continue to consider the effects of sea level rise, other potential flooding, and severe weather effects into long-term planning.

3. RHS will continue to provide funding for the following programs that have been designed to lessen the need for fossil fuels, promote renewable energy, and increase energy efficiency in an effort to reduce the effects of climate change:

- Multi-family Housing Energy Efficiency Initiative

- Multi-family Housing Portfolio Manager, Capital Needs Assessment/Utility Usage

- Energy Independence and Security Act compliance (affects new construction of single family housing)

- Climate Action Plan installation of 100 megawatt capacity onsite renewable energy multifamily housing by 2020

\section{Rural Business-Cooperative Service}

RBS administers programs that lessen the need for fossil fuels by promoting biomass utilization, renewable energy, and greater energy efficiency within all of the Climate Hub regions. The Rural Energy for America Program lowers the demand on base plants by investing in energy efficiency and renewable energy. Lower base load demand conserves water and helps to reduce GHGs that contribute to climate change. Renewable energy investments can provide extra resiliency by distributing energy resources.

RBS is investing in alternative fuels, renewable chemicals, biogas, wastewater conservation, and harvesting combustible forest thinnings for advanced biofuel.

\section{Rural Utilities Service}

RUS administers programs that provide clean and safe drinking water and sanitary water facilities, broadband, telecommunications, and electric power generation and transmission/distribution within all of the Regional Climate Hub areas. 
The following programs or measures will help address resiliency and lessen the effect of droughts, floods, and other natural disasters and increase energy efficiency:

- National Rural Water Association (NRWA) Grant. An energy efficiency program designed to promote energy efficient practices in small water and wastewater systems. Performs energy assessments, recommends energy-efficient practices and technologies, and provides support in achieving recommendations.

- Memorandum of Agreement between the U.S. Environmental Protection Agency and the U.S. Department of Agriculture - Rural Development Rural Utilities Service - Promoting Sustainable Rural Water and Wastewater Systems. The goals of this memorandum of agreement are to increase the sustainability of drinking water and wastewater systems nationwide to ensure the protection of public health, water quality, and sustainable communities, to ensure that rural systems have a strong foundation to address 21 st century challenges, and assist rural systems in implementing innovative strategies and tools to allow them to achieve short- and long-term sustainability in management and operations.

- Emergency Community Water Assistance Grants (ECWAG). These grants assist rural communities that have experienced a significant decline in quantity or quality of drinking water due to an emergency, or in which such decline is considered imminent, to obtain or maintain adequate quantities of water that meets the standards set by the Safe Drinking Water Act. Emergencies are considered to include incidents such as but not limited to drought, earthquake, flood, tornado, hurricane, disease outbreak, or chemical spill, leakage, or seepage.

- Electric Program - Energy Efficiency and Conservation Loan Program (EECLP). The program is "for the purpose of assisting electric borrowers to implement demand side management, energy efficiency and conservation programs, and on-grid and off-grid renewable energy systems." Goals include: 1 ) increasing energy efficiency at the end user level; 2) modifying electric load such that there is a reduction in overall system demand; 3) effecting a more efficient use of existing electric distribution, transmission and generation facilities; 4) attracting new businesses and creating jobs in rural communities by investing in energy efficiency; and 5) encouraging the use of renewable energy fuels for either demand side management or the reduction of conventional fossil fuel use within the service territory.

- Principles, Requirements and Guidelines (PR\&G). Application of the revised PR\&G in the near future to RUS water and wastewater program planning will include consideration of, among other factors, effects on and effects of climate change.

- Rural Development Climate Change Adaptation Planning Document. This document, from June 2012, would apply to all three Rural Development agencies. The plan was prepared to in support of Departmental efforts to respond to EO 13514 (Federal Leadership in Environmental, Energy, and Economic Performance) and DR 1070-001. The planning document discusses increased efforts at risk assessment, and identifies five specific actions related to climate change planning and adaptation.

- Engineering Design Standards and Approved Materials. The RUS electric program envisions increased incorporation of climate change-related effects as it revised its standards and materials for RUS-financed infrastructure. Some borrowers (e.g., in coastal areas and the Great Plains) have already received agency approval for hardened electric poles and lines.

\subsection{Risk Management Agency}

RMA provides a variety of actuarially sound crop- and livestock-related insurance products to help farmers and ranchers manage the risks associated with agricultural production. Coverage is provided against agricultural production losses due to unavoidable natural perils such as drought, excessive 
moisture, hail, wind, hurricane, tornado, lightning, insects, etc. In 2014, the Federal crop insurance program provided U.S. agricultural producers with more than $\$ 109.8$ billion in protection for agricultural commodities. These policies provide financial stability for agricultural producers and rural communities, and are frequently required by lenders.

Southwest specific vulnerabilities include:

- Crop programs for crops such as rice and grains will have more crop insurance loss payments for "prevented planting" as a result of the drought conditions.

- Water management challenges for irrigated crops, such as quantity and timing of water required to produce a marketable crop.

- Issues with water availability for perennial crops such as almonds, citrus, and grapes.

- Potential for production losses due to increase use of low-quality water (higher salinity/boron).

- Increase of disease and pest due to temperature changes.

- Potential for production losses due to decreased chill hours.

Because climate change is an ongoing process, the risk environment for agricultural production will also be undergoing constant change (e.g., some perils may occur with greater or lesser frequency and/or severity). Climate change will also promote adaptive responses by producers such as adopting new production practices, planting new varieties, or shifting the locations of farming operations.

RMA continually strives to improve the effectiveness of its programs by refining insurance offers to recognize changes in production practices; and where appropriate, adjusting program parameters (e.g., premium rates, planting dates, etc.) within each county to recognize structural changes to the risks of growing the crop in those areas. In that regard, RMA monitors climate change research and, to the extent that climate changes emerge over time, updates these program parameters to reflect such adaptation or other changes. RMA also updates loss adjustment standards, underwriting standards, and other insurance program materials to ensure that they are appropriate for prevailing production technologies. Additional materials related to the drought in California are available on the RMA website. ${ }^{17}$

The RMA regional office in Davis, California, manages crop insurance programs in the Southwest Climate Hub Region in Arizona, California, Hawaii, Nevada, and Utah. The RMA regional office in Oklahoma City, Oklahoma, manages crop insurance programs in New Mexico.

In 2010, RMA's crop insurance National liability (book of business) was \$78 billion. In 2014, RMA's national liability was $\$ 109.8$ billion. The six States located in the Southwest Climate Hub region accounted for more than $\$ 4.9$ billion in liability in 2010 , and liability almost doubled to more than $\$ 8.3$ billion in 2014. The Southwest region makes up a large book of business for specialty crop insurance programs and plays an important role in managing risks for fruit, vegetables, nuts, and livestock producers, which are important to this region of the United States. In California, the crops that use the most water in production (climate-related challenge) are alfalfa, rice, cotton, almonds, and corn. Water issues continue to be a problem in California, and the losses that RMA has paid out in recent years shows how the severity of the drought is affecting both perennial crops, and cotton and rice production in the region.

\footnotetext{
${ }^{17}$ Davis RO issued Frequently Asked Questions about the 2014 Drought in California: http://www.rma.usda.gov/help/faq/cadrought.html

RMA Davis Regional Office issued: Information About Available Irrigation Water: http://www.rma.usda.gov/fields/ca_rso/2014/irrigationassessment.pdf

Partnership with California Department of Agriculture for drought information website: http://www.cdfa.ca.gov/drought/
} 
Over the last 5 years (2010-2014) participation has grown in these six States. Crop insurance liabilities for the top three states (California, Arizona, and New Mexico) also increased.

- California has by far the largest liability in the Southwest: total liability rose from $\$ 4.4$ billion in 2010 to more than $\$ 7.6$ billion in 2014 ,

- The total liability in Arizona rose from \$213 million in 2010 to more than \$267 million in 2014, and

- The total liability in New Mexico rose from $\$ 123$ million in 2010 to more than $\$ 208$ million in 2014.

Over the last 5 years (2010-2014), the crops with the highest losses reported in California due to natural disasters such as drought were cherries, grapes, cotton - Extra Long Staple (ELS), and mandarin oranges. In 2014, due to the continued severity of the drought, the crops with the highest loss payments were eotton ELS ( $\$ 83$ million), cherries ( $\$ 51$ million), rice ( $\$ 50$ million), almonds ( $\$ 39$ million), naval oranges (\$27 million), grapes (\$28 million), and pistashios (\$19 million).

In 2014, almonds had the most liability exposure for California, with a liability of $\$ 2.1$ billion. The nexthighest liability was grapes, with $\$ 1.3$ billion; then rice, with a liability of $\$ 543$ million; tomatoes, with a liability of \$534 million; and walnuts, with liability of \$349 million. These five crops have the highest liability exposure for the Federal crop insurance program in the Southwest Climate Hubs region.

The RMA regional offices in Davis and Oklahoma City will continue to monitor crop disasters such as drought conditions and prevented planting. RMA regional offices will respond to Approved Insurance Providers and producer inquiries during these events. In addition, they will continue to provide estimates of liabilities, losses, and the potential effect that natural disasters have on the Federal crop insurance program to RMA headquarters in Washington, D.C., as needed.

\subsection{Animal and Plant Health Inspection Service}

APHIS is responsible for protecting and promoting U.S. agricultural and forest health, regulating certain genetically engineered (GE) organisms, enforcing the Animal Welfare Act, and carrying out wildlife damage management activities. APHIS is constantly working to defend U.S. plant and animal resources from agricultural and forest pests and diseases. Once a pest or disease is detected, APHIS works in partnership with affected regions to manage and eradicate the outbreak. In its new Strategic Plan for 2015, APHIS lists seven goals:

1. Prevent the entry and spread of agricultural pests and diseases.

2. Ensure the humane treatment and care of vulnerable animals.

3. Protect forests, urban landscapes, rangelands and other natural resources, as well as private working lands from harmful pests and diseases.

4. Ensure the safety, purity, and effectiveness of veterinary biologics and protect plant health by optimizing our oversight of GE organisms.

5. Ensure the safe trade of agricultural products, creating export opportunities for U.S. producers.

6. Protect the health of U.S. agricultural resources, including addressing zoonotic disease issues and incidences, by implementing surveillance, preparedness and response, and control programs.

7. Create an APHIS for the 21st century that is high-performing, efficient, adaptable, and embraces civil rights.

APHIS works to achieve these goals through the actions of several mission area Program staffs and support units. The text below describes the APHIS programs and their respective responsibilities, and their expected vulnerabilities due to climate and the measures in place to minimize risks from these 
vulnerabilities. As an agency with nationwide regulatory concerns, APHIS programs are typically national in scope and application.

\section{Animal Care}

The mission of the Animal Care (AC) program is to protect animal welfare by administering the Animal Welfare Act and the Horse Protection Act. AC also protects the safety and well-being of pet owners and their pets by supporting the Federal Emergency Management Agency (FEMA).

AC's supporting role in the safety of pet owners during disasters may be vulnerable to climate change. An increase in storms and the severity of storms as the climate warms may increase the frequency of evacuations. In anticipation of the increase in emergency response activities, AC proactively organizes and participates in emergency planning together with FEMA, Emergency Support Function No. $11,{ }^{18}$ and other response partners to strengthen the Nation's capacity to respond to natural disasters. These efforts will help reduce the effects of disasters and help people and their animals recover more quickly.

\section{Biotechnology Regulatory Services}

To protect plant health, Biotechnology Regulatory Services (BRS) implements the APHIS regulations for GE organisms that may pose a risk to plant health. APHIS coordinates these responsibilities along with the other designated Federal agencies as part of the Federal Coordinated Framework for the Regulation of Biotechnology.

Although no BRS actions are directly "vulnerable" to climate change because climate change will likely affect the distribution of some agricultural crops and other plants, BRS actions related to conducting inspections of field trials for GE plants could be affected. Therefore, if growing areas for regulated GE plants shift, BRS would need to conduct inspections in those new locations.

BRS has in place a flexible staffing plan and practice — not all of its staff members are centrally located; they are set up to provide mobile inspection service to wherever GE crops are growing in field trials. Additionally, BRS receives reports each year from those holding permits for conducting field trials. BRS uses this information to plan inspections throughout the life cycle of the field trials. The flexibility and regular use of new information inherent in BRS planning and practice will help minimize risks from climate change.

\section{Plant Protection and Quarantine}

Plant Protection and Quarantine (PPQ) is responsible for safeguarding and promoting U.S. agricultural health. PPQ is constantly working to defend U.S. plant and forest resources from agricultural pests and diseases. Once a quarantine plant pest or disease (one not previously found in the U.S. or if found, is under official control) is detected, PPQ works in partnership with affected regions to manage and eradicate the outbreak. PPQ has three strategic goals:

1. Strengthen PPQ's pest exclusion system,

2. Optimize PPQ's domestic pest management and eradication programs, and

3. Increase the safety of agricultural trade to expand economic opportunities in the global marketplace.

In the face of an increasingly variable climate and more erratic weather conditions, PPQ will continue to play a central role in responding to risk and managing vulnerabilities. In this capacity, PPQ operates primarily on a national level with regional emphasis as needed to address and divert pest incursions.

${ }^{18}$ http://www.fema.gov/pdf/emergency/nrf/nrf-esf-11.pdf

USDA Programs

Page $\mid 58$ 
PPQ is tasked with assessing pest risk by predicting where an invasive plant pest may be introduced and establish, and by modeling its subsequent spread. These assessments are often based on climatic conditions and host availability. As climate changes, host distribution and landscape conditions deviate from what is considered "normal." PPQ assessments are based on available data that often reflect past conditions. As climate changes, the relevance of these data may lessen our ability to accurately predict and understand risk.

Some of the challenges in predicting future risk under climate change require a shift from analyzing mean responses (e.g. increase of 2-3 degrees temperature on average), and instead to focus on trying to understand how pest invasiveness and the potential for establishment change with increased weather variability and increased extreme events. For example, several years of warmer than normal weather can allow the establishment of invading pest populations and result in their spread to new areas. Once arriving in new areas, if such pest populations can secure warmer microclimates to survive the winter, they can become more prevalent earlier the following season. Anticipating global trade shifts in response to climate change is another challenge, as is the subsequent risk of new crop pests and diseases associated with them.

PPQ partners with other agencies, universities, and the climate hubs to obtain, analyze, and implement data models that inform climate change-specific policies and pest programs. PPQ is increasing its capacity to perform pest risk modeling at regional, national and global levels with new platforms. These platforms are designed to project climate change scenarios onto the landscape to model geographic shifts in climatic suitability and host availability. PPQ is also applying phenological models that can be used to analyze how climate change and increased weather variability might affect temporal sequencing of pest development and subsequent population response. Being able to produce robust projections of such shifts will improve the efficacy of PPQ's early detection surveillance programs conducted in cooperation with States.

\section{Veterinary Services}

Veterinary Services (VS) is responsible for regulating the importation and interstate movement of animals and their products in order to prevent the introduction and spread of foreign animal diseases of livestock. If a foreign animal disease were to be detected in the United States, VS is responsible for responding to the outbreak, in coordination with States, Tribes and producers. VS also regulates the licensing of veterinary biologics such as vaccines.

\section{Climate change vulnerabilities and potential mitigations}

\section{Changing Vector Distribution}

- Vulnerabilities: Climate change could mediate changes in the dispersal and redistribution of arthropod vectors along with the ability of these vectors to transmit economically important pathogens, potentially allowing their spread from areas where they are already established to new locations. This change in distribution could result in significant increases in morbidity and mortality to livestock, wildlife, and people, along with a reduction in market value of animals from affected areas.

- Current measures addressing vulnerabilities: VS conducts passive-as well as some activesurveillance for arthropod-borne diseases such as vesicular stomatitis virus (VSV), equine encephalitis viruses (EEE, WEE, and VEE), ${ }^{19}$ and hemorrhagic disease viruses (EHDV and $\mathrm{BTV}) .{ }^{20}$ This surveillance activity may help identify any changes in vector populations and inform recommended changes to disease surveillance and production practices. VS could identify other mitigations through further research in this area. Such projects may include using climate

\footnotetext{
${ }^{19}$ Eastern, western, and Venezuelan equine encephalitis viruses, respectively.

${ }^{20}$ Epizootic hemorrhagic disease virus and blue tongue virus, respectively.
} 
models and scenario analyses to identify geographic areas likely to undergo environmental changes that would lead to an increased risk of infection with selected pathogens, and simulating economic effects of potential vector and pathogen range expansion to livestock and wildlife industries.

\section{Increased Wildlife-Livestock Interaction}

- Vulnerabilities: Increased pest infestation, fires, and expansion of the wildland-urban interface could alter wild animal distribution, movements and feeding patterns, thereby increasing contact and the potential for disease exchange with agricultural animal populations. For example, the recent widespread epidemic of mountain pine beetles throughout the western United States and Canada may lead to widespread tree death and fire followed by variable regrowth in forested and transient grassy areas as trees re-grow. This may improve habitat suitability for species such elk, bighorn sheep, and feral swine, which could increase contact and subsequent disease transmission between these wild species and livestock.

- Current measures addressing vulnerabilities: VS is a collaborator in an APHIS Wildlife Services-led program to investigate and mitigate agricultural and natural resource damage and disease risks from feral swine. VS is involved in studying and responding to wildlife-livestock interactions with regard to disease transmission, such as brucellosis in the Greater Yellowstone Area.

\section{Heat Stress on Livestock}

- Vulnerabilities: In highly optimized, intensive livestock production systems, small changes in maximum temperatures can reduce productivity through decreases in weight gain or milk production or through losses of livestock.

- Potential measures to address vulnerabilities: Measures may include shifting the distribution of livestock facilities to cooler areas. For example, parts of the north central Plains and into central Canada may become more productive for livestock, as other areas become too warm. Adding ventilation or other cooling systems may assist with this issue.

Decrease in Potable Water

- Vulnerabilities: Water availability could be severely affected in the Southwest; water resources are already tapped beyond demand. Drought could affect water availability for livestock and for crops grown to feed livestock. Grazing lands could also be affected.

- Potential measures addressing vulnerabilities: Livestock may need to be shifted to new areas; greater efficiency in crop and livestock production may decrease demand for water.

Aquaculture

- Vulnerabilities: Marine and freshwater food fish populations have already experienced significant declines due to warming waters and the attendant effects that include acidification, oxygen depletion, algal blooms, and increased pathogen loads. These effects exacerbate the effects of overharvesting, which has depleted many wild fish populations. Decreases in the wild fish catch places more pressure on the aquaculture industry for higher production and mitigation of health effects.

- Potential measures addressing vulnerabilities: As demands on the aquaculture industry for fish protein increases, VS will rely more heavily on coordinated efforts targeting disease control and improved health of aquacultured species. VS partners with the commercial aquaculture industry and Federal and State agencies to work collectively to protect and certify the health of farmed raised aquatic animals and facilitate their trade as well as to safeguard the nation's wild aquatic animal populations and resources. 


\section{Policy and Program Development}

Policy and Program Development (PPD) performs economic, environmental, and other analyses to support the actions of all APHIS programs. PPD analyses would be more robust over time if they were better able to incorporate economic and environmental effects of climate change to relevant agricultural systems and ecosystems. Robust projections of climate change and their effect on the distribution of production areas for various commodities, as well as anticipated needs for commodity movements at an international and domestic scale, can inform our economic analyses. These projections, along with information on pollinators, water and other resources, as well as effects to low-income, minority and Tribal communities, will better inform our environmental analyses.

PPD is incorporating climate change into many of its environmental compliance (e.g., National Environmental Policy Act (NEPA) documents and is leading an agency-wide effort to develop guidance for addressing climate change in our NEPA documents.

\section{Wildlife Services}

The mission of Wildlife Services (WS) is to provide Federal leadership and expertise to resolve wildlife conflicts to allow people and wildlife to coexist. WS conducts program delivery, research, and other activities through its regional and State offices, the National Wildlife Research Center (NWRC) and its Field Stations, as well as through its national programs. Because the work of WS is greatly influenced by distributions of wildlife, which are expected to shift as the climate changes, much of this work will be changing, as well. The following examples reflect some of those changes that are likely to effect the Southwest:

\section{Predator management}

As climate changes, so may landscapes and habitats shift along with changes in prey distribution and abundance. Changes in native vegetation, and therefore forage, will alter feeding patterns of omnivorous predators, such as black bears and coyotes. These shifts will influence the distribution and abundance of such predators and will alter the predictive ability of models related to spatial patterns, behavior, abundance, and habitat use by predators. Results of climate-informed models may be needed to inform predator management strategies in order to adapt to climate change. NWRC researchers based near the USDA Southwest Hub are gathering data on changes in species distribution and abundance, behavior, and habitat use for predators from around the country that are already affected by climate change (e.g., polar bears) and will use these studies as a foundation for incorporating climate change into studies of species found locally. NWRC is also incorporating climate change models into projections about future habitat availability for predators (e.g., models for wolverine habitat).

\section{Wildlife management for aviation safety}

As climate changes, so may the breeding and wintering ranges of birds that affect aviation safety. Airports and military installations should be prepared to address new challenges associated with changes in bird ranges. Also, species' migration patterns may change. As an example, NWRC has developed migration models for osprey in relation to military aircraft movements. These very well could become outdated as climate, and therefore species' migration patterns, change. Proper habitat management is crucial to successful management of wildlife hazards to aviation. Distribution of plant species that grow on airports and military installations may change in the future. Thus, habitat management strategies may also need to adapt to a changing climate. NWRC is gathering data on species and habitat distribution, so it should be able to detect changes in species ranges, as well as migration and movement patterns, and therefore adjust its habitat management strategies accordingly. NWRC is also researching alternative land covers that could be used at airports and military installations in the Southwest and across the United States as conditions change. 


\section{Managing diseases spread by wildlife}

Climate change will likely have dramatic effects on the distribution of both agricultural diseases of concern as well as on zoonotic diseases, both of which can be spread by wildlife. It is expected that some areas will experience a decrease in endemic disease risks, whereas others may have new diseases emerge in areas where they were not previously documented. Given the sensitivity of insect vectors to changes in weather related variables, it is likely that initial changes in disease distribution resulting from climate change will take place for those diseases that are vector-borne. NWRC is conducting surveillance and research on diseases and vectors to gather baseline data on their distribution for use in climate change models and future studies. NWRC also maintains tissue archives of wildlife samples that are made available for retrospective research on diseases to identify changes in pathogen distribution and prevalence.

\section{Wildlife management to protect agriculture}

WS conducts research and management on wildlife and invasive species such as feral swine, which can have a significant effect on agricultural commodities. As climate changes, the distribution of these species and the agricultural crops they effect will also change. Information on population densities and distribution of target species is important for understanding how climate change will affect production of these agricultural commodities. 


\section{References}

Abatzoglou, JT, \& Brown, TJ. (2012). A Comparison of Statistical Downscaling Methods Suited for Wildfire Applications. International Journal of Climatology, 32(5), 772-780. doi:

$10.1002 /$ joc. 2312

Agricultural Marketing Service. (2014, October 1, 2014). Definition of Specialty Crops. Retrieved January 21, 2015, from http://www.ams.usda.gov/AMSv1.0/scbgpdefinitions

Alabama Precision Ag Extension. (2011). Variable-Rate Technology. Retrieved February 24, 2015, from http://www.aces.edu/anr/precisionag/VRT.php

Allan, P. (1996). Modification of Microclimate of Macadamias and Deciduous Vines by Evaporative Cooling. Paper presented at the Challenges for Horticulture in the Tropics: Proceedings of the Third Australian Society of Horticultural Science and the First Australian Macadamia Society Research Conference, Broadbeach, Gold Coast, Australia.

Almond Board of California. (2013). 2013 Almond Almanac (pp. 42). Modesto, CA: Almond Board of California.

Ault, TR, Cole, JE, Overpeck, JT, Pederson, GT, \& Meko, DM. (2014). Assessing the Risk of Persistent Drought Using Climate Model Simulations and Paleoclimate Data. Journal of Climate, 27(20), 7529-7549. doi: 10.1175/JCLI-D-12-00282.1

Bachelet, D, Neilson, RP, Lenihan, JM, \& Drapek, RJ. (2001). Climate Change Effects on Vegetation Distribution and Carbon Budget in the United States. Ecosystems, 4(3), 164-185. doi: 10.1007/s10021-001-0002-7

Baldocchi, D, \& Wong, S. (2008). Accumulated Winter Chill Is Decreasing in the Fruit Growing Regions of California. Climatic Change, 87(1), 153-166. doi: 10.1007/s10584-007-9367-8

Battany, M. (2012). Climate Change in California: Vineyard Cultural Practices. Paper presented at the CDFA Climate Change Consortium, Modesto, CA.

Bender, GS, Menge, JA, Faber, BA, Marsh, RE, Morse, JG, Eskalen, A, Hoddle, M, Platt, RG, \& Salmon, T. (2013). Avocado Production in California: A Cultural Handbook for Growers (Book Two Cultural Care) (2nd ed.). Oakland, CA: University of California Division of Agriculture and Natural Resources.

Bentz, BJ, Regniere, J, Fettig, CJ, Hansen, EM, Hayes, JL, Hicke, JA, Kelsey, RG, Negron, JF, \& Seybold, SJ. (2010). Climate Change and Bark Beetles of the Western United States and Canada: Direct and Indirect Effects. Bioscience, 60(8), 602-613. doi: 10.1525/bio.2010.60.8.6

Bierbaum, R, Lee, A, Smith, J, Blair, M, Carter, LM, Chapin, I, F.S., Fleming, P, Ruffo, S, McNeeley, S, Stults, M, Verduzco, L, \& Seyller, E. (2014). Adaptation. . In J. M. Melillo, T. C. Richmond, \& G. W. Yohe (Eds.), Climate Change Impacts in the United States: The Third National Climate Assessment

(pp. 670-706): U.S. Global Change Research Program. 
Blumenstock, DI, \& Price, S. (1972). Climate of the States: Hawaii. In E. A. Kay (Ed.), A Natural History of the Hawaiian Islands. Selected Readings. Honolulu: University of Hawaii Press.

Bonfils, C, Santer, B, Lobell, D, Duffy, P, Pierce, DW, Hidalgo, H, Bala1, G, Das, T, Barnett, T, Cayan, D, Doutriaux, C, Wood, A, Mirin, A, \& Nozawa, T. (2012). Historical Changes in Climate, Water Resources and Perennial Crops in Western United States. Paper presented at the CDFA Climate Change Consortium, Modesto, CA.

Bower, AD, St Clair, B, \& Erickson, V. (2014). Generalized Provisional Seed Zones for Native Plants. Ecological Applications, 24(5), 913-919.

Bradley, BA, Houghton, RA, Mustard, JF, \& Hamburg, SP. (2006). Invasive Grass Reduces Aboveground Carbon Stocks in Shrublands of the Western Us. Global Change Biology, 12(10), 1815-1822. doi: 10.1111/j.1365-2486.2006.01232.x

Breshears, DD, Cobb, NS, Rich, PM, Price, KP, Allen, CD, Balice, RG, Romme, WH, Kastens, JH, Floyd, ML, Belnap, J, Anderson, JJ, Myers, OB, \& Meyer, CW. (2005). Regional Vegetation Die-Off in Response to Global-Change-Type Drought. Proceedings of the National Academy of Sciences of the United States of America, 102(42), 15144-15148. doi: 10.1073/pnas.0505734102

Brown, PW. (2008). Cotton Heat Stress (pp. 10). Tucson, AZ: The University of Arizona Cooperative Extension.

Brownsey, P, Oviedo, JL, Huntsinger, L, \& Allen-Diaz, B. (2013). Historical Forage Productivity and Cost of Capital for Cow-Calf Production in California. Rangeland Ecology \& Management, 66(3), 339-347. doi: 10.2111/rem-d-11-00059.1

Bruegman, MM. (1996). Hawaii's Dry Forests. Endangered Species Bulletin, 11, 26-27.

Brunson, MW, \& Huntsinger, L. (2008). Ranching as a Conservation Strategy: Can Old Ranchers Save the New West? Rangeland Ecology \& Management, 61(2), 137-147. doi: 10.2111/07-063.1

Bureau of Land Management. (2014). Authorized Use of Bureau of Land Management Administered Grazing Lands. Retrieved October/November 2014, 2014, from 1947-1995:

rangenet.org/tools/blmgrazing1996-2012: www.blm.gov/public_land_statistics/index.htm

Burke, JJ, Mahan, JR, \& Hatfield, JL. (1988). Crop-Specific Thermal Kinetic Windows in Relation to Wheat and Cotton Biomass Production. Agron. J., 80(4), 553-556. doi:

10.2134/agronj1988.00021962008000040001x

Cabin, RJ, Weller, SG, Lorence, DH, Cordell, S, Hadway, LJ, Monygomery, R, Goo, D, \& Urakam, A. (2002). Effects of Light, Alien Grass, and Native Species Additions on Hawaiian Dry Forest Restoration. Ecological Applications, 12(6), 1595-1610.

Cabrera, M, Cavanaugh, M, \& Will, N. (2014, September 8, 2014). California Drought Forces Farmers to Adapt. KPBS Radio. Retrieved from http://www.kpbs.org/news/2014/sep/08/california-droughtforces-farmers-adapt/

California Department of Food and Agriculture. (2013). Climate Change Consortium for Specialty Crops: Impacts and Strategies for Resilience (pp. 76). Sacramento, CA: CDFA. 
California Department of Food and Agriculture. (2014). 2013 Walnut Nursery Sales Report (pp. 2). Sacramento, CA: USDA National Agricultural Statistics Service.

California Rice Commission. (2013). California Rice Information. Retrieved 21 January 2015, from http://calrice.org/pdf/CA+Rice+at+a+glance+2014.pdf

California Strawberry Commission. (1999). Crop Profile for Strawberries in California (pp. 72): University of California Division of Agriculture and Natural Resources.

Campbell, K. (2006). Weather Taunts Almond Crop, but Damage Unknown. Retrieved December 12, 2012, from http://www.agalert.com/story/?id=542

Campbell, K. (2014, November 12, 2014). Orange Growers Assess Drought Impact on Crop. AgAlert. Retrieved from http://www.agalert.com/story/?id=7295

Carr, MKV. (2012). The Water Relations and Irrigation Requirements of Macadamia (Macadamia Spp.): A Review. Experimental Agriculture, 49(01), 74-90. doi: 10.1017/s0014479712000804

Castellon, D. (2014, August 25, 2014). Farmers and Consumers Are Going Nuts for Pistachios. Visalia Times-Delta. Retrieved from http://www.visaliatimesdelta.com/story/news/local/2014/08/23/going-nuts-pistachios/14444245/

Cho, JJ, A., YR, \& James, H. (2007). Hawaiian Kalo, Past and Future: College of Tropical Agriculture and Human Resources, University of Hawaii.

Chu, P-S, \& Chen, H. (2005). Interannual and Interdecadal Rainfall Variations in the Hawaiian Islands. Journal of Climate, 18, 4796-4813.

Chu, P-S, Ruan, CY, \& Thomas, S. (2010). Changes in Precipitation Extremes in the Hawaiian Islands in a Warming Climate. Journal of Climate, 23(18), 4881--4900. doi: 10.1175/2010jcli3484.1

Cobb, KM, Niko, W, R., SH, T., WJ, Di Lorenzo, E, Cheng, H, Edwards, RL, \& Charles, C, D. (2013). Highly Variable El Nino-Southern Oscillation Throughout the Holocene. Science, 339(6115), 6770. doi: $10.1126 /$ science. 1228246

Cole, RJ, Litton, CM, Koontz, MJ, \& Loh, RK. (2012). Vegetation Recovery 16 Years after Feral Pig Removal from a Wet Hawaiian Forest. Biotropica, 44(4), 463-471. doi: 10.1111/j.17447429.2011.00841.x

Coppock, Dl. (2011). Ranching and Multiyear Droughts in Utah: Production Impacts, Risk Perceptions, and Changes in Preparedness.

Cordell, S, J., CR, \& J., HL. (2002). Physiological Ecology of Native and Alien Dry Forest Shrubs in Hawaii *. Biological Invasions, 4, 387-396.

Craine, JM, Elmore, AJ, Olson, KC, \& Tolleson, D. (2010). Climate Change and Cattle Nutritional Stress. Global Change Biology, 16(10), 2901-2911. doi: 10.1111/j.1365-2486.2009.02060.x

Daugovish, O, Cahn, M, Koike, S, Natwick, E, Cantwell, M, \& Takele, E. (2008). Cabbage Production in California. In University of California Division of Agriculture and Natural Resources (Ed.), (Vol. 7208). Oakland, CA. 
Denslow, JS, Uowolo, AL, \& Hughes, RF. (2006). Limitations to Seedling Establishment in a Mesic Hawaiian Forest. Oecologia, 148(1), 118-128. doi: 10.1007/s00442-005-0342-7

Deschenes, O, \& Kolstad, C. (2011). Economic Impacts of Climate Change on California Agriculture. Climatic Change, 109(1), 365-386. doi: 10.1007/s10584-011-0322-3

Diaz, HF, Giambelluca, TW, \& Eischeid, JK. (2011). Changes in the Vertical Profiles of Mean Temperature and Humidity in the Hawaiian Islands. Global and Planetary Change, 77, 21-25. doi: DOI: 10.1016/j.gloplacha.2011.02.007

Dominati, E, Patterson, M, \& Mackay, A. (2010). A Framework for Classifying and Quantifying the Natural Capital and Ecosystem Services of Soils. Ecological Economics, 69(9), 1858-1868. doi: http://dx.doi.org/10.1016/j.ecolecon.2010.05.002

Doye, D, Sahs, R, \& Peel, D. (2012). Financing Herd Rebuilding after Drought-Induced Liqudations. Paper presented at the Agricultural \& Applied Economics Association's 2012 AAEA Annual Meeting, Seattle, Washington.

Economic Research Service. (2011). Arms Farm Financial and Crop Production Practices. Washington, DC: U.S. Department of Agriculture, Economic Research Service.

Economic Research Service. (2014). Major Land Uses. Retrieved 2014

Elison Timm, O, Giambelluca, TW, \& Diaz, H. (2015). Statistical Downscaling of Rainfall Changes in Hawaii Based on the Cmip5 Global Model Projections. Journal of Geophysical Research: Atmospheres, 120, 92-112. doi: Doi: 10.1002/2014jd022059

Faber, BA. (2014). Strategizing for Water Cutbacks - Avocado and Citrus. Retrieved December 12, 2014, from http://ucanr.edu/blogs/blogcore/postdetail.cfm?postnum=13122

Fortini, L, Price, J, Jacobi, J, Vorsino, A, Burgett, J, Brinck, K, Amidon, F, Miller, S, Ohukani'oho'a Gon III, S, Koob, G, \& Paxton, E. (2013). A Landscape-Based Assessment of Climate Change Vulnerability for All Native Hawaiian Plants (pp. 134). Hilo, Hawaii: Hawaii Cooperative Studies Unit, University of Hawaii at Hilo.

Frisvold, GB, Jackson, LE, Pritchett, JG, \& Ritten, JP. (2013). Agriculture and Ranching. In G. Garfin, A. Jardine, R. Merideth, M. Black, \& S. LeRoy (Eds.), Assessment of Climate Change in the Southwest United States: a Report Prepared for National Climate Assessment Regional Technical Input Report Series (Vol. Chap 11, pp. 218-239). Washington, D.C.: Island Press.

Galyean, ML, Ponce, C, \& Schutz, J. (2011). The Future of Beef Production in North America. Animal Frontiers, 1(2), 29-36. doi: 10.2527/af.2011-0013

Giambelluca, TW, Chen, Q, Frazier, AG, Price, JP, Chen, Y-L, Chu, P-S, Eischeid, JK, \& Delparte, DM. (2013). Online Rainfall Atlas of Hawai'I. Bulletin of the American Meteorological Society, 94, 313-316. doi: 10.1175/bams-d-11-00228.1

Giambelluca, TW, Diaz, HF, \& Luke, MSA. (2008). Secular Temperature Changes in Hawai'I. Geophysical Research Letters, 35(12), L12702. doi: 10.1029/2008gl034377 
Giardina, CP. (2012). Hawaii and the U.S.-Affiliated Pacific Islands Effects of Climate Variability and Change on Forest Ecosystems: A Comprehensive Science Synthesis for the U.S. Forest Sector (Vol. PNW-GTR-870, pp. 210-214): USDA Forest Service.

Gingerich, SB, Yeung, T-J, Ibarra, N, \& Engott, JA. (2007). Water Use in Wetland Kalo Cultivation in Hawaii Open File Report: USGS.

Golino, DA, Weber, E, Sim, S, \& Rowhani, A. (2008). Leafroll Disease Is Spreading Rapidly in a Napa Valley Vineyard. California Agriculture, 62(4), 156-160.

Greenwood, DL, \& Weisberg, PJ. (2008). Density-Dependent Tree Mortality in Pinyon-Juniper Woodlands. Forest Ecology and Management, 255(7), 2129-2137. doi: 10.1016/j.foreco.2007.12.048

Grismer, ME, Snyder, RL, \& Faber, B. (2000). Avocado and Citrus Orchards Along the Coast May Use Less Water. California Agriculture, 54(3), 25-29.

Gutierrez, AP, Daane, KM, Ponti, L, Walton, VM, \& Ellis, CK. (2008). Prospective Evaluation of the Biological Control of Vine Mealybug: Refuge Effects and Climate. Journal of Applied Ecology, 45(2), 524-536. doi: 10.1111/j.1365-2664.2007.01356.x

Hamann, A, Gylander, T, \& Chen, PY. (2011). Developing Seed Zones and Transfer Guidelines with Multivariate Regression Trees. Tree Genetics \& Genomes, 7(2), 399-408. doi: 10.1007/s11295010-0341-7

Hannah, L, Roehrdanz, PR, Ikegami, M, Shepard, AV, Shaw, MR, Tabor, G, Zhi, L, Marquet, PA, \& Hijmans, RJ. (2013). Climate Change, Wine, and Conservation. Proceedings of the National Academy of Sciences, 110(17), 6907-6912. doi: 10.1073/pnas.1210127110

Hansen, LJ, J.L., B, \& J.R., H (Eds.). (2003). Buying Time: A User's Manual for Building Resistance and Resilience to Climate Change in Natural Systems Berlin: WWF Climate Change Program.

Hartz, T, Miyao, G, Mickler, J, LeStrange, M, Stoddard, S, Nuñez, J, \& Aegerter, B. (2008). Processing Tomato Production in California. In University of California Division of Agriculture and Natural Resources (Ed.), (Vol. 7228). Oakland, CA.

Hatfield, J, Boote, KJ, Kimball, BA, Ziska, LH, Izaurralde, RC, Ort, D, Thomson, A, \& Wolfe, D. (2011). Climate Impacts on Agriculture: Implications for Crop Production. Agronomy Journal, 103(2), 351-370. doi: doi:10.2134/agronj2010.0303

Hayes, R. (2013). Crop Breeding for Drought Tolerance. Paper presented at the CDFA Climate Change Consortium, Sacramento, CA.

Heikkinen, RK, Luoto, M, Araujo, MB, Virkkala, R, Thuiller, W, \& Sykes, MT. (2006). Methods and Uncertainties in Bioclimatic Envelope Modelling under Climate Change. Progress in Physical Geography, 30(6), 751-777. doi: 10.1177/0309133306071957

Hess, SC, Banko, PC, Brenner, GJ, \& Jacobi, JD. (1999). Factors Related to the Recovery of Subalpinewoodland on Mauna Kea, Hawai. Biotropica(31), 212-219. 
Hijmans, RJ, Cameron, SE, Parra, JL, Jones, PG, \& Jarvis, A. (2005). Very High Resolution Interpolated Climate Surfaces for Global Land Areas. International Journal of Climatology, 25(15), 19651978. doi: 10.1002/joc.1276

Holden, ZA, Morgan, P, \& Evans, JS. (2009). A Predictive Model of Burn Severity Based on 20-Year Satellite-Inferred Burn Severity Data in a Large Southwestern Us Wilderness Area. Forest Ecology and Management, 258(11), 2399-2406. doi: 10.1016/j.foreco.2009.08.017

Huang, CY, \& Anderegg, WRL. (2012). Large Drought-Induced Aboveground Live Biomass Losses in Southern Rocky Mountain Aspen Forests. Global Change Biology, 18(3), 1016-1027. doi: 10.1111/j.1365-2486.2011.02592.x

ICF International. (2013). Greenhouse Gas Mitigation Options and Costs for Agricultural Land and Animal Production within the United States. In S. D. Biggar, D. Man, K. Moffroid, D. Pape, M. Riley-Gilbert, R. Steele, \& V. Thompson (Eds.), (Vol. Prepared under USDA Contract No. AG3142-P-10-0214). Washington DC: U.S. Department of Agriculture, Office of the Chief Economist.

Intergovernmental Panel on Climate Change. (2006). 2006 Ipcc Guidelines for National Greenhouse Gas Inventories, Volume 4: Agriculture, Forestry and Other Land Use.

Isaac-Renton, MG, Roberts, DR, Hamann, A, \& Spiecker, H. (2014). Douglas-Fir Plantations in Europe: A Retrospective Test of Assisted Migration to Address Climate Change. Global Change Biology, 20(8), 2607-2617. doi: 10.1111/gcb.12604

Jackson, L, Haden, VR, Wheeler, SM, Hollander, AD, Perlman, J, O'Geen, T, Mehta, VK, Clark, V, \& Williams, J. (2012). Vulnerability and Adaptation to Climate Change in California Agriculture (pp. 113). Sacramento, CA: California Energy Commission.

Johnson, DM, Buentgen, U, Frank, DC, Kausrud, K, Haynes, KJ, Liebhold, AM, Esper, J, \& Stenseth, NC. (2010). Climatic Warming Disrupts Recurrent Alpine Insect Outbreaks. Proceedings of the National Academy of Sciences of the United States of America, 107(47), 20576-20581. doi: 10.1073/pnas.1010270107

Johnson, RS, Phene, B, Trout, T, \& Day, K. (2006). Developing a Method for Saving Substantial Amounts of Irrigation Water after Harvest in Early Maturing Peach Orchard California Tree Fruit Agreement 2006 Annual Research Report (pp. 145-153). Oakland, CA: University of California Division of Agriculture and Natural Recources.

Joyce, LA, Briske, DD, Brown, JR, Polley, HW, McCarl, BA, \& Bailey, DW. (2013). Climate Change and North American Rangelands: Assessment of Mitigation and Adaptation Strategies. Rangeland Ecological Management, 66, 512-528. doi: 10.2111/rem-d-12-00142.1

Keener, VW, Hamilton, K, Izuka, SK, Kunkel, KE, Stevens, LE, \& Sun, L. (2013). Noaa Technical Report Nesdis 142-8 Regional Climate Trends and Scenarios for the U . S . National Climate Assessment Part 8 . Climate of the Pacific Islands (pp. 52). Washington, D.C.

Keener, VW, J., MJ, Finucane, ML, Spooner, D, \& Smith, MH. (2012). Climate Change and Pacific Islands: Indicators and Impacts. Report for the 2012 Pacific Islands Regional Climate Assessment (Pirca) (pp. 170). Washington D.C. 
Kenny, JF, Barber, NL, Hutson, SS, Linsey, KS, Lovelace, JK, \& Maupin, MA. (2009). Estimated Use of Water in the United States in 2005 USGS Circular 1344 (pp. 52).

Kerns, BK, Naylor, BJ, Buonopane, M, Parks, CG, \& Rogers, B. (2009). Modeling Tamarisk (Tamarix Spp.) Habitat and Climate Change Effects in the Northwestern United States. Invasive Plant Science and Management, 2(3), 200-215. doi: 10.1614/ipsm-08-120.1

Knapp, E, North, M, Benech, M, \& Estes, B. (2012). The Variable-Density Thinning Study at StanislausTuolumne Experimental Forest. In M. North (Ed.), Managing Sierra Nevada Forests, General Technical Report Psw-Gtr-237 (pp. 127-140). Albany, CA: USDA Forest Service, Pacific Southwest Research Station.

Koba, M. (2014, September 10, 2014). California Drought Could Claim Quarter of Rice Crop. NBC News. Retrieved from http://www.nbcnews.com/storyline/california-drought/california-droughtcould-claim-quarter-rice-crop-n200326

Koepke, DF, Kolb, TE, \& Adams, HD. (2010). Variation in Woody Plant Mortality and Dieback from Severe Drought among Soils, Plant Groups, and Species within a Northern Arizona Ecotone. Oecologia, 163(4), 1079-1090. doi: 10.1007/s00442-010-1671-8

Koike, ST, Cahn, M, Cantwell, M, Fennimore, S, LeStrange, M, Natwick, E, Smith, R, \& Takele, E. (2009). Cauliflower Production in California. In University of California Division of Agriculture and Natural Resources (Ed.), (Vol. 7219). Oakland, CA.

Kremen, C. (2013). Integrated Crop Pollination for Resilience against Climate Change (and Other Problems). Paper presented at the CDFA Climate Change Consortium, Sacramento, CA.

Kunkel, KE, Stevens, LE, Stevens, SE, Sun, L, Janssen, E, Wuebbles, D, Redmond, KT, \& Dobson, JG. (2013). Regional Climate Trends and Scenarios for the U.S. National Climate Assessment Part 5. Climate of the Southwest U.S. (pp. 142-145, 179 pp): NOAA Technical Report NESDIS.

Lancaster, N, \& Baas, A. (1998). Influence of Vegetation Cover on Sand Transport by Wind: Field Studies at Owens Lake, California. Earth Surface Processes and Landforms, 23, 69-82.

Langford, S, Stevenson, S, \& Noone, D. (2014). Analysis of Low-Frequency Precipitation Variability in Cmip5 Historical Simulations for Southwestern North America. Journal of Climate, 27(7), 27352756.

Lauer, A, Zhang, C, Elison-Timm, O, Wang, Y, \& Hamilton, K. (2013). Downscaling of Climate Change in the Hawaii Region Using Cmip5 Results: On the Choice of the Forcing Fields. Journal of Climate, 26(24), 10006-10030. doi: 10.1175/jcli-d-13-00126.1

Lee, J, De Gryze, S, \& Six, J. (2011). Effect of Climate Change on Field Crop Production in California's Central Valley. Climatic Change, 109, 335-353. doi: 10.1007/s10584-011-0305-4

Lenihan, JM, Drapek, R, Bachelet, D, \& Neilson, RP. (2003). Climate Change Effects on Vegetation Distribution, Carbon, and Fire in California. Ecological Applications, 13(6), 1667-1681. doi: $10.1890 / 025295$ 
LeStrange, M, Cahn, M, Koike, S, Smith, RF, Daugovish, O, Fennimore, S, Natwick, E, Dara, SK, Takele, E, \& Cantwell, M. (2010). Broccoli Production in California. In University of California Division of Agriculture and Natural Resources (Ed.), (Vol. 7211). Oakland, CA.

LeStrange, M, Schrader, WL, \& Hartz, TK. (2000). Fresh-Market Tomato Production in California. In University of California Division of Agriculture and Natural Resources (Ed.), (Vol. 8017). Oakland, CA.

Licht, S. (2014, August 7, 2014). Fruit Growers Adapt to Warmer Winters, Drought. Retrieved December 12, 2014, from http://calclimateag.org/fruit-growers-adapt-to-warmer-winters-drought/

Lobell, D, Cahill, KN, \& Field, CB. (2007). Historical Effects of Temperature and Precipitation on California Crop Yields. Climatic Change, 81, 187-203. doi: 10.1007/s10584-006-9141-3

Lobell, D, \& Field, C. (2011). California Perennial Crops in a Changing Climate. Climatic Change, 109(1), 317-333. doi: 10.1007/s10584-011-0303-6

Lobell, DB, Field, CB, Cahill, KN, \& Bonfils, C. (2006). Impacts of Future Climate Change on California Perennial Crop Yields: Model Projections with Climate and Crop Uncertainties. Agricultural and Forest Meteorology, 141(2-4), 208-218. doi: 10.1016/j.agrformet.2006.10.006

Lobell, DB, Torney, A, \& Field, CB. (2011). Climate Extremes in California Agriculture. Climatic Change, 109, 355-363. doi: 10.1007/s10584-011-0304-5

Ludwig, F, \& Asseng, S. (2006). Climate Change Impacts on Wheat Production in a Mediterranean Environment in Western Australia. Agricultural Systems, 90(1), 159-179.

Luedeling, E. (2012). Climate Change Impacts on Winter Chill for Temperate Fruit and Nut Production: A Review. Scientia Horticulturae, 144(0), 218-229. doi: http://dx.doi.org/10.1016/j.scienta.2012.07.011

Luedeling, E, Zhang, M, \& Girvetz, EH. (2009). Climatic Changes Lead to Declining Winter Chill for Fruit and Nut Trees in California During 1950 - 2099. PLOS ONE, 4(7). doi:

10.1371/journal.pone.0006166

Luedeling, E, Zhang, M, Luedeling, V, \& Girvetz, EH. (2009). Sensitivity of Winter Chill Models for Fruit and Nut Trees to Climatic Changes Expected in California's Central Valley. Agriculture, Ecosystems \& Environment, 133(1-2), 23-31. doi: http://dx.doi.org/10.1016/j.agee.2009.04.016

Lydersen, JM, North, MP, Knapp, EE, \& Collins, BM. (2013). Quantifying Spatial Patterns of Tree Groups and Gaps in Mixed-Conifer Forests: Reference Conditions and Long-Term Changes Following Fire Suppression and Logging. Forest Ecology and Management, 304, 370-382. doi: 10.1016/j.foreco.2013.05.023

Mader, TL, Frank, KL, Harrington, J, Jr., Hahn, GL, \& Nienaber, J. (2009). Potential Climate Change Effects on Warm-Season Livestock Production in the Great Plains. Climatic Change, 97(3-4), 529-541. doi: 10.1007/s10584-009-9615-1

Martin, G, \& Magne, MA. (2015). Agricultural Diversity to Increase Adaptive Capacity and Reduce Vulnerability of Livestock Systems against Weather Variability - a Farm-Scale Simulation Study. Agriculture, Ecosystems \& Environment, 199(1), 301-311. doi: 10.1016/j.agee.2014.10.006 
McKenzie, D, Peterson, DL, \& Littell, JJ. (2009). Global Warming and Stress Complexes in Forests of Western North America. Wildland Fires and Air Pollution, 8, 319-337. doi: 10.1016/s14748177(08)00015-6

McLachlan, JS, Hellmann, JJ, \& Schwartz, MW. (2007). A Framework for Debate of Assisted Migration in an Era of Climate Change. Conservation Biology, 21(2), 297-302. doi: 10.1111/j.15231739.2007.00676.x

Medellín-Azuara, J, Howitt, R, MacEwan, D, \& Lund, JR. (2012). Related Agricultural Yield Losses in California. Paper presented at the CDFA Climate Change Consortium, Modesto, CA.

Mekonnen, MM, \& Hoekstra, AY. (2011). The Green, Blue and Grey Water Footprint of Crops and Derived Crop Products. Hydrol. Earth Syst. Sci., 15(5), 1577-1600. doi: 10.5194/hess-15-15772011

Millar, C, Neilson, RP, Bachelet, D, Drapek, RJ, \& Lenihan, JM. (2006). Climate Change at Multiple Scales Forests, Carbon and Climate Change (pp. 31-62). Portland, OR: Oregon Forest Resources Institute.

Mohamed, SJ, Jellings, AJ, \& Fuller, MP. (2013). Positive Effects of Elevated Co2 and Its Interaction with Nitrogen on Safflower Physiology and Growth. Agronomy for Sustainable Development, 33, 497-505. doi: 10.1007/s13593-013-0137-x

Moore, AD, \& Ghahramani, A. (2014). Climate Change and Broadacre Livestock Production across Southern Australia. 3. Adaptation Options Via Livestock Genetic Improvement. Animal Production Science, 54(2), 111-124. doi: http://dx.doi.org/10.1071/AN13052

NASS. (2013). National Agricultural Statistics Service. Retrieved October/November 2013, 2013, from www.nass.usda.gov

National Agricultural Statistics Service. (2012). Census of Agriculture Hawaii Farm Facts: U.S. Department of Agriculture,

National Agricultural Statistics Service. (2013). California Agricultural Statistics: 2012 Crop Year (pp. 100). Sacramento, CA: United States Department of Agriculture.

National Agricultural Statistics Service. (2014a). 2013 State Agriculture Overview: Hawaii.

National Agricultural Statistics Service. (2014b). Vegetables: Final Estimates 2008-2012 (pp. 111). Washington, DC: US Department of Agriculture.

National Oceanic and Atmospheric Administration. (2015). Global Surface Temperature Anomalies. Retrieved March 13, 2015, 2015, from http://www.ncdc.noaa.gov/monitoringreferences/faq/anomalies.php

Natural Resources Conservation Service. (2006). Land Resource Regions and Major Land Resource Areas of the United States, the Caribbean, and the Pacific Basin (pp. 682). Washington, DC: US Department of Agriculture. 
Natural Resources Conservation Service. (2014). Ecological Site Description System. Retrieved October/November 2014, 2014, from esis.sc.egov/welcome/pgESDWelcome.aspx

Nelson, S, Brooks, F, \& Teves, G. (2011). Taro Leaf Blight in Hawaii Plant Disease Bulletin (Vol. PD71). Hawaii: College of Tropical Agriculture and Human Resources, University of Hawaii.

Nicholas, KA, Matthews, MA, Lobell, DB, Willits, NH, \& Field, CB. (2011). Effect of Vineyard-Scale Climate Variability on Pinot Noir Phenolic Composition. Agricultural and Forest Meteorology, 151(12), 1556-1567. doi: 10.1016/j.agrformet.2011.06.010

North, M, Stine, P, O'Hara, K, Zielinski, W, \& Stephens, SL. (2009). An Ecosystem Management Strategy for Sierran Mixed-Conifer Forests. Gen. Tech. Rep. (Vol. PSW-GTR-220. , pp. 49). Albany, CA: Department of Agriculture, Forest Service, Pacific Southwest Research Station. .

O'Neal, MR, Nearing, MA, Vining, RC, Southworth, J, \& Pfeifer, RA. (2005). Climate Change Impacts on Soil Erosion in Midwest United States with Changes in Crop Management. CATENA, 61(2-3), 165-184. doi: http://dx.doi.org/10.1016/j.catena.2005.03.003

O'Neill, GA, Stoehr, M, \& Jaquish, B. (2014). Quantifying Safe Seed Transfer Distance and Impacts of Tree Breeding on Adaptation. Forest Ecology and Management, 328, 122-130. doi: 10.1016/j.foreco.2014.05.039

Olesen, JE, Borgesen, CD, Elsgaard, L, Palosuo, T, Rotter, RP, Skjelvag, AO, Peltonen-Sainio, P, Borjesson, T, Trnka, M, Ewert, F, Siebert, S, Brisson, N, Eitzinger, J, van Asselt, ED, Oberforster, M, \& van der Fels-Klerx, HJ. (2012). Changes in Time of Sowing, Flowering and Maturity of Cereals in Europe under Climate Change. Food Additives and Contaminants Part aChemistry Analysis Control Exposure \& Risk Assessment, 29(10), 1527-1542. doi: 10.1080/19440049.2012.712060

Oosterhuis, DM. (1999). Yield Response to Environmental Extremes in Cotton Cotton Research Meeting (Vol. Report 193). Fayetteville, AR: Arkansas Agric. Exp. Stn.

Ortiz, EM. (2014, May 11, 2014). Drought's Latest Effect? Sacramento Valley Farmers Fallow Rice Land. Sacramento Bee. Retrieved from http://www.sacbee.com/news/local/article2598509.html

Ottman, M, \& Mostafa, A. (2013). Summer Slump in Alfalfa. Progressive Forage Growth. Retrieved 210ct14, from http://www.progressiveforage.com/forage-types/alfalfa/summer-slump-in-alfalfa

Overpeck, J, Garfin, G, Jardine, A, Busch, DE, Cayan, D, Dettinger, M, Fleishman, E, Gershunov, A, MacDonald, G, Redmond, KT, Travis, WR, \& Udall., B. (2013). Summary for Decision Makers. Assessment of Climate Change in the Southwest United States: A Report Prepared for the National Climate Assessment.

Ozores-Hampton, M, Kiran, F, \& McAvoy, G. (2012). Blossom Drop, Reduced Fruit Set, and PostPollination Disorders in Tomato (Vol. HS1195, pp. 6). Gainesville, FL: University of Florida Institute for Food and Agricultural Sciences Extension.

Paddock, E. (2013). Driscoll's Water Commitment: Pajaro Valley Groundwater Basin. Paper presented at the CDFA Climate Change Consortium, Sacramento, CA. 
Parker, WC, Colombo, SJ, Cherry, ML, Flannigan, MD, Greifenhagen, S, McAlpine, RS, Papadopol, C, $\&$ Scarr, T. (2000). Third Millennium Forestry: What Climate Change Might Mean to Forests and Forest Management in Ontario. Forest. Chron., 76, 445-463.

Pedlar, JH, McKenney, DW, Beaulieu, J, Colombo, SJ, McLachlan, JS, \& O'Neill, GA. (2011). The Implementation of Assisted Migration in Canadian Forests. Forestry Chronicle, 87(6), 766-777.

Pierson, D. (2014, November 22, 2014). Drought Revives 'Forgotten Art' at Wineries: Farming without Irrigation. Los Angeles Times. Retrieved from http://www.latimes.com/business/la-fi-dry-farmwine-20141123-story.html

Polley, HW, Briske, DD, Morgan, JA, Wolter, K, Bailey, DW, \& Brown, JR. (2013). Climate Change and North American Rangelands: Trends, Projections, and Implications. Rangeland Ecology \& Management, 66(5), 493-511. doi: http://dx.doi.org/10.2111/REM-D-12-00068.1

Pope, KS. (2012). Climate Change Adaptation: Temperate Perennial Crops. Paper presented at the CDFA Climate Change Consortium, Modesto, CA.

Price, S. (1983). Climate. In R. W. Armstrong (Ed.), Atlas of Hawaii (pp. 59-63). Manoa, HI: University of Hawaii Press.

Putnam, DH, \& Ottman, M (Producer). (2013, 27Oct14). Your Alfalfa Crop Got the Blues? It May Be 'Summer Slump'. Alfalfa and Forage News: News and information from UC Cooperative Extension about alfalfa and forage production. Retrieved from http://ucanr.edu/blogs/blogcore/postdetail.cfm?postnum=11134

Qiao, CG, Basford, KE, DeLacy, IH, \& Cooper, M. (2004). Advantage of Single-Trial Models for Response to Selection in Wheat Breeding Multi-Environment Trials. Theoretical and Applied Genetics, 108(7), 1256-1264. doi: 10.1007/s00122-003-1541-4

Reddy, E, Van Vuren, DH, Scowcroft, PG, Kauffman, JB, \& Perry, L. (2012). Long-Term Response of the Mamane Forest to Feral Herbivore Management on Mauna Kea, Hawaii. Pacific Conservation Biology, 18(2), 123-132.

Reddy, VR, Reddy, KR, \& Baker, DN. (1991). Temperature Effect on Growth and Development of Cotton During the Fruiting Period. Agronomy Journal, 83(1), 211-217.

Rehfeldt, GE, Crookston, NL, Saenz-Romero, C, \& Campbell, EM. (2012). North American Vegetation Model for Land-Use Planning in a Changing Climate: A Solution to Large Classification Problems. Ecological Applications, 22(1), 119-141.

Ribaudo, M, Delgado, J, Hansen, L, Livingston, M, Mosheim, R, \& Williamson, J. (2011). Nitrogen in Agricultural Systems: Implications for Conservation Policy (Vol. ERS Report Number 127): U.S. Department of Agriculture, Economic Research Service.

Robbins, J. (2014, April 14, 2014). Paying Farmers to Welcome Birds. New York Times. Retrieved from http://www.nytimes.com/2014/04/15/science/paying-farmers-to-welcome-birds.html

Sanden, B. (2007). Fall Irrigation Management in a Drought Year for Almonds, Pistachios and Citrus. In U. o. C. D. o. A. a. N. Resources (Ed.), (pp. 8). Bakersfield, CA: University of California Division of Agriculture and Natural Resources. 
Sato, S, Peet, MM, \& Thomas, JF. (2000). Physiological Factors Limit Fruit Set of Tomato (Lycopersicon Esculentum Mill.) under Chronic, Mild Heat Stress. Plant, Cell \& Environment, 23(7), 719-726. doi: $10.1046 /$ j.1365-3040.2000.00589.x

Schwankl, LJ, Prichard, TL, Hanson, BR, \& Elkins, RB. (2007). Understanding Your Orchard's Water Requirements. In University of California Division of Agriculture and Natural Resources (Ed.), (Vol. 8212). Oakland, CA.

Shaw, MR, Pendleton, L, Cameron, DR, Morris, B, Bachelet, D, Klausmeyer, K, MacKenzie, J, Conklin, DR, Bratman, GN, Lenihan, J, Haunreiter, E, Daly, C, \& Roehrdanz, PR. (2011). The Impact of Climate Change on California's Ecosystem Services. Climatic Change, 109, 465-484. doi: 10.1007/s10584-011-0313-4

Singh, D, Jackson, G, Hunter, D, Fullerton, R, Lebot, V, Taylor, M, Iosefa, T, Okpul, T, \& Tyson, J. (2012). Taro Leaf Blight—a Threat to Food Security. Agriculture, 2(4), 182-203. doi: 10.3390/agriculture2030182

Smith, P, Polomski, B, \& Shaughnessy, D. (2003). Lettuce (Vol. HGIC 1312, pp. 3). Clemson, SC: Clemson University Cooperative Extension.

Smith, R. (2014) Greater Incidence of Calcium Disorders in 2014. Salinas Valley Agriculture: University of California Agriculture and Natural Resources.

Smith, RF, Cahn, M, Daugovish, O, Koike, S, Natwick, E, Smith, H, Subbarao, K, Takele, E, \& Turini, T. (2011). Leaf Lettuce Production in California. In University of California Division of Agriculture and Natural Resources (Ed.), (Vol. 7216). Oakland, CA.

Snider, JL, Oosterhuis, DM, \& Kawakami, EM. (2011). Diurnal Pollen Tube Growth Rate Is Slowed by High Temperature in Field-Grown Gossypium Hirsutum Pistils. Journal of Plant Physiology, 168(5), 441-448. doi: http://dx.doi.org/10.1016/j.jplph.2010.08.003

Sohmer, SH, \& Gustafson, R. (1994). Vegetation Zones. In E. A. Kay (Ed.), A Natural History of the Hawaiian Islands: Selected Readings Ii (pp. 145-154). Hawaii: University of Hawaii Press.

Spann, T. (2014). Coping with Drought (Spring 2014 ed.). Irvine, CA: California Avocado Commission.

St-Pierre, NR, Cobanov, B, \& Schnitkey, G. (2003). Economic Losses from Heat Stress by Us Livestock Industries. Journal of Dairy Science, 86, Supplement(0), E52-E77. doi: http://dx.doi.org/10.3168/jds.S0022-0302(03)74040-5

Starrs, PF, \& Goin, P. (2010). Field Guide to California Agriculture. Berkeley, CA: University of California Press.

Stephens, SL, Millar, CI, \& Collins, BM. (2010). Operational Approaches to Managing Forests of the Future in Mediterranean Regions within a Context of Changing Climates. Environmental Research Letters, 5(2). doi: 10.1088/1748-9326/5/2/024003

Stephenson, RA, Gallegher, EC, \& Doogan, VJ. (2003). Macadamia Response to Mild Water Stress at Different Phenological Stages. Australian Journal of Agricultural Research, 54, 67-75. 
Stephenson, RA, \& Trochoulias, T. (1994). Macadamia. In B. Schaffer \& P. C. Andersen (Eds.), Handbook of Environmental Physiology of Fruit Crops - Volume Ii: Sub-Tropical and Tropical Crops (pp. 147-163). Boca Raton, FL: CRC Press.

Stine, P, Hessburg, P, Spies, T, Kramer, M, Fettig, CJ, Hansen, A, Lehmkuhl, J, O'Hara, K, Polivka, K, Singleton, P, Charnley, S, Merschel, A, \& White, R. (2014). The Ecology and Management of Moist Mixed-Conifer Forests in Eastern Oregon and Washington: A Synthesis of the Relevant Biophysical Science and Implications for Future Land Management. Gen. Tech Rep (Vol. PNWGTR-897, pp. 254). Portland, OR: U.S. Department of Agriculture, Forest Service, Pacific Northwest Research Station.

Strum, KM, Reiter, ME, Hartman, CA, Iglecia, MN, Kelsey, TR, \& Hickey, CM. (2013). Winter Management of California's Rice Fields to Maximize Waterbird Habitat and Minimize Water Use. Agriculture Ecosystems \& Environment, 179, 116-124. doi: 10.1016/j.agee.2013.08.003

Svejcar, T, Angell, R, Bradford, JA, Dugas, W, Emmerich, W, Frank, AB, Gilmanov, T, Haferkamp, M, Johnson, DA, Mayeux, H, Mielnick, P, Morgan, J, Saliendra, NZ, Schuman, GE, Sims, PL, \& Snyder, K. (2008). Carbon Fluxes on North American Rangelands. Rangeland Ecology \& Management, 61(5), 465-474. doi: 10.2111/07-108.1

Tack, J, Barkley, A, \& Nalley, LL. (2014). Heterogeneous Effects of Warming and Drought on Selected Wheat Variety Yields. Climatic Change, 125(3-4), 489-500. doi: 10.1007/s10584-014-1185-1

Tepe, TL, \& Meretsky, VJ. (2011). Forward-Looking Forest Restoration under Climate Change - Are U.S. Nurseries Ready? Restoration Ecology, 19(3), 295-298. doi: 10.1111/j.1526100X.2010.00748.x

Turini, T, Cahn, M, Cantwell, M, Jackson, L, Koike, S, Natwick, E, Smith, R, Subbarao, K, \& Takele, E. (2011). Iceberg Lettuce Production in California. In University of California Division of Agriculture and Natural Resources (Ed.), (Vol. 7215). Oakland, CA.

U.S. Census Bureau. (2015). Lists of Population, Land Area, and Percent Urban and Rural in 2010 and Changes from 2000 to 2010. Dataset.

U.S. Department of Agriculture. (2011). U.S. Agriculture and Forestry Greenhouse Gas Inventory: 19902008 (C. C. P. Office, Trans.) (Vol. Technical Bulletin No., 1930, pp. 159): U.S. Department of Agriculture, Office of the Chief Economist.

U.S. Department of Agriculture. (2013). National Agricultural Statistics Service. Retrieved October/November 2013, 2013, from www.nass.usda.gov

U.S. Department of Agriculture. (2014). Quantifying Greenhouse Gas Fluxes in Agriculture and Forestry: Methods for Entity-Scale Inventory. In M. Eve, D. Pape, M. Flugge, R. Steele, D. Man, M. RileyGilbert, \& S. Biggar (Eds.), (Vol. Technical Bulletin Number 1939, pp. 606). Washington, DC: U.S. Department of Agriculture, Office of the Chief Economist.

U.S. Environmental Protection Agency. (2014). Inventory of U.S. Greenhouse Gas Emissions and Sinks: 1990-2012 (pp. 529). Washington D.C.: U.S. Environmental Protection Agency 
U.S. Forest Service. (2012). Future of America's Forest and Rangelands: Forest Service 2010 Resources Planning Act Assessment (F. Service, Trans.) (Vol. General Technical Report WO-87, pp. 198). Washington, DC: U.S. Department of Agriculture, Forest Service.

U.S. Forest Service. (2014). Restoration. Retrieved December 17, 2014, from http://www.fs.fed.us/restoration/

University of California Davis. (2013). Uc Pest Management Guidelines for Walnuts: Codling Moth. Retrieved January 23, 2015, from http://www.ipm.ucdavis.edu/PMG/r881300211.html

University of California Davis. (2014, October 2014). Year-Round Ipm Program for Pistachio. Retrieved January 23, 2015, from http://www.ipm.ucdavis.edu/PMG/C605/m605yi01.html

University of California Division of Agriculture and Natural Resources. (2013). California Rice Production Manual: University of California Cooperative Extension.

University of California Division of Agriculture and Natural Resources. (2014). Crop Irrigation Strategies: Individual Crop Deficit Irrigation Information. Retrieved December 13, 2014, from http://ucmanagedrought.ucdavis.edu/Agriculture/Crop_Irrigation_Strategies/

Vicente-Serrano, SM, Camarero, JJ, \& Azorin-Molina, C. (2014). Diverse Responses of Forest Growth to Drought Time-Scales in the Northern Hemisphere. Global Ecology and Biogeography, 23(9), 1019-1030.

Walker, MA, Lund, K, Aguero, C, Riaz, S, Fort, K, Heinitz, C, \& Romero, N. (2014). Breeding Grape Rootstocks for Resistance to Phylloxera and Nematodes - It's Not Always Easy. Vi International Phylloxera Sypmposium, 1045, 89-97.

Walthall, CL, Hatfield, J, Backlund, P, Lengnick, L, Marshall, E, Walsh, M, Adkins, S, Aillery, M, Ainsworth, EA, Ammann, C, Anderson, CJ, Bartomeus, I, Baumgard, LH, Booker, F, Bradley, B, Blumenthal, DM, Bunce, J, Burkey, K, Dabney, SM, Delgado, JA, Dukes, J, Funk, A, Garrett, K, Glenn, M, Grantz, DA, Goodrich, D, Hu, S, Izaurralde, RC, Jones, RAC, Kim, S-H, Leaky, ADB, Lewers, K, Mader, TL, McClung, A, Morgan, J, Muth, DJ, Nearing, M, Oosterhuis, DM, Ort, D, Parmesan, C, Pettigrew, WT, Polley, HW, Rader, R, Rice, C, Rivington, M, Rosskopf, E, Salas, WA, Sollenberger, LE, Srygley, R, Stöckle, C, Takle, ES, Timlin, D, White, JW, Winfree, R, Wright-Morton, L, \& Ziska, LH. (2012). Climate Change and Agriculture in the United States: Effects and Adaptation. Usda Technical Bulletin 1935. (Technical Bulletin 1935). Washington, DC.

Westerling, AL, Hidalgo, HG, Cayan, DR, \& Swetnam, TW. (2006). Warming and Earlier Spring Increase Western Us Forest Wildfire Activity. Science, 313(5789), 940-943. doi: 10.1126/science. 1128834

Whittaker, RH. (1975). Communities and Ecosystems. Second Edition. New York: MacMillan Publishing.

Williams, MI, \& Dumroese, RK. (2013). Preparing for Climate Change: Forestry and Assisted Migration. Journal of Forestry, 111(4), 287-297. doi: 10.5849/jof.13-016

Worrall, JJ, Marchetti, SB, Egeland, L, Mask, RA, Eager, T, \& Howell, B. (2010). Effects and Etiology of Sudden Aspen Decline in Southwestern Colorado, USA. Forest Ecology and Management, 260, 638-648. doi: 10.1016/j.foreco.2010.05.020 